\title{
Body weight loss and maintenance as affected by environment and genetic predisposition
}

Citation for published version (APA):

Verhoef, S. P. M. (2013). Body weight loss and maintenance as affected by environment and genetic predisposition. [Doctoral Thesis, Maastricht University]. BOXPress.

https://doi.org/10.26481/dis.20130531sv

Document status and date:

Published: 01/01/2013

DOI:

10.26481/dis.20130531sv

Document Version:

Publisher's PDF, also known as Version of record

\section{Please check the document version of this publication:}

- A submitted manuscript is the version of the article upon submission and before peer-review. There can be important differences between the submitted version and the official published version of record.

People interested in the research are advised to contact the author for the final version of the publication, or visit the DOI to the publisher's website.

- The final author version and the galley proof are versions of the publication after peer review.

- The final published version features the final layout of the paper including the volume, issue and page numbers.

Link to publication

\footnotetext{
General rights rights.

- You may freely distribute the URL identifying the publication in the public portal. please follow below link for the End User Agreement:

www.umlib.nl/taverne-license

Take down policy

If you believe that this document breaches copyright please contact us at:

repository@maastrichtuniversity.nl

providing details and we will investigate your claim.
}

Copyright and moral rights for the publications made accessible in the public portal are retained by the authors and/or other copyright owners and it is a condition of accessing publications that users recognise and abide by the legal requirements associated with these

- Users may download and print one copy of any publication from the public portal for the purpose of private study or research.

- You may not further distribute the material or use it for any profit-making activity or commercial gain

If the publication is distributed under the terms of Article $25 \mathrm{fa}$ of the Dutch Copyright Act, indicated by the "Taverne" license above, 
Body weight loss and maintenance as affected by environment and genetic predisposition 


\section{itution}

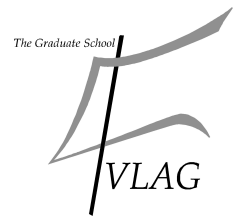

The studies presented in this thesis were performed at the School for Nutrition, Toxicology and Metabolism (NUTRIM), which participated in the Graduate School VLAG (Food Technology, Agrobiotechnology, Nutrition and Health Sciences), accredited by the Royal Netherlands Academy of Arts and Sciences (KNAW).

The research described in chapter 2 of this thesis was sponsored by Sensus.

The research described in chapter 3 of this thesis was sponsored by Lipid Nutrition.

Financial support by Sensus for the publication of this thesis is gratefully acknowledged.

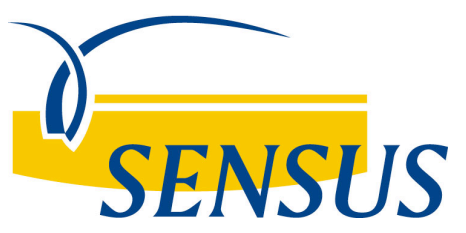

Cover design: Wendy Bergervoet - van de Ven Layout: Sanne Verhoef

Printed by: Proefschriftmaken.nl, uitgeverij boxPress

(C) copyright Sanne Verhoef, Maastricht 2013

ISBN 9789088916069 


\title{
Body weight loss and maintenance as affected by environment and genetic predisposition
}

\author{
PROEFSCHRIFT \\ ter verkrijging van de graad van doctor aan de Universiteit Maastricht, \\ op gezag van de Rector Magnificus, Prof. L.L.G. Soete \\ volgens het besluit van het College van Decanen, \\ in het openbaar te verdedigen op \\ vrijdag 31 mei 2013 om 10:00 uur
}

door

SANNE PETRA MARIA VERHOEF

Geboren te Elsloo op 22 november 1984 


\section{Promotoren}

Prof. Dr. KR Westerterp

Prof. Dr. ECM Mariman

\section{Beoordelingscommissie}

Prof. dr. W.H. Lamers (voorzitter)

Prof. dr. R.A.H. Adan, UMC Utrecht

Prof. dr. R.P. Mensink

Dr. A.G. Nieuwenhuizen, Wageningen Universiteit

Prof. dr. M.P. Zeegers 


\section{TABLE OF CONTENTS}

$\begin{array}{lll}\text { Chapter } 1 & \text { General Introduction } & 7\end{array}$

Chapter 2 Effects of oligofructose on appetite profile, GLP-1 and PYY con- 17 centrations and energy intake

Chapter 3 No effects of Korean pine nut triacylglycerol on satiety and en- 29 ergy intake

Chapter 4 Genetic predisposition, dietary restraint and disinhibition in relation to weight loss and maintenance

Chapter 5 Relative shrinkage of adipocytes by paraffin in proportion to plastic embedding in human adipose tissue before and after weight loss

Chapter 6 Physiological response of adipocytes to weight loss and maintenance

Chapter 7 Concomitant changes in sleep duration and body-weight and body-composition during weight-loss and 3-month weightmaintenance

Chapter 8 General Discussion 89

Summary $\quad 99$

$\begin{array}{ll}\text { Samenvatting } & 103\end{array}$

$\begin{array}{ll}\text { Dankwoord } & 107\end{array}$

List of publications $\quad 111$

$\begin{array}{ll}\text { Curriculum vitae } & 115\end{array}$ 



\section{CHAPTER 1 \\ General Introduction}


The prevalence of overweight and obesity has increased worldwide to epidemic proportions (1). Overweight and obesity result from a positive energy balance, with energy intake exceeding energy expenditure, resulting in storage of excessive energy as fat. The increased prevalence of obesity coincided with technological developments, like cars, washing machines and television, contributing to sedentary lifestyles, suggesting a causal link (2-6). However, experimental designs are too weak to provide evidence for such causal link (7-9). It is unlikely that changes to a more sedentary lifestyle are responsible for the obesity epidemic through lowered energy expenditure, since physical activity energy expenditure has not declined over the same period that the prevalence of obesity increased dramatically (10). The latter implies that an increased energy intake is responsible for the energy imbalance resulting in the obesity epidemic. This is supported by the fact that during the same period dietary habits changed with increased portion sizes, changed meal composition and eating out, and the fact that palatable, energy-dense foods became readily available in our western society $(5,6,8)$.

The obesogenic environment cannot fully explain the development of obesity at an individual level, since there are still many individuals who manage to remain lean. This raises the question which factors determine the individual susceptibility to become obese. Environmental factors, such as social, psychological, cultural or economic status influence an individuals' behaviour and energy consumption patterns. In addition, there is evidence for a genetic predisposition to become obese (11). However, identifying genetic variants determining predisposition has been difficult. Genegene interactions complicate the identification of genetic variants and the ones identified so far only explain a small fraction (12). An individual with a genetic predisposition is unlikely to develop obesity without being exposed to an obesity-promoting environment, suggesting gene-environment interaction effects (13-17). Environment and genetics determine our physiology as well as our behaviour, which in turn determine energy intake and energy expenditure. This complex multi-layered network makes it difficult to elucidate the factors determining the individual susceptibility to become obese.

Obesity and its co-morbidities like diabetes and cardiovascular disease can be reversed by weight loss. Weight loss through a negative energy balance is most commonly achieved by dieting. In the long-term, successful weight loss is uncommon. Successful long-term weight loss, defined as losing $10 \%$ of the initial body weight and maintaining the loss for at least 1 year, is only achieved in around $20 \%$ of the cases (18). Weight loss maintenance is counteracted by physiological adaptations in response to weight loss. Increased feelings of hunger in response to weight loss make adherence to weight loss and weight maintenance diets difficult. The first part of this thesis encompasses food components that might help to reduce weight gain by decreasing the risk of overeating by suppressing appetite. The second part of this thesis encompasses factors involved in weight loss and weight maintenance thereafter. 


\section{Decreasing the risk of overeating}

Some food components might help to prevent weight gain or weight regain after weight loss by decreasing the risk of overeating. Potential effects are lowering portion size, decreasing meal frequencies and/or lowering the energy density of a meal. Decreasing the risk of overeating might be accomplished by satiety-enhancing or appetite-suppressing properties of food components. The first part of this thesis focuses on two potential appetite suppressing food components, namely oligofructose and Korean pine nut oil.

A conceptual framework to examine the impact of food components on appetite is the satiety cascade (19). The cascade indicates a number of measurable targets, by linking physiological mechanisms to subjective feelings of appetite that determine appetite control (20). Potential mechanisms of appetite suppressing food components are slowing gastric emptying and the intestinal transit in order to promote satietyenhancing neuroendocrine feedback responses $(21,22)$. Potential appetite suppressing food components are found to increase concentrations of the 'satiety' peptides glucagon like peptide-1 (GLP-1) and peptide YY (PYY), increase satiety feelings and/or reduce energy intake (23-32). However, results are inconsistent and often not sufficient to substantiate appetite-related claims (21).

The inconsistent results might be a consequence of the large variation in study designs. Effectiveness of a food component depends among other things on the amount consumed. For many appetite suppressing food components, the minimal dosage necessary for establishing beneficial effects is still unknown, emphasizing the need to perform dose-response studies. Comparing studies is hampered by variation in methods used in these studies. Methods to determine an effect on energy intake varied from self-reported energy intake (30) to directly measuring energy intake by assessing consumption of an ad libitum meal $(23,26,32)$. The timing of the measurements is crucial and depends on the type and form, like solid or liquid, of the food component $(33,34)$. The supposed mechanism of action of the food component should be taken into account and piloting is essential for optimizing timing within a study design. To eventually support a health claim, an acute effect found in a shortterm study should be additionally tested in a long-term study to eliminate potential compensation (35). Furthermore, food components should be tested in a study population resembling the intended users. Taken together, studies determining the effect of food components on appetite should be well designed, with thoroughly considering the dosage, timing of dosing regime, methods and study population.

\section{Factors involved in weight loss and weight maintenance thereafter}

Successful long-term weight loss is counteracted by homeostatic adaptations in response to weight loss that create an elevated appetite and suppressed energy expenditure promoting weight regain (36). Thus to prevent weight regain energy restriction should be sustained. Some individuals manage to keep off the lost weight, while others regain all their lost weight. Like predisposition to develop overweight and obesity, individual susceptibility to successful weight loss and weight maintenance 
seems to be determined by multiple factors. Genetic as well as behavioural and physiological factors shown to have a relationship with body weight might directly or indirectly affect weight loss and weight maintenance. Factors influence successful weight loss maintenance by changing in response to weight loss, thereby either returning to a pre-obese state or favoring weight regain. The second part of this thesis encompasses factors involved in weight loss and weight maintenance thereafter, in particular genetic predisposition, adipose tissue metabolism and sleep.

\section{Genetic predisposition}

Despite the apparent dominant role of environmental factors in the obesity epidemic, genetic factors are known to affect the inter-individual susceptibility to develop obesity. Based on family and twin studies the genetic contribution is estimated at 40 $70 \%(11,37)$. Since the start of the genome-wide association studies (GWAS), numerous loci have been identified to be unequivocally associated with obesity relatedtraits (12). However, the separate effects of these loci on obesity-susceptibility are small and explain only a small fraction of the total variation with a poor predictive ability $(12,38,39)$. Studying GWAS-identified loci in longitudinal cohort studies can contribute to elucidating new physiological pathways that underlie obesitysusceptibility. These studies are complicated since a large population size is needed and gene-gene and gene-environment interaction effects can mask the effect of a genetic variant (40).

Longitudinal cohort studies already associated many genetic variants or single nucleotide polymorphisms (SNPs) with obesity, like polymorphisms in the fat mass and obesity associated (FTO) gene (41-46) and the melanocortin 4 receptor (MC4R) gene (47-49). Also individual differences in weight loss maintenance may in part be explained by a genetic predisposition to resist weight loss or to promote weight gain (50). Twin studies have demonstrated a much larger variability between pairs than within pairs on the response to long-term negative energy balance $(51,52)$. Some SNPs already associated with obesity might also be related to weight loss maintenance. In this thesis the focus is on six SNPs that already showed associations with obesity-related traits and the possible association with weight loss maintenance.

\section{Adipose tissue metabolism}

Adipose tissue is a major energy-storing tissue, and an endocrine organ functionally responding to disturbances of energy balance. Under a negative energy balance, adipocytes will release fatty acids, whereas under a positive energy balance adipocytes will actively take up and store fatty acids. Fat mass expansion is determined by both an increase in adipocyte size (hypertrophy) and number (hyperplasia) $(53,54)$. Metabolic disturbances associated with obesity, like insulin resistance, are typically associated with adipocyte hypertrophy (55), emphasizing the important role of adipose tissue in obesity. During weight loss, the decrease in fat mass results in a decrease in adipocyte size. Adipocyte metabolism is determined by adipocyte size, which reflects the amount of triacylglycerol stored in the adipocyte. In accordance with the link between adipocyte size and metabolism, metabolic processes in adipocytes of obese 
subjects are dysregulated, and after weight loss either normalize to a pre-obese status or change in favor of weight regain (56-60). Thus, changes in adipocyte glucose and fatty acid metabolism should be determined in relation to changes in adipocyte size during weight loss and maintenance.

\section{Sleep}

The increased prevalence of obesity coincides with a decrease in average sleep duration $(61,62)$. Epidemiological studies suggest that short sleep is a determinant of obesity $(63,64)$. A curvilinear relationship between sleep duration and body mass index (BMI) suggests that both short $(<7 \mathrm{hrs})$ and long ( $>8 \mathrm{hrs})$ sleep have a negative effect on body weight $(63,65)$. Sleep deprivation results in a positive energy balance by disrupting the circadian rhythm, affecting physiological regulation mechanisms and behavioural factors $(66,67)$. However, the exact mechanisms by which sleep influences body weight need to be assessed and might involve both sides of the energy balance equation. Sleep deprivation can increase energy intake through alteration in the neuroendocrine control of appetite and reward (67-72). Short sleep duration can decrease energy expenditure by a decline in physical activity (73), or by an altered thermogenesis (74). In turn, it might be argued that the relationship between sleep duration and body weight is bi-directional. In addition to sleep influencing body weight, an increased body weight results in mechanical changes that increase work of breathing, causing deteriorated sleep quality. Obese subjects are prone to develop sleep abnormalities like obstructive sleep apneu and sleep-disordered breathing (75). Since cause and effect cannot be disentangled the interpretation of results is complicated.

Most studies on sleep were short or medium-term studies, where long-term studies are necessary to determine the relation between sleep and body weight changes during weight loss. During periods of energy restriction sufficient sleep contributes to the preservation of human fat-free body mass and an increase in sleep duration from a short to a healthier length was associated with an attenuation of fat mass gain $(74$, 76). Therefore, to optimize success in weight loss and maintenance it is important to include sleep in the list of factors influencing body weight and assess the relationship between sleep duration and body weight.

\section{Outline of the thesis}

The research presented in the first part of this thesis is focussed on food components that might help to decrease the risk of overeating. Two types of potential appetite suppressing food components were tested in studies, in which the dosage, timing of dosing regime and methods were considered. The minimal dosage of oligofructose necessary for establishing beneficial long-term effects on the appetite profile, GLP-1 and PYY concentrations and energy intake was determined in normal-weight and overweight men and women (chapter 2). Chapter 3 describes the effect of two dosages Korean pine nut oil on appetite ratings and energy intake at a previously determined sensitive moment in time. 
The research presented in the second part of this thesis has a focus on factors involved in weight loss and weight maintenance. Chapter 4 describes a study in which it was examined whether body weight and short and long-term weight loss were affected by six candidate single nucleotide polymophisms (SNPs) and by changes in eating behaviour or by an interaction between these genetic and behavioural factors. Adipose tissue has a central role in the homeostatic adaptations in response to weight loss. As adipocyte size is a major modulator of endocrine functioning, methods allowing accurate determination of adipocyte size are important in studying adipose tissue metabolism. In chapter $\mathbf{5}$ the relative shrinkage of adipocytes was assessed before and after weight loss by comparing adipose tissue from the same subjects embedded in paraffin and plastic. Thereafter changes in adipocyte glucose and fatty acid metabolism were assessed in relation to adipocyte size during weight loss and maintenance to determine whether metabolic processes in adipose tissue change in response to weight loss either in line with a return to a pre-obese status or with favoring weight regain (chapter 6). Now, sleep is recognized as a determinant of obesity. Therefore, it is important to understand the temporal sequence of the relationship between sleep duration and changes in body weight and composition during short and long-term weight loss, which was assessed in the study described in chapter 7.

Finally, the results of the above-described studies are summarized and discussed in chapter 8.

\section{References}

1. Caballero B. The global epidemic of obesity: an overview. Epidemiol Rev. 2007;29:1-5.

2. Brantley PJ, Myers VH, Roy HJ. Environmental and lifestyle influences on obesity. J La State Med Soc. 2005;157:S19-27.

3. Manson JE, Skerrett PJ, Greenland P, Vanltallie TB. The escalating pandemics of obesity and sedentary lifestyle. A call to action for clinicians. Arch Intern Med. 2004;164:249-58.

4. Ng SW, Popkin BM. Time use and physical activity: a shift away from movement across the globe. Obes Rev. 2012;13:659-80.

5. Popkin BM. The nutrition transition and obesity in the developing world. J Nutr. 2001;131:871S-873S.

6. Sallis JF, Glanz K. Physical activity and food environments: solutions to the obesity epidemic. Milbank Q. 2009;87:123-54.

7. Jebb SA, Moore MS. Contribution of a sedentary lifestyle and inactivity to the etiology of overweight and obesity: current evidence and research issues. Med Sci Sports Exerc. 1999;31:S534-41.

8. Jeffery RW, Utter J. The changing environment and population obesity in the United States. Obes Res. 2003;11:12S-22S.

9. Sorensen $\mathrm{TI}$. The changing lifestyle in the world. Body weight and what else? Diabetes Care. 2000;23:B1-4.

10. Westerterp KR, Speakman JR. Physical activity energy expenditure has not declined since the 1980s and matches energy expenditures of wild mammals. Int $J$ Obes (Lond). 2008;32:1256-63.

11. Maes HH, Neale MC, Eaves LJ. Genetic and environmental factors in relative body weight and human adiposity. Behav Genet. 1997;27:325-51.

12. Loos RJ. Genetic determinants of common obesity and their value in prediction. Best Pract Res Clin Endocrinol Metab. 2012;26:211-26. 
13. Speakman JR. Obesity: the integrated roles of environment and genetics. J Nutr. 2004;134:2090S-2105S.

14. Vogels N, Mariman ECM, Bouwman FG, Kester ADM, Diepvens K, Westerterp-Plantenga MS. Relation of weight maintenance and dietary restraint to peroxisome proliferator-activated receptor \{gamma\}2, glucocorticoid receptor, and ciliary neurotrophic factor polymorphisms. Am J Clin Nutr. 2005;82:740-746.

15. den Hoed M, Smeets AJPG, Veldhorst MAB, Mariman ECM, Westerterp-Plantenga MS, Westerterp KR. SNP analyses of postprandial responses in (an)orexigenic hormones and feelings of hunger reveal long-term physiological adaptations to facilitate homeostasis. Appetite. 2008;51:362-362.

16. den Hoed M, Westerterp-Plantenga MS, Bouwman FG, Mariman ECM, Westerterp KR. Postprandial responses in hunger and satiety are associated with the rs9939609 single nucleotide polymorphism in FTO. Am J Clin Nutr. 2009;90:1426-1432.

17. Joosen AM, Gielen M, Vlietinck R, Westerterp KR. Genetic analysis of physical activity in twins. Am J Clin Nutr. 2005;82:1253-9.

18. Wing RR, Phelan S. Long-term weight loss maintenance. Am J Clin Nutr. 2005;82:222S225S.

19. Blundell JE, Goodson S, Halford JC. Regulation of appetite: role of leptin in signalling systems for drive and satiety. Int J Obes Relat Metab Disord. 2001;25:S29-34.

20. Blundell JE, Lawton CL, Hill AJ. Mechanisms of appetite control and their abnormalities in obese patients. Horm Res. 1993;39:72-6.

21. Halford JC, Harrold JA. Satiety-enhancing products for appetite control: science and regulation of functional foods for weight management. Proc Nutr Soc. 2012;71:350-62.

22. Wilde PJ. Eating for life: designing foods for appetite control. J Diabetes Sci Technol. 2009;3:366-70.

23. Archer BJ, Johnson SK, Devereux HM, Baxter AL. Effect of fat replacement by inulin or lupin-kernel fibre on sausage patty acceptability, post-meal perceptions of satiety and food intake in men. Br J Nutr. 2004;91:591-9.

24. Beglinger C, Degen L. Fat in the intestine as a regulator of appetite--role of CCK. Physiology \& Behaviour. 2004;83:617-621.

25. Burton-Freeman B, Davis PA, Schneeman BO. Plasma cholecystokinin is associated with subjective measures of satiety in women. Am J Clin Nutr. 2002;76:659-667.

26. Cani PD, Joly E, Horsmans $Y$, Delzenne NM. Oligofructose promotes satiety in healthy human: a pilot study. Eur J Clin Nutr. 2006;60:567-72.

27. Cani PD, Lecourt E, Dewulf EM, Sohet FM, Pachikian BD, Naslain D, et al. Gut microbiota fermentation of prebiotics increases satietogenic and incretin gut peptide production with consequences for appetite sensation and glucose response after a meal. Am J Clin Nutr. 2009;90:1236-1243.

28. Flint A, Raben A, Astrup A, Holst J. Glucagon-like peptide 1 promotes satiety and suppresses energy intake in humans. J Clin Invest. 1998;101:515-520.

29. Lawton C, Delargy H, Brockman J, Smith F, Blundell J. The degree of saturation of fatty acids influences post-ingestive satiety. $\mathrm{Br} \mathrm{J}$ Nutr. 2000;83:473-82.

30. Parnell JA, Reimer RA. Weight loss during oligofructose supplementation is associated with decreased ghrelin and increased peptide $\mathrm{YY}$ in overweight and obese adults. Am J Clin Nutr. 2009;89:1751-9.

31. Pasman W, Heimerikx J, Rubingh C, van den Berg R, O'Shea M, Gambelli L, et al. The effect of Korean pine nut oil on in vitro CCK release, on appetite sensations and on gut hormones in post-menopausal overweight women. Lipids in Health and Disease. 2008;7:10.

32. Hughes G, Boyland E, Williams N, Mennen L, Scott C, Kirkham T, et al. The effect of Korean pine nut oil (PinnoThinTM) on food intake, feeding behaviour and appetite: A double-blind placebo-controlled trial. Lipids in Health and Disease. 2008;7:6. 
33. Martens MJ, Lemmens SG, Born JM, Westerterp-Plantenga MS. A solid high-protein meal evokes stronger hunger suppression than a liquefied high-protein meal. Obesity (Silver Spring). 2011;19:522-7.

34. Martens MJ, Westerterp-Plantenga MS. Mode of consumption plays a role in alleviating hunger and thirst. Obesity (Silver Spring). 2012;20:517-24.

35. EFSA Panel on Dietetic Products NaAN. DRAFT SCIENTIFIC OPINION 1. Guidance on the scientific requirements for health claims related to appetite ratings, weight management, and blood glucose concentrations. EFSA Journal. 2012;10:2604-2615.

36. Maclean $P$, Bergouignan A, Cornier M-A, Jackman M. Biology's response to dieting: the impetus for weight regain. American journal of physiology. Regulatory, integrative and comparative physiology. 2011;301:581-600.

37. Loos RJ, Bouchard C. Obesity--is it a genetic disorder? J Intern Med. 2003;254:401-25.

38. Li S, Zhao JH, Luan J, Luben RN, Rodwell SA, Khaw KT, et al. Cumulative effects and predictive value of common obesity-susceptibility variants identified by genome-wide association studies. Am J Clin Nutr. 2010;91:184-90.

39. Speliotes EK, Willer CJ, Berndt SI, Monda KL, Thorleifsson G, Jackson AU, et al. Association analyses of 249,796 individuals reveal 18 new loci associated with body mass index. Nat Genet. 2010;42:937-48.

40. Andreasen $\mathrm{CH}$, Andersen G. Gene-environment interactions and obesity--further aspects of genomewide association studies. Nutrition. 2009;25:998-1003.

41. Andreasen CH, Stender-Petersen KL, Mogensen MS, Torekov SS, Wegner L, Andersen G, et al. Low physical activity accentuates the effect of the FTO rs9939609 polymorphism on body fat accumulation. Diabetes. 2008;57:95-101.

42. Cornes BK, Lind PA, Medland SE, Montgomery GW, Nyholt DR, Martin NG. Replication of the association of common rs9939609 variant of FTO with increased BMI in an Australian adult twin population but no evidence for gene by environment $(G \times E)$ interaction. Int $J$ Obes (Lond). 2009;33:75-9.

43. Franks PW, Jablonski KA, Delahanty LM, McAteer JB, Kahn SE, Knowler WC, et al. Assessing gene-treatment interactions at the FTO and INSIG2 loci on obesity-related traits in the Diabetes Prevention Program. Diabetologia. 2008;51:2214-23.

44. Frayling TM, Timpson NJ, Weedon MN, Zeggini E, Freathy RM, Lindgren CM, et al. A Common Variant in the FTO Gene Is Associated with Body Mass Index and Predisposes to Childhood and Adult Obesity. Science. 2007;316:889-894.

45. Johnson L, van Jaarsveld CH, Emmett PM, Rogers IS, Ness AR, Hattersley AT, et al. Dietary energy density affects fat mass in early adolescence and is not modified by FTO variants. PLoS One. 2009;4:e4594.

46. Lappalainen TJ, Tolppanen AM, Kolehmainen M, Schwab U, Lindstrom J, Tuomilehto J, et al. The common variant in the FTO gene did not modify the effect of lifestyle changes on body weight: the Finnish Diabetes Prevention Study. Obesity (Silver Spring). 2009;17:832-6.

47. Haupt A, Thamer C, Heni M, Tschritter O, Machann J, Schick F, et al. Impact of variation near MC4R on whole-body fat distribution, liver fat, and weight loss. Obesity (Silver Spring). 2009;17:1942-5.

48. Kring SI, Holst C, Toubro S, Astrup A, Hansen T, Pedersen O, et al. Common variants near MC4R in relation to body fat, body fat distribution, metabolic traits and energy expenditure. Int J Obes (Lond). 2010;34:182-9.

49. Loos RJ, Lindgren CM, Li S, Wheeler E, Zhao JH, Prokopenko I, et al. Common variants near MC4R are associated with fat mass, weight and risk of obesity. Nat Genet. 2008;40:768-75.

50. Mariman E. Human Biology of Weight Maintenance after Weight Loss. Journal of nutrigenetics and nutrigenomics. 2012;5:13-38. 
51. Bouchard C, Tremblay A, Despres JP, Theriault G, Nadeau A, Lupien PJ, et al. The response to exercise with constant energy intake in identical twins. Obes Res. 1994;2:40010.

52. Hainer V, Stunkard AJ, Kunesova M, Parizkova J, Stich V, Allison DB. Intrapair resemblance in very low calorie diet-induced weight loss in female obese identical twins. Int $\mathrm{J}$ Obes Relat Metab Disord. 2000;24:1051-7.

53. Arner P, Spalding KL. Fat cell turnover in humans. Biochem Biophys Res Commun. 2010;396:101-4.

54. Spalding KL, Arner E, Westermark PO, Bernard S, Buchholz BA, Bergmann O, et al. Dynamics of fat cell turnover in humans. Nature. 2008;453:783-7.

55. Farnier C, Krief S, Blache M, Diot-Dupuy F, Mory G, Ferre P, et al. Adipocyte functions are modulated by cell size change: potential involvement of an integrin/ERK signalling pathway. Int J Obes Relat Metab Disord. 2003;27:1178-86.

56. Aubin D, Gagnon A, Grunder L, Dent R, Allen M, Sorisky A. Adipogenic and antiapoptotic protein levels in human adipose stromal cells after weight loss. Obes Res. 2004;12:1231-4.

57. Bennetzen MF, Wellner N, Ahmed SS, Ahmed SM, Diep TA, Hansen HS, et al. Investigations of the human endocannabinoid system in two subcutaneous adipose tissue depots in lean subjects and in obese subjects before and after weight loss. Int $\mathrm{J}$ Obes (Lond). 2005;35:1377-84

58. Capel F, Viguerie N, Vega N, Dejean S, Arner P, Klimcakova E, et al. Contribution of energy restriction and macronutrient composition to changes in adipose tissue gene expression during dietary weight-loss programs in obese women. $J$ Clin Endocrinol Metab. 2008;93:4315-22.

59. Langin D, Dicker A, Tavernier G, Hoffstedt J, Mairal A, Ryden M, et al. Adipocyte lipases and defect of lipolysis in human obesity. Diabetes. 2005;54:3190-7.

60. Walewski JL, Ge F, Gagner M, Inabnet WB, Pomp A, Branch AD, et al. Adipocyte accumulation of long-chain fatty acids in obesity is multifactorial, resulting from increased fatty acid uptake and decreased activity of genes involved in fat utilization. Obes Surg. 2010;20:93-107.

61. Marshall NS, Glozier N, Grunstein RR. Is sleep duration related to obesity? A critical review of the epidemiological evidence. Sleep Med Rev. 2008;12:289-98.

62. Patel SR, Hu FB. Short sleep duration and weight gain: a systematic review. Obesity (Silver Spring). 2008;16:643-53.

63. Chaput JP, Despres JP, Bouchard C, Tremblay A. The association between sleep duration and weight gain in adults: a 6-year prospective study from the Quebec Family Study. Sleep. 2008;31:517-23.

64. Nielsen LS, Danielsen KV, Sorensen TI. Short sleep duration as a possible cause of obesity: critical analysis of the epidemiological evidence. Obes Rev. 2011;12:78-92.

65. Knutson KL, Spiegel K, Penev P, Van Cauter E. The metabolic consequences of sleep deprivation. Sleep Med Rev. 2007;11:163-78.

66. Nedeltcheva AV, Kilkus JM, Imperial J, Kasza K, Schoeller DA, Penev PD. Sleep curtailment is accompanied by increased intake of calories from snacks. Am J Clin Nutr. 2009;89:12633.

67. Spiegel K, Tasali E, Penev P, Van Cauter E. Brief communication: Sleep curtailment in healthy young men is associated with decreased leptin levels, elevated ghrelin levels, and increased hunger and appetite. Ann Intern Med. 2004;141:846-50.

68. Gonnissen HK, Hursel R, Rutters F, Martens EA, Westerterp-Plantenga MS. Effects of sleep fragmentation on appetite and related hormone concentrations over $24 \mathrm{~h}$ in healthy men. $\mathrm{Br}$ J Nutr. 2012;1-9.

69. Gonnissen HK, Rutters F, Mazuy C, Martens EA, Adam TC, Westerterp-Plantenga MS. Effect of a phase advance and phase delay of the 24-h cycle on energy metabolism, appetite, and related hormones. Am J Clin Nutr. 2012;96:689-97. 
70. Hursel R, Rutters F, Gonnissen HK, Martens EA, Westerterp-Plantenga MS. Effects of sleep fragmentation in healthy men on energy expenditure, substrate oxidation, physical activity, and exhaustion measured over $48 \mathrm{~h}$ in a respiratory chamber.Am J Clin Nutr. 2011;94:804-8.

71. Leproult R, Van Cauter E. Role of sleep and sleep loss in hormonal release and metabolism. Endocr Dev. 2010;17:11-21.

72. Rutters F, Gonnissen HK, Hursel R, Lemmens SG, Martens EA, Westerterp-Plantenga MS. Distinct associations between energy balance and the sleep characteristics slow wave sleep and rapid eye movement sleep. Int J Obes (Lond). 2012;

73. Garaulet M, Ortega FB, Ruiz JR, Rey-Lopez JP, Beghin L, Manios Y, et al. Short sleep duration is associated with increased obesity markers in European adolescents: effect of physical activity and dietary habits. The HELENA study. Int J Obes (Lond). 2011;35:1308-17.

74. Nedeltcheva AV, Kilkus JM, Imperial J, Schoeller DA, Penev PD. Insufficient sleep undermines dietary efforts to reduce adiposity. Ann Intern Med. 2010;153:435-41.

75. Hernandez TL, Ballard RD, Weil KM, Shepard TY, Scherzinger AL, Stamm ER, et al. Effects of maintained weight loss on sleep dynamics and neck morphology in severely obese adults. Obesity (Silver Spring). 2009;17:84-91.

76. Chaput JP, Despres JP, Bouchard C, Tremblay A. Longer sleep duration associates with lower adiposity gain in adult short sleepers. Int J Obes (Lond). 2012; 


\section{CHAPTER 2 Effects of oligofructose on appetite profile, GLP-1 and PYY concentrations and energy intake}

Verhoef SPM, Meyer D, Westerterp KR $B J N, 2011 ; 106(11): 1757-62$ 


\begin{abstract}
In rats oligofructose has been shown to stimulate satiety hormone secretion, reduce energy intake and promote weight loss. This study aimed to examine the effect of oligofructose supplementation on appetite profiles, satiety hormone concentrations and energy intake in humans. Thirty-one healthy subjects (10 men, 21 women) aged $28 \pm 3$ y with a BMI of $24.8 \pm 0.3 \mathrm{~kg} / \mathrm{m}^{2}$ were included in a randomized double blind, crossover study. Subjects received $10 \mathrm{~g}$ oligofructose, $16 \mathrm{~g}$ oligofructose or $16 \mathrm{~g}$ placebo (maltodextrin) daily for 13 days, with a 2-week washout period between the treatments. Appetite profile, active glucagon-like peptide 1 (GLP-1) and peptide YY336 (PYY) concentrations and energy intake were assessed on day 0 and 13 of the treatment period. Time-by-treatment interaction revealed a trend for a reduction in energy intake over day $0-13$ by oligofructose $(p=0.068)$. Energy intake was significantly reduced (11\%) over time on day 13 compared to day 0 with $16 \mathrm{~g} / \mathrm{d}$ oligofructose $(2801 \pm 301$ vs. $3217 \pm 320 \mathrm{~kJ}, \mathrm{P}<0.05)$. Moreover, energy intake was significantly lower with $16 \mathrm{~g} / \mathrm{d}$ compared with $10 \mathrm{~g} / \mathrm{d}$ oligofructose on day $13(2801 \pm 301 \mathrm{vs}$. $3177 \pm 276 \mathrm{~kJ}$, $\mathrm{P}<0.05)$. Area under the curve (AUC) for GLP-1 on day 13 was significantly higher with $16 \mathrm{~g} / \mathrm{d}$ compared to $10 \mathrm{~g} / \mathrm{d}$ oligofructose $(45 \pm 4$ vs. $41 \pm 3 \mathrm{pmol} / \mathrm{Lxh}, \mathrm{P}<0.05)$. In the morning until the lunch $\mathrm{AUC}_{0-230 \mathrm{~min}}$ for $\mathrm{PYY}$ on day 13 was significantly higher with $16 \mathrm{~g} / \mathrm{d}$ compared to $10 \mathrm{~g} / \mathrm{d}$ oligofructose and placebo $(409 \pm 35$ vs. $222 \pm 19$ and $211 \pm 20$ $\mathrm{pg} / \mathrm{mlxh}, \mathrm{P}<0.01$ ). In conclusion, 16 and not $10 \mathrm{~g} / \mathrm{d}$ oligofructose may be an effective dose to reduce energy intake, possibly supported by higher GLP-1 and PYY concentrations.
\end{abstract}




\section{Introduction}

The prevalence of obesity has increased worldwide to epidemic proportions. Weight gain occurs when energy intake exceeds energy expenditure for a prolonged period of time. Therefore, novel foods that promote satiety and thereby reduce energy intake may be promising tools in weight management. A potential candidate ingredient for such foods is oligofructose, a fructan obtained as a partial enzymatic hydrolysate from chicory root inulin. It is fermented in the colon and it is especially known for its prebiotic effects and associated physiological effects (1-3).

The hypothesis that oligofructose might have beneficial effects on energy intake is based upon rat studies $(4,5)$. In rats, energy intake was decreased over time in the animals fed with oligofructose compared to the animals fed with a control diet. This resulted in a decrease in epidydimal fat mass and visceral adipose tissue at the end of the treatment $(6,7)$. In addition, glucagon-like peptide-1 (GLP-1) amide and proglucagon mRNA concentrations were found to be higher in the oligofructose-fed rats $(6,7)$. GLP-1 is released from enteroendocrine $L$ cells in response to nutrient ingestion. Fermentation of oligofructose into short-chain fatty acids (SCFA) in the gut has been shown to promote enteroendocrine L-cell differentiation in the proximal colon by upregulation of the differentiation factors (neurogenin 3 and NeuroD), thereby contributing to a higher endogenous GLP-1 production (8). GLP-1 was found to be essential in the control of food intake by oligofructose, since the beneficial effects of oligofructose were totally prevented in the presence of a GLP-1 receptor antagonist (9). In addition, GLP-1 receptor knockout mice $\left(\mathrm{GLP}-1 \mathrm{R}^{-/}\right.$) were completely insensitive to the actions of oligofructose (9).

Although animal studies suggest that oligofructose may be a promising tool in the nutritional approach to controlling obesity, only a few studies have investigated the effect of oligofructose in humans. For instance plasma GLP-1 concentrations significantly increased after oligofructose feeding of $20 \mathrm{~g} / \mathrm{d}$ for 7 days in patients with gastro esophageal reflux disease (10). It also has been demonstrated that inulin typefructans, added in food as fat-replacement, were able to lower energy intake (11). In a pilot study by Cani et al. (12), a two-week treatment with $16 \mathrm{~g} / \mathrm{d}$ oligofructose has been shown to promote satiety following breakfast and dinner, and to reduce hunger and prospective food consumption following dinner. Total energy intake per day was $5 \%$ lower during the oligofructose treatment than during the control treatment (12). These investigators also showed that with a different type of inulin consumption of $16 \mathrm{~g} / \mathrm{d}$ led to increased plasma levels of GLP-1 and PYY (13). Recently, a 12-week treatment with $21 \mathrm{~g} / \mathrm{d}$ oligofructose has been shown to increase the area under the curve (AUC) for the anorexigenic hormone peptide $Y$ (PYY) and to decrease the AUC for the orexigenic hormone ghrelin (14). Self-reported energy intake was significantly lower in the oligofructose group and there was a reduction in body weight of about $1 \mathrm{~kg}$ over 12 weeks (14).

However, information on the minimal dosage of oligofructose necessary for establishing beneficial effects is still lacking. Therefore, we performed a placebo-controlled crossover study to examine the effect of 10 and $16 \mathrm{~g} / \mathrm{d}$ oligofructose for 13 days on 
appetite profile, GLP-1 and PYY concentrations and energy intake in normal weight and overweight men and women.

\section{Subjects and methods}

\section{Subjects}

Thirty-one healthy subjects (10 men, 21 women) aged 20-60 y with a BMI of 23$28 \mathrm{~kg} / \mathrm{m}^{2}$ were recruited by advertisements in local newspapers and on notice boards at the university. Subjects underwent a screening and all were in good health, nonsmokers, not using medication (except for oral contraception) and moderate alcohol users. None of the subjects had a food allergy, gained or lost more than $5 \mathrm{~kg}$ in three months prior to the study, or were cognitive dietary restrained $(F 1>9)$ as assessed by a validated Dutch translation of the Three Factor Eating Questionnaire (TFEQ) (15). This study was conducted according to the guidelines laid down in the Declaration of Helsinki and all procedures involving human subjects were approved by the Central Committee on Human Research and by the Medical Ethical Committee of the University of Maastricht. Written informed consent was obtained from all subjects.

\section{Study design}

The study had a randomized, placebo-controlled crossover design. It consisted of three 13-day supplementation periods wherein oligofructose (Fructalose ${ }^{\circledR}$ L92, 10 or $16 \mathrm{~g}$, Sensus, Roosendaal, The Netherlands) or placebo (maltodextrin, 16g) supplements were consumed daily, separated by a 2-week washout period. Maltodextrin was selected as a placebo following previous studies on the effect of oligofructose $(12,14)$. Furthermore, maltodextrin has a similar taste and appearance as oligofructose. The supplements were provided in one-shot fruit drinks of $100 \mathrm{ml}$. Daily supplements were divided into two equal portions of either 5 or $8 \mathrm{~g}$, each to be consumed at home during breakfast and lunch. To determine the compliance, subjects kept the empty bottles and handed them in on later visits to the university. Potential adverse effects including flatulence, bloated feeling, abdominal rumbling and abdominal pain were monitored daily using a diary. Subjects were asked not to gain or lose weight consciously and to avoid pre- and probiotic foods as indicated on a provided list with food products. The subjects reported to the university six times at $0800 \mathrm{~h}$ after an overnight fast on day 0 and 13 of each intervention interval. They were asked to abstain from strenuous physical activity and alcohol, and not to eat or drink from 2200h the night before each test day. Energy intake and appetite profile ratings were determined on day 0 and 13. GLP-1 and PYY concentrations were determined on day 13.

\section{Study protocol}

On each test day subject's body weight was measured with minimal clothing in the fasted state. Subjects received a standardized breakfast at $0830 \mathrm{~h}$ consisting of $20 \%$ of the subject's individual daily energy requirements. Subject-specific daily energy 
requirements were derived from basal metabolic rate, which was calculated with the equation of Harris-Benedict (16). Basal metabolic rate was multiplied by an activity index of 1.5 , as indicated for a sedentary day (17). Breakfast consisted of brown bread with cheese and marmalade, and fruit yogurt (21, 62 and 17 En\% from respectively protein, carbohydrate, fat). At $1230 \mathrm{~h}$ subjects received a standardized lunch, which provided $40 \%$ of the subject's individual daily energy requirements. The lunch consisted of brown bread with egg and tuna sandwich salad, tomato soup and grape juice (18, 55 and 27 En\% from respectively protein, carbohydrate, fat). Food and energy intake were assessed on day 0 and 13 via an ad libitum dinner at 1700h, which consisted of a homogeneous hot pasta meal. The dinner was weighed before and after eating. Subjects were instructed to eat till they were comfortably full. The lasagna (1350g) provided $5 \mathrm{~kJ} / \mathrm{g} \mathrm{(31,45}$ and $24 \mathrm{En \%}$ from respectively protein, carbohydrate, fat). Appetite profile ratings were measured 16 times with regular intervals between 0830 and $2000 \mathrm{~h}$ on day 0 and 13 . On day 13, nine blood samples were collected at $0820,0900,0930,1030,1220,1300,1330,1430$ and $1530 \mathrm{~h}$, respectively in order to obtain GLP-1 and PYY concentrations over the day.

\section{Appetite profile}

Appetite profile ratings were evaluated using anchored $100-\mathrm{mm}$ visual analogue scales (VAS) $(18,19)$. Hunger, fullness, satiety, thirst, desire to eat and prospective food consumption were measured. The scale was anchored from 'not at all' on the left to 'extremely' on the right. Participants were instructed to rate their feelings by marking the scale with a vertical line at the point that was most appropriate at that time. The distance from the left end of the scale to this vertical line on the scale was measured in $\mathrm{mm}$; changes from baseline were calculated by subtracting the baseline score from the score at a certain time point. On each test day these questionnaires were completed at 0830, 0900, 0930, 1030, 1130, 1230, 1300,1330,1430, 1530h, 1630, $1700,1730,1800,1900$ and 2000h.

\section{Blood sampling}

On day 0 and day 13 a catheter was placed into the antecubital vein for blood sampling. Blood samples were collected in tubes containing EDTA, 10 $\mu$ I DPPIV per ml blood and 50 $\mathrm{ul}$ aprotonin per $\mathrm{ml}$ blood for measurements of PYY concentrations. For GLP-1 measurements, blood was collected in EDTA tubes containing 10 $\mu$ I DPPIV per $\mathrm{ml}$ blood. Plasma was obtained by centrifugation $\left(4^{\circ} \mathrm{C}, 1000 \times \mathrm{g}, 10 \mathrm{~min}\right)$ and stored at $-80^{\circ} \mathrm{C}$ until analyzed. PYY3-36 concentrations were measured with a specific and sensitive radioimmunoassay (Linco Research Inc., St Charles, MO, USA). Plasma active GLP-1 concentrations were measured by enzyme-linked immunoradiometric assay (EGLP-35K; Linco Research Inc., St Charles, MO, USA).

\section{Statistical analysis}

Data are presented as mean changes from baseline and their standard errors, unless otherwise indicated. Area under the curve (AUC) of changes from baseline over time 
was calculated by using the trapezoid method. A student's $t$ test (two-tailed distribution) was carried out to determine possible differences between the conditions. ANOVA repeated measures was carried out with a repeated covariance structure to determine possible differences in appetite ratings and energy intake between conditions, and time-by-treatment interactions. Significance was defined as $P<0.05$. All of the statistical analyses were executed with SPSS version 16.0 for Macintosh OS $X$ (SPSS Inc, Chicago, IL).

\section{Results}

\section{Subject characteristics}

Two subjects dropped out because of personal reasons. Twenty-nine subjects (9 men, 20 women) completed the study. The baseline characteristics of these subjects are presented in table 1. As expected, body weight and height were significantly different between men and women. Body weight did not change over time and there were no significant differences in body weight between the conditions. Moreover, no sex differences were present with respect to changes in measured variables, so the whole group was analyzed together.

Table 1: Subject characteristics (mean \pm SEM)

\begin{tabular}{llll}
\hline & $\mathrm{N}=29$ & Men $(\mathrm{n}=9)$ & Women $(\mathrm{n}=20)$ \\
\cline { 2 - 4 } Age $(\mathrm{y})$ & $28 \pm 3$ & $32 \pm 6$ & $26 \pm 3$ \\
Height $(\mathrm{m})$ & $1.73 \pm 0.02$ & $1.80 \pm 0.03$ & $1.70 \pm 0.02^{3}$ \\
Body Weight $(\mathrm{kg})$ & $74.7 \pm 2.0$ & $83.1 \pm 3.8$ & $70.9 \pm 1.8^{3}$ \\
BMI $^{1}\left(\mathrm{~kg} / \mathrm{m}^{2}\right)$ & $24.8 \pm 0.3$ & $25.5 \pm 0.6$ & $24.5 \pm 0.4$ \\
Dietary restraint $^{2}$ & $6.0 \pm 0.6$ & $4.8 \pm 1.0$ & $6.2 \pm 0.7$ \\
\hline
\end{tabular}

${ }^{1} \mathrm{BMI}=$ Body Mass Index

${ }^{2}$ Dietary restraint $=$ Factor 1 of the Three-Factor Eating Questionnaire ${ }^{(15)}$

${ }^{3}$ Significantly different from men, $\mathrm{P}<0.01$ (ANOVA)

\section{Appetite profile}

On day 0 AUC for appetite profile ratings was not significantly different between the three conditions. No time $x$ treatment differences were present with respect to the appetite profile ratings.

\section{$P Y Y$ and $G L P-1$}

Fasting PYY concentrations, but not fasting GLP-1 concentrations were significantly lower on day 13 compared to day 0 in all conditions $(49.9 \pm 4.4$ vs $71.2 \pm 3.9 \mathrm{pg} / \mathrm{mL}$ for placebo, $46.9 \pm 4.6$ vs $71.9 \pm 3.6 \mathrm{pg} / \mathrm{mL}$ for $10 \mathrm{~g} / \mathrm{d}$ oligofructose and $53.8 \pm 4.7$ vs $74.1 \pm 3.9 \mathrm{pg} / \mathrm{mL}$ for $16 \mathrm{~g} / \mathrm{d}$ oligofructose, $\mathrm{P}<0.01$ ). 
After the meals, PYY concentrations significantly increased in all conditions (figure 1A-B, $P<0.05)$. In the morning until the lunch AUC0-230min for PYY was significantly higher with $16 \mathrm{~g} / \mathrm{d}$ oligofructose than with $10 \mathrm{~g} / \mathrm{d}$ oligofructose and placebo $(409 \pm 35$ vs $222 \pm 19$ and $211 \pm 20 \mathrm{pg} / \mathrm{mLxh}, \mathrm{P}<0.01)$. This gradually diminished over the day, resulting in a trend for a larger total AUC for PYY with $16 \mathrm{~g} / \mathrm{d}$ than with $10 \mathrm{~g} / \mathrm{d}$ oligofructose or placebo $(P=0.065)$.

After the meals, GLP-1 concentrations also increased significantly in all conditions (figure 1C-D P<0.05). AUC for GLP-1 was significantly higher with 16g/d oligofructose compared to $10 \mathrm{~g} / \mathrm{d}$ oligofructose $(P<0.05)$. In addition, AUC for $G L P-1$ with $10 \mathrm{~g} / \mathrm{d}$ oligofructose was significantly lower compared to placebo $(P<0.05)$.

\section{Compliance and side effects}

Compliance was high, as shown by the empty packages returned at the end of each treatment. Incidentally subjects returned a full package, indicating a missed dose. The subjects also reported this in their diary, showing that missing doses remained below $5 \%$. Only a small proportion of these missing doses was on the day prior to the measurements, and no doses were missed on the day of the measurements.

Adverse effects, like flatulence, abdominal rumbling, bloated feeling and cramps were significantly higher for 10 and $16 \mathrm{~g} / \mathrm{d}$ oligofructose compared to placebo at several days during the treatment, respectively $(P<0.05$, data not shown). However, none of the subjects did complain about side effects and there were no significant time-by treatment interactions. Also, side effects did not influence compliance, since compliance was similar in the placebo treatment as with 10 and $16 \mathrm{~g} / \mathrm{d}$ oligofructose.

\section{Energy intake}

On day 0 , energy intake during the ad libitum dinner was similar for all the conditions $(2788 \pm 251,3127 \pm 267$ and $3217 \pm 321 \mathrm{~kJ}$ for respectively placebo, $10 \mathrm{~g} / \mathrm{d}$ and $16 \mathrm{~g} / \mathrm{d}$ oligofructose). Subsequently, energy intake was significantly lower on day 13 after the $16 \mathrm{~g} / \mathrm{d}$ oligofructose teatment $(11 \%, p<0.05)$ compared to $10 \mathrm{~g} / \mathrm{d}$ oligofructose $(2801 \pm 301$ vs. $3177 \pm 276 \mathrm{~kJ}, \mathrm{P}<0.05$, figure 2), but not compared to placebo $(2979 \pm 276 \mathrm{~kJ})$. 

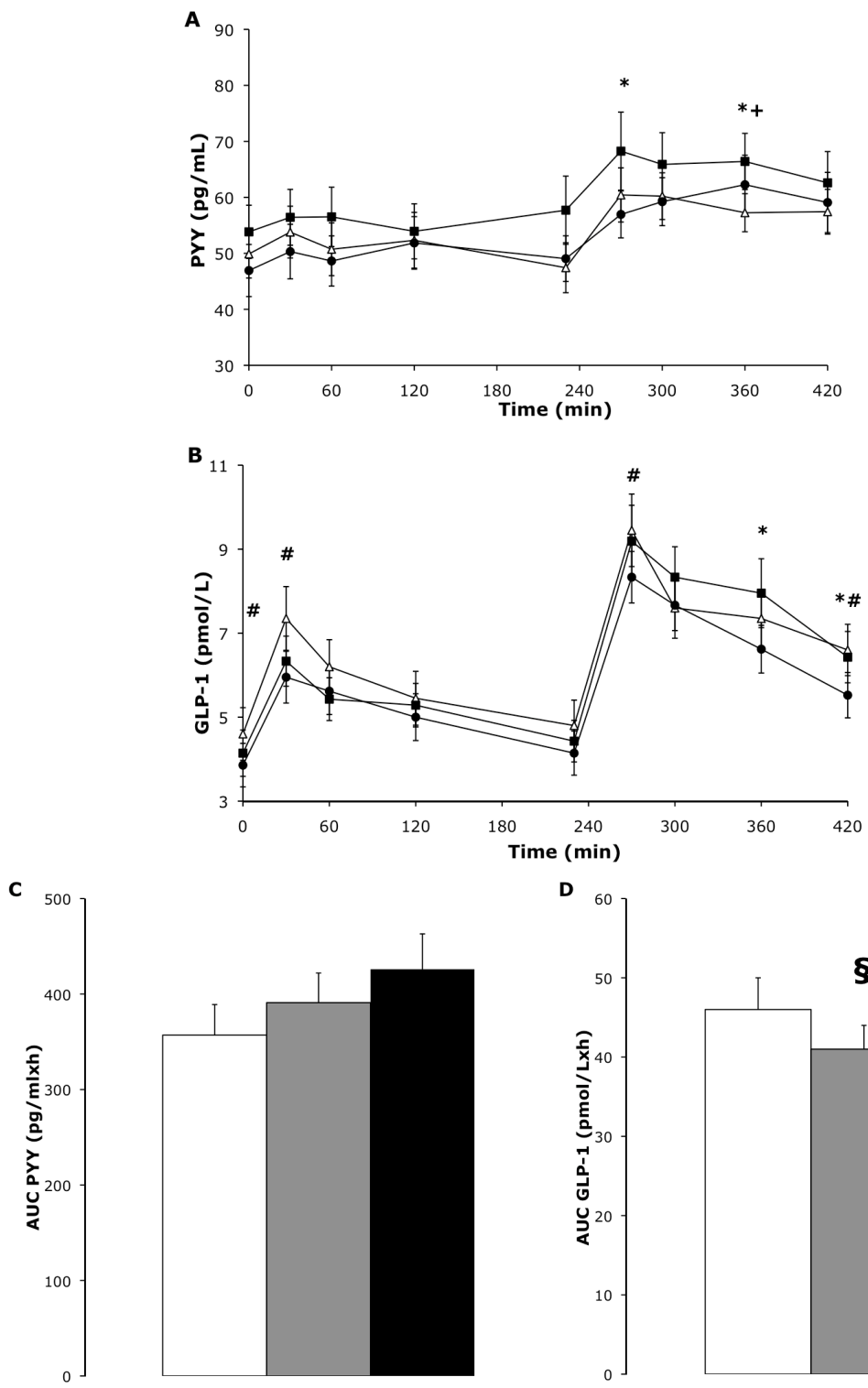

§
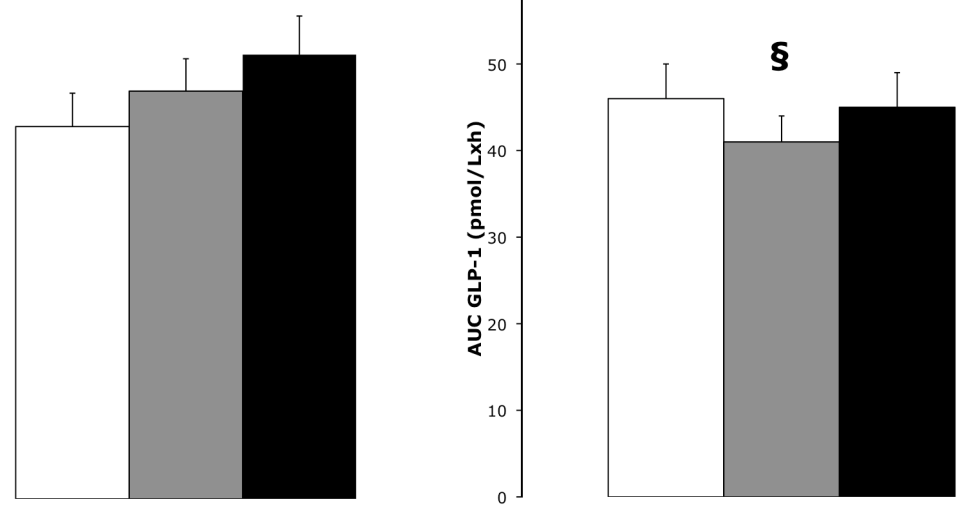

Figure 1. Mean ( \pm SEM) values for plasma $(A)$ peptide $Y Y 3-36$ (PYY; time-by-treatment interaction $\mathrm{P}=0.065$ ), and $(\mathrm{B})$ active glucagon-like peptide 1 (GLP-1; time-by-treatment interaction $\mathrm{P}=0.041)$ concentrations during day 13 as absolute concentrations $(\mathrm{pg} / \mathrm{mL}$, pmol/L) with breakfast consumed at $10 \mathrm{~min}$ and lunch at $250 \mathrm{~min}$, area under the curve (AUC) for (C) PYY3-36 and (D) active GLP-1 (pg/mmlxh, pmol/Lxh). 16g/d oligofructose ( $\square$, black), 10g/d oligofructose ( $\bullet$, grey) and placebo ( $\Delta$, white). * Significant difference between $16 \mathrm{~g} / \mathrm{d}$ oligofructose and $10 \mathrm{~g} / \mathrm{d}$ oligofructose, $\mathrm{P}<0.05$; + significant difference between $16 \mathrm{~g} / \mathrm{d}$ oligofructose and placebo, $\mathrm{P}<0.05$; \# significant difference between $10 \mathrm{~g} / \mathrm{d}$ oligofructose and placebo, $\mathrm{P}<0.05$; § significant difference between $10 \mathrm{~g} / \mathrm{d}$ oligofructose and $16 \mathrm{~g} / \mathrm{d}$ oligofructose and placebo, $P<0.05$ (ANOVA repeated measures). 


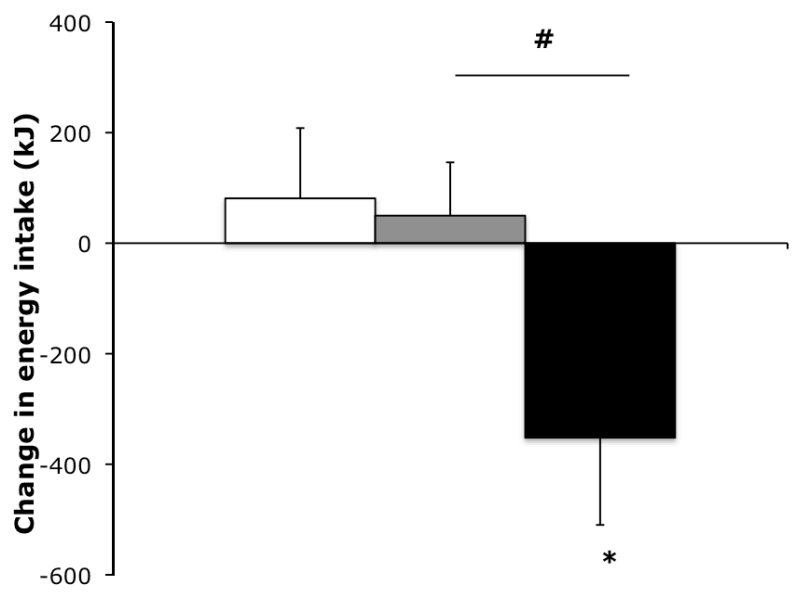

Figure 2. Changes in energy intake $(\mathrm{kJ})$ between day 0 and 13 after placebo, $10 \mathrm{~g} / \mathrm{d}$ oligofructose and $16 \mathrm{~g} / \mathrm{d}$ oligofructose treatment. Time-by-treatment interaction $\mathrm{P}=0.068$ \# significant difference between the conditions, ${ }^{*}$ significantly different from baseline, $\mathrm{P}<0.05$ (ANOVA repeatedmeasures).

\section{Discussion}

In this study the effect of oligofructose supplementation on appetite profiles, satiety hormone concentrations and energy intake in humans was examined. Energy intake decreased over time with $16 \mathrm{~g} / \mathrm{d}$ oligofructose, whereas consumption of $10 \mathrm{~g} / \mathrm{d}$ oligofructose did not change energy intake. There were no significant associations of the oligofructose-induced reduction in energy intake with appetite profile ratings.

Reduced energy intake on day 13 , with $16 \mathrm{~g} / \mathrm{d}$ oligofructose was underscored by higher $A U C_{0-230 m i n}$ of PYY hormone concentrations with $16 \mathrm{~g} / \mathrm{d}$ compared to $10 \mathrm{~g} / \mathrm{d}$ oligofructose and placebo, and higher $\mathrm{AUC}_{\text {total }}$ of GLP-1 hormone concentrations with $16 \mathrm{~g} / \mathrm{d}$ compared to $10 \mathrm{~g} / \mathrm{d}$ oligofructose, although not significantly different from placebo. Based on rat studies $(6,9,7)$, it is suggested that oligofructose intake results in increased GLP-1 and PYY concentrations mediated via the SCFA, which are produced by the fermentation of oligofructose. Previous studies in humans showed an increased AUC for PYY with 21 g/d oligofructose, whereas GLP-1 did not change (14). Moreover, fasting PYY concentrations on day 13 compared to day 0 were decreased in all conditions, suggesting an effect not specifically due to oligofructose consumption. However, the subjects may have experienced a different feedback of SCFA from the colon due to consumption of a different macronutrient and particularly fiber composition in general, resulting in an overall reduction of PYY.

The results on appetite profile ratings suggest that oligofructose does not suppress appetite. This is not consistent with previous findings (12). On the other hand, Archer et al. (11) could not find an effect for inulin on appetite at a lower dosage, but 
they did find a decrease in energy intake. However, differences in study design, such as standardized meals versus ad libitum and free choice meals, and differences in population size and type of inulin used complicate comparison between studies. In addition, measuring subjective appetite ratings with VAS can result in high variability $(18,19)$. Probably, oligofructose does not affect appetite feelings sufficiently to be detected with the use of VAS.

Observations on side effects as reported in the literature are not consistent. Several measurement methods are used, like diaries, questionnaires with 4-point scale (20) or VAS questionnaires (14). In addition, some studies report about side effects without explaining measurement procedures (12), or do not report about side effects at all (11). This makes it difficult to compare results between studies. We combined the VAS questionnaires with diaries to analyze occurrence of side effects over time. Consumption of 10 and $16 \mathrm{~g}$ oligofructose daily for 2 weeks did result in minor gastrointestinal side effects. However, no subjects complained, compliance was not affected by the side effects, and we did not observe a relation of side effects with energy intake.

The observed reduction of energy intake induced by $16 \mathrm{~g} / \mathrm{d}$ oligofructose over a time interval of 13 days is in agreement with earlier findings $(12,14)$. However, differences between $16 \mathrm{~g} / \mathrm{d}$ oligofructose and placebo were not significant. Since the placebo is a polysaccharide, there might be an effect of $16 \mathrm{~g} / \mathrm{d}$ maltodextrin itself on energy intake, through which the differences between placebo and $16 \mathrm{~g} / \mathrm{d}$ oligofructose become too small in order to reach significance. Maltodextrin, in higher concentrations (62.9g), has been shown to lower energy intake (21).

Energy intake did not change with $10 \mathrm{~g} / \mathrm{d}$ oligofructose. This suggests that only $16 \mathrm{~g} / \mathrm{d}$ oligofructose is a minimal dosage to induce an effect of oligofructose on energy intake. Our results suggest that oligofructose-induced reduction in energy intake might be exerted via increased GLP-1 and PYY concentrations.

A limitation of this study is the nature of the treatment. With such a minimum dosage, i.e. $16 \mathrm{~g} / \mathrm{d}$ as compared to $21 \mathrm{~g} / \mathrm{d}$ in other studies, the study needs more sensitivity. A larger number of subjects and a longer period of time may have shown more robust results. However, we found for consumption of $16 \mathrm{~g} / \mathrm{d}$ oligofructose a trend for a time-by-treatment effect over 13 days, as well as lower energy intakes at the final day of treatment. The latter was supported by higher AUC concentrations of GLP-1 and for PYY in the morning. Another limitation of this study is that we did not measure SCFA. Although measuring SCFA in vivo in humans is challenging, combining SCFA measurements in both faeces and blood could contribute to explaining the mechanism behind the effect of oligofructose on energy intake.

In conclusion, 16 and not $10 \mathrm{~g} / \mathrm{d}$ oligofructose may be an effective dose to reduce energy intake in normal weight and overweight men and women, underscored by elevated GLP-1 and PYY concentrations.

\section{Acknowledgments}

D. Meyer designed the study. S.P.M. Verhoef collected and analyzed the data and wrote the manuscript. K.R. Westerterp contributed to the interpretation of the data en 
reviewed the manuscript. The study was executed under supervision of K.R. Westerterp. All authors read and approved the final manuscript. The study was financially supported by Sensus. None of the authors had any conflict of interest.

\section{References}

1. Delzenne NM, Kok N. Effects of fructans-type prebiotics on lipid metabolism. Am J Clin Nutr. 2001;73:456S-458S.

2. Meyer D, Stasse-Wolthuis M. The bifidogenic effect of inulin and oligofructose and its consequences for gut health. Eur J Clin Nutr. 2009;63:1277-1289.

3. Roberfroid MB. Inulin-type fructans: functional food ingredients. J Nutr. 2007;137:2493S$2502 S$.

4. Delzenne NM, Cani PD, Daubioul C, Neyrinck AM. Impact of inulin and oligofructose on gastrointestinal peptides. Br J Nutr. 2005;93 Suppl 1:S157-161.

5. Delzenne NM, Cani PD, Neyrinck AM. Modulation of glucagon-like peptide 1 and energy metabolism by inulin and oligofructose: experimental data. J Nutr. 2007;137:2547S-2551S.

6. Cani PD, Dewever C, Delzenne NM. Inulin-type fructans modulate gastrointestinal peptides involved in appetite regulation (glucagon-like peptide-1 and ghrelin) in rats. $\mathrm{Br} \mathrm{J}$ Nutr. 2004;92:521-526.

7. Cani PD, Neyrinck AM, Maton N, Delzenne NM. Oligofructose promotes satiety in rats fed a high-fat diet: involvement of glucagon-like Peptide-1. Obes Res. 2005;13:1000-1007.

8. Cani PD, Hoste S, Guiot Y, Delzenne NM. Dietary non-digestible carbohydrates promote Lcell differentiation in the proximal colon of rats. Br J Nutr. 2007;98:32-37.

9. Cani PD, Knauf C, Iglesias MA, Drucker DJ, Delzenne NM, Burcelin R. Improvement of glucose tolerance and hepatic insulin sensitivity by oligofructose requires a functional glucagon-like peptide 1 receptor. Diabetes. 2006;55:1484-1490.

10. Piche T, des Varannes SB, Sacher-Huvelin S, Holst JJ, Cuber JC, Galmiche JP. Colonic fermentation influences lower esophageal sphincter function in gastroesophageal reflux disease. Gastroenterology. 2003;124:894-902.

11. Archer BJ, Johnson SK, Devereux HM, Baxter AL. Effect of fat replacement by inulin or lupin-kernel fibre on sausage patty acceptability, post-meal perceptions of satiety and food intake in men. Br J Nutr. 2004;91:591-599.

12. Cani PD, Joly E, Horsmans $Y$, Delzenne NM. Oligofructose promotes satiety in healthy human: a pilot study. Eur J Clin Nutr. 2006;60:567-572.

13. Cani PD, Lecourt E, Dewulf EM, Sohet FM, Pachikian BD, Naslain D, De Backer F, Neyrinck AM, Delzenne NM. Gut microbiota fermentation of prebiotics increases satietogenic and incretin gut peptide production with consequences for appetite sensation and glucose response after a meal. Am J Clin Nutr. 2009;90:1236-1243.

14. Parnell JA, Reimer RA. Weight loss during oligofructose supplementation is associated with decreased ghrelin and increased peptide $\mathrm{YY}$ in overweight and obese adults. Am J Clin Nutr. 2009;89:1751-1759.

15. Stunkard AJ, Messick S. The three-factor eating questionnaire to measure dietary restraint, disinhibition and hunger. J Psychosom Res. 1985;29:71-83.

16. Harris J, Benedict F. A Biometric Study of Human Basal Metabolism in Man. Carnegie institution of Washington: Washington, DC. 1919.

17. Westerterp KR, Kester AD. Physical activity in confined conditions as an indicator of freeliving physical activity. Obes Res. 2003;11:865-868.

18. Flint A, Raben A, Blundell JE, Astrup A. Reproducibility, power and validity of visual analogue scales in assessment of appetite sensations in single test meal studies. Int $\mathrm{J}$ Obes Relat Metab Disord. 2000;24:38-48. 
19. Stubbs RJ, Hughes DA, Johnstone AM, Rowley E, Reid C, Elia M, Stratton R, Delargy H, King N, Blundell JE. The use of visual analogue scales to assess motivation to eat in human subjects: a review of their reliability and validity with an evaluation of new hand-held computerized systems for temporal tracking of appetite ratings. Br J Nutr. 2000;84:405-415.

20. Peters HP, Boers HM, Haddeman E, Melnikov SM, Qvyjt F. No effect of added beta-glucan or of fructooligosaccharide on appetite or energy intake. Am J Clin Nutr. 2009;89:58-63.

21. Yeomans MR, Gray RW, Conyers TH. Maltodextrin preloads reduce food intake without altering the appetiser effect. Physiol Behav. 1998;64:501-506. 


\section{Chapter 3 No effects of Korean pine nut triacylglycerol on satiety and energy intake}

Verhoef SPM and Westerterp KR Nutr \& Metab, 2011; 8(1):79 


\begin{abstract}
Triacylglycerols (TAG) have been shown to have potential appetite suppressing effects. This study examined the effects of $3 \mathrm{~g}$ and $6 \mathrm{~g}$ Korean pine nut triacylglycerols (PinnoThin) on appetite and energy intake. $130 \mathrm{~g}$ Isoenergetic yogurt containing either placebo (milk fat) or PinnoThin TAG was consumed as a breakfast, after an overnight fast, in a double blind randomized crossover design. Appetite profile ratings were determined by visual analogue scale at regular intervals for a period of $4 \mathrm{~h}$ after the breakfast. In phase I, $6 \mathrm{~g}$ PinnoThin TAG and placebo was tested in thirty-three healthy women (mean $\pm S D$, BMI $26.4 \pm 3.8 \mathrm{~kg} / \mathrm{m}^{2}$; age $28 \pm 10$ y) to determine the appetite suppressing effect in time. In phase II, an additional dose of $3 \mathrm{~g}$ PinnoThin TAG, as well as $6 \mathrm{~g}$ PinnoThin TAG and placebo, was tested in thirty-four women (BMI $25.8 \pm 2.9 \mathrm{~kg} / \mathrm{m}^{2}$; age $25 \pm 9$ y) to determine energy intake from an ad libitum lunch offered at $210 \mathrm{~min}$ after the breakfast, at which maximal differences in appetite profile ratings were present in phase I. Area under the curve of appetite profile ratings was not significantly different between the conditions. Energy intake was $9.5 \%$ lower after $6 \mathrm{~g}$ PinnoThin TAG compared with $3 \mathrm{~g}$ PinnoThin TAG, but there was no significant difference with the placebo. To conclude, a dosage of $6 \mathrm{~g}$ PinnoThin TAG is not sufficient to suppress appetite and energy intake.
\end{abstract}




\section{Introduction}

An effective strategy to prevent the positive energy balance resulting in obesity is still lacking. It has been shown that a positive energy balance of $50 \mathrm{kcal}$ per day already results in an increase in body weight of at least one kilo per year (1). A potential prevention strategy is by reducing food intake via the use of (natural) appetite suppressants.

Different macronutrients exert various postprandial effects and stimulate the release of satiety hormones to different degrees. Fat intake is known to induce the release of gastro-intestinal hormones, like cholecystokinin (CCK) and glucagon-like peptide-1 (GLP-1). Both CCK and GLP-1 have shown to be involved in the development of satiation, by suppressing appetite and energy intake (2-5). The satiating effect of fat is influenced by chain length and the degree of saturation of the fatty acids. Only fatty acids with chain lengths $\geq \mathrm{C} 12$ are capable of reducing food intake and releasing CCK and GLP-1 $(6,7)$. Furthermore, long-chain fatty acids have been shown to be more effective than medium-chain fatty acids $(8,9)$. Regarding the degree of saturation, it has been shown that polyunsaturated fatty acids (PUFAs) have a more potent effect on reducing food intake and increasing the release of satiety hormones than monounsaturated fatty acids (MUFAs) (8).

PinnoThin is an oil from Korean pine nuts (Pinus Koraiensis) which consists of 66\% polyunsaturated fatty acids (PUFAs; linoleic (C18:2) and pinolenic acid (C18:3)) and 26\% monounsaturated fatty acids (MUFAs; oleic acid (C18:1)) (10). The large amounts of PUFAs in PinnoThin suggest that PinnoThin might be able to reduce appetite by the induction of satiety hormones.

Previous studies have shown that PinnoThin triacylglycerol (TAG) and free fatty acids (FFA) can produce an increase in CCK and GLP-1 release in post-menopausal overweight women (11). AUC of appetite ratings were not significantly different after the consumption of PinnoThin (FFA and TAG) (11), probably because the study was underpowered with only 18 overweight postmenopausal women. Moreover, observations were not corrected for baseline measurements, leading to the question whether the results were based upon clear statistically significant differences between treatment and placebo. No effects of PinnoThin TAG on appetite ratings were found in a study with 42 overweight women (12). In contrast, in the same study $2 \mathrm{~g}$ PinnoThin FFA resulted in a trend for reduced energy intake (7\% reduction, $P=0.09)$ (12). The authors suggest that the lack of an effect of PinnoThin TAG could be attributed to the timing of the dosing regime. Absorption of fatty acids in the gut from TAG is slower compared to FFA, consequently the time between consumption of PinnoThin TAG and the ad libitum lunch (30 min) was probably too short to detect an effect.

The present study was designed to measure the effect of PinnoThin TAG (66\% PUFAs and $26 \%$ MUFAs), in a sufficient number of subjects. In a first phase, the effect of PinnoThin TAG on appetite ratings was evaluated. To overcome the problem of timing of the dosing regime we determined the sensitive moment in time, at which maximal differences between one dosage of PinnoThin TAG and placebo in appetite profile ratings were present, in this first phase. In a second phase, the effect of two 
dosages of PinnoThin TAG vs. placebo on energy intake at this previously determined relevant time point was evaluated to determine the minimum effective dosage.

\section{Subjects and methods}

\section{Subjects}

Thirty-nine healthy women aged 18-45 y with a BMI of $23-30 \mathrm{~kg} / \mathrm{m}^{2}$ were recruited by advertisements in local newspapers and on notice boards at the university. All subjects underwent a screening and were in good health, regularly consuming breakfast, nonsmokers, not using medication (except for oral contraception) and at most moderate alcohol users. None of the subjects had a food allergy, had gained or lost more than $5 \mathrm{~kg}$ in three months prior to the study, or were cognitively dietary restrained (F1 $>13$ ) as assessed by a validated Dutch translation of the Three Factor Eating Questionnaire (TFEQ) (13). This study was conducted according to the guidelines laid down in the Declaration of Helsinki and all procedures involving human subjects were approved by the Central Committee on Human Research and by the Medical Ethical Committee of the University of Maastricht. Written informed consent was obtained from all subjects.

\section{Study protocol}

The study had a double blind, randomized, crossover design. Test day were scheduled in the same phase of the subjects' menstrual cycle, at least one menstrual cycle apart. Subjects were provided with a meal to consume at home on the evening prior to each test day. They were asked to abstain from strenuous physical activity and not to eat or drink from $2200 \mathrm{~h}$ the night before the test day. The subjects reported to the university at $0845 \mathrm{~h}$ after an overnight fast. At $0900 \mathrm{~h}$ the subjects received a yogurt breakfast $(130 \mathrm{~g})$ containing either PinnoThin TAG or placebo (milk fat).

The study consisted of two phases, with the results of phase I determining the timing of the measurement in phase II. During phase I, appetite ratings were determined at regular intervals for a period of $4 \mathrm{~h}$ after the test breakfast with $6 \mathrm{~g}$ PinnoThin TAG or $6 \mathrm{~g}$ placebo. In phase II, an ad libitum lunch was offered at the previously determined sensitive moment in time, based on the maximal differences in appetite profile ratings in phase $\mathrm{I}$. In addition to $6 \mathrm{~g}$ PinnoThin TAG and $6 \mathrm{~g}$ placebo, an extra dose of $3 \mathrm{~g}$ PinnoThin TAG was tested with a yogurt breakfast containing a mixture of $3 \mathrm{~g}$ PinnoThin TAG and $3 \mathrm{~g}$ milk fat.

\section{Appetite ratings}

Appetite was evaluated using anchored $100-\mathrm{mm}$ visual analogue scales (VAS) in both phase I and II $(14,15)$. Hunger, fullness, satiety, thirst, desire to eat, prospective food consumption and nausea were assessed. The scale was anchored from 'not at all' on the left to 'extremely' on the right. On each test day, these questionnaires were com- 
pleted before breakfast at $0855 \mathrm{~h}$, after breakfast at 0915 and $0930 \mathrm{~h}$ and every 30 minutes thereafter (1000, 1030, 1100, 1130, 1200, 1230 and 1300h).

\section{Yogurt breakfast}

Breakfast was a yogurt (130 g) containing either $6 \mathrm{~g}$ milk fat, $3 \mathrm{~g}$ PinnoThin TAG and $3 \mathrm{~g}$ milk fat or $6 \mathrm{~g}$ PinnoThin TAG, which provided 46, 11 and 43 En\% from carbohydrate, protein and fat respectively. The energy content of the breakfast was 523kJ. PinnoThin TAG consists of $66 \%$ polyunsaturated fatty acids (PUFAs; linoleic (C18:2) and pinolenic acid (C18:3)) and 26\% monounsaturated fatty acids (MUFAs). The subjects were instructed to consume the yogurt within 5 minutes and to hold each spoon of yogurt in their mouth for $5-10$ seconds before swallowing.

The yogurts were produced by NIZO Food Research b.v. (Ede, The Netherlands) with either PinnoThin TAG (Lipid Nutrition b.v., Wormerveer, The Netherlands) or milk fat (Corman b.v., Goé, Belgium) and were flavored with a mixture of orange, apple (SVZ, Breda, The Netherlands), lemon and passion fruit (Givaudan b.v., Barneveld, The Netherlands). The yogurts did not differ in color, flavour or viscosity.

\section{Energy intake}

Food and energy intake were determined using an ad libitum lunch in phase II. Lunch consisted of Turkish bread $(330 \mathrm{~g})$ with egg salad $(600 \mathrm{~g})$ and was weighed before and after eating. Subjects were instructed to eat till they were comfortably full. The lunch had an energy density of $11.5 \mathrm{~kJ} / \mathrm{g}$ with 44,17 and $39 \mathrm{En} \%$ from carbohydrate, protein and fat respectively.

\section{Statistical analysis}

Since baseline values did not differ, data are presented as mean changes from baseline and their standard errors, unless otherwise indicated. The area under the curve (AUC) of changes from baseline over time (4h for appetite ratings) was calculated using the trapezoid method. A repeated-measures ANOVA was carried out to determine possible differences in appetite ratings and energy intake between the PinnoThin TAG ( $3 \mathrm{~g}$ and $6 \mathrm{~g}$ ) and placebo breakfast. Significance was defined as $P<0.05$, unless otherwise indicated. A power calculation was performed to determine the number of subjects required and was based on a difference in food intake after intake of $2 \mathrm{~g}$ PinnoThin FFA observed in a previous study (12). With an observed difference of $7 \%$ and a standard deviation of $10 \%$, it was calculated that after taking a $15 \%$ dropout into account 30 subjects were needed to achieve sufficient power $(90 \%)$ to observe significant $(\mathrm{P}<0.05)$ changes in food intake as a result of the treatment. All of the statistical analyses were executed with SPSS version 16.0 for Macintosh OS X (SPSS Inc, Chicago, IL). 


\section{Results}

\section{Subject characteristics}

Thirty-three women participated in phase I. Five women of this group did not participate in phase II, because of personal reasons and/or lack of time. Six new female subjects were recruited for phase II, and together with the remaining 28 , a total of 34 women completed the second set of experiments. Subject characteristics of both phases are presented in table 1.

Table 1: Subject characteristics (mean \pm SEM)

\begin{tabular}{lll}
\hline & Phase I & Phase II \\
\cline { 2 - 3 } Age $(\mathrm{y})$ & 33 women & 34 women \\
\cline { 2 - 3 } Height $(\mathrm{m})$ & $1.69 \pm 0.01$ & $25 \pm 2$ \\
Body Weight $(\mathrm{kg})$ & $75.6 \pm 1.9$ & $1.70 \pm 0.01$ \\
BMI $\left(\mathrm{kg} / \mathrm{m}^{2}\right)$ & $26.4 \pm 0.4$ & $74.3 \pm 1.7$ \\
Dietary restraint & $7.1 \pm 0.7$ & $25.8 \pm 0.5$ \\
\hline
\end{tabular}

$\mathrm{BMI}=$ Body Mass Index

"28 subjects completed both phases. Five women dropped out before phase II was completed and therefore six new subjects were recruited for phase II.

"Dietary restraint $=$ Factor 1 score of the Three-Factor Eating Questionnaire (13)

\section{Phase I}

Hunger ratings were significantly decreased after $6 \mathrm{~g}$ PinnoThin TAG compared with placebo at 210 min after the breakfast (6 (SEM 4) v. 14 (SEM 4) mm VAS; $P<0.05$; figure 1a). Prospective food consumption was decreased after PinnoThin TAG compared to placebo at 210 min after the breakfast (0 (SEM 4) v. 8 (SEM 3) mm VAS; P < 0.05 ; figure 1e). The time-by-treatment interaction did not reach significance and the AUC for the appetite ratings was not significantly different between the treatments. Based on these results, in phase II an ad libitum lunch was offered at 210 min after breakfast with placebo, $3 \mathrm{~g}$ or $6 \mathrm{~g}$ PinnoThin TAG.

\section{Phase II}

The time-by-treatment interaction did not reach significance and also the AUC for the appetite ratings was not significantly different between the treatments. Appetite ratings over time were comparable between phase I and II.

Energy intake was decreased significantly by $9.5 \%$ after the breakfast with $6 \mathrm{~g}$ PinnoThin TAG compared with the breakfast with $3 \mathrm{~g}$ PinnoThin TAG $(\mathrm{P}<0.05$; table 2). The lowered energy intake after $6 \mathrm{~g}$ PinnoThin TAG did not reach significance compared with the placebo. In addition, there was no significant difference between energy intake after $3 \mathrm{~g}$ PinnoThin TAG and placebo. These results remain similar after correcting energy intake for body weight, height and age of each subject. This was done by defining energy intake as a \% of energy requirement (ER), calculated according to the Harris-Benedict equations, multiplied by an activity index of 1.7 (16). 

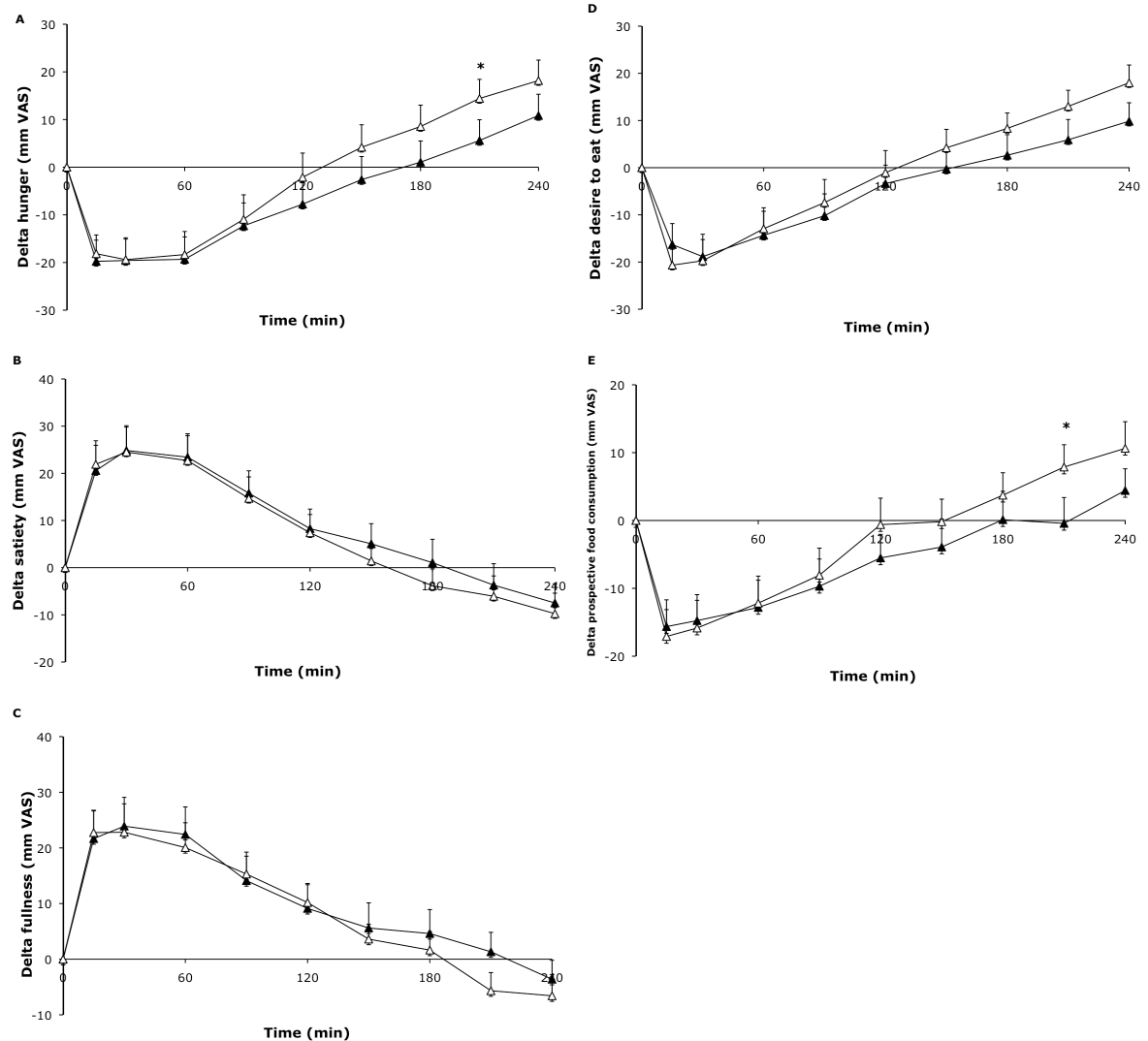

Time $(\min )$

Figure 1. Changes in hunger (A), satiety (B), fullness (C), desire to eat (D) and prospective food consumption (E) (all in $\mathrm{mm}$ visual analogue scale; VAS) over time (min) after a yogurt breakfast with either placebo $(\Delta)$ or $6 g$ PinnoThin TAG $(\boldsymbol{\Delta})$ expressed as changes from baseline in 33 women (phase I). Values are means, with standard errors represented by vertical bars. " $P<0.05$ with repeated-measures ANOVA.

Ratings of liking of the yogurt breakfast, nausea and thirst were not different between the treatments. Nausea ratings were extremely low and changes from baseline over time did not become positive. No adverse events were reported.

Table 2. Food (gram) and energy (kJ) measured with an ad libitum lunch $210 \mathrm{~min}$ after a breakfast with placebo, $3 \mathrm{~g}$ and $6 \mathrm{~g}$ PinnoThin TAG in 34 women in phase II (mean \pm SEM)

Food intake (gram)

\begin{tabular}{lll} 
Placebo & $3 \mathrm{~g}$ TAG & $6 \mathrm{~g}$ TAG \\
\hline $312 \pm 13$ & $327 \pm 11$ & $296 \pm 11^{*}$ \\
$3594 \pm 150$ & $3766 \pm 134$ & $3409 \pm 130^{*}$
\end{tabular}

Energy intake (kJ)

Significant different from $3 \mathrm{~g}$ PinnoThin: $\mathrm{P}<0.05$ (repeated-measures ANOVA). 


\section{Discussion}

The time-by-treatment interaction and differences in AUC for the appetite ratings were not significant in both phases. Energy intake was reduced by $9.5 \%$ after supplementation of $6 \mathrm{~g}$ PinnoThin TAG compared with $3 \mathrm{~g}$ PinnoThin TAG. However, the reduction in energy intake after $6 \mathrm{~g}$ PinnoThin TAG when compared with placebo did not reach significance.

If PinnoThin TAG indeed acts as an appetite suppressant, it would be expected that PinnoThin TAG suppresses appetite measured via appetite profile ratings with VAS. However, the time-by-treatment interaction was not significant. In the study of Hughes et al. (12), there were also no effects of $6 \mathrm{~g}$ PinnoThin TAG on appetite ratings, and in the study of Pasman et al. (11) PinnoThin TAG only marginally affected appetite ratings. These studies had major differences between the study protocols. For example, PinnoThin was consumed $3.5 \mathrm{~h}$ after the breakfast in the Hughes study, instead of simultaneously with a breakfast after an overnight fast in this study, as well as the Pasman study. Previous studies supplemented PinnoThin in a capsule (11, 12), whereas in this study PinnoThin TAG was incorporated in a yogurt breakfast. Also, milk fat instead of olive oil was used as a placebo in this study. In addition, the Pasman study was underpowered with only 18 postmenopausal overweight women (11). Our sample size was sufficiently large to reach power.

Differences between FFA and TAG also cause the contradictory results in the literature. FFAs have a stronger effect on CCK release, fullness and hunger ratings and energy intake compared with TAGs (17). FFAs can directly exert effects in the gut, whereas FFAs from TAGs are released during intestinal lipolysis. In the Hughes study food intake (grams), and not energy intake $(\mathrm{kJ})$, was reduced during an ad libitum lunch 30 min after supplementation of $2 \mathrm{~g}$ FFA, while PinnoThin TAG did not have an effect on food nor energy intake (12). It has been suggested that the short amount of time between PinnoThin TAG supplementation and the ad libitum lunch can explain the absence of an effect on energy intake in Hughes study (12). The rate of small intestinal lipolysis of TAGs is unknown, and seems to depend on several factors (17), like the rate of pancreatic lipase secretion and also the rate of entry of TAGs into the duodenum. In turn, the latter depends on the rate of gastric emptying, which varies with the amount and physical properties of the meal (18). Therefore, the concentration of FFA required in the intestine to suppress energy intake is still unclear (17). Furthermore, only two out of three fatty acids will become available from TAG. This suggests that a same dosage of FFA would elicit a stronger effect on energy intake compared with TAG. To get around these unknown variables we optimized the measurements by determining energy intake at a previous determined sensitive moment in time, at which maximal differences in appetite profile ratings were present. However, the reduction in energy intake after $6 \mathrm{~g}$ PinnoThin TAG when compared with placebo did not reach significance. The observed effects of PinnoThin TAG may become stronger when a higher dose is supplemented. However, a higher dose is not desirable for physiological and industrial reasons. With PinnoThin TAG being a fat, a higher dose might not result in a net reduction of total daily fat intake. Furthermore, the acute effects of a single dose of PinnoThin TAG could be different from the effects 
after a long-term trial, but no studies thus far have investigated the effect of PinnoThin TAG in the long term.

In this study, unlike earlier studies, the effect of 2 dosages PinnoThin TAG on energy intake is determined at a previously determined sensitive moment in time, in a sufficiently large number of subjects to reach power (to detect an effect size of $7 \%$ with a power of $90 \%$ at $\mathrm{P}=0.05)$. Although no appetite suppressing effect of PinnoThin TAG is found in the concentrations used in this study, the results significantly contribute to the field of research on potential appetite suppressants. Clearly, a lowest dosage as possible is preferred for physiological as well as industrial reasons. In order to find a minimum effective dosage it is important to perform studies with several dosages. Further studies need to be done to determine whether higher concentrations of PinnoThin TAG do have an appetite suppressing effect. From these results we conclude that a dosage of $6 \mathrm{~g}$ PinnoThin TAG is not sufficient to suppress appetite sensations and energy intake.

\section{Acknowledgements}

SV collected and analyzed the data and wrote the manuscript. KW contributed to the interpretation of the data and reviewed the manuscript. The study was executed under supervision of KW. All authors read and approved the final manuscript. We would like to thank dr. A.G. Nieuwenhuizen and dr. L. Mennen for participation in designing the study. The authors declare that they have no competing interests.

\section{References}

1. Brown W, Williams L, Ford J, Ball K, Dobson A. Identifying the energy gap: magnitude and determinants of 5-year weight gain in midage women. Obes Res. 2005;13:1431-1441.

2. Beglinger $C$, Degen $L$. Fat in the intestine as a regulator of appetite--role of CCK. Physiology \& Behavior. 2004;83:617-621.

3. Burton-Freeman B, Davis PA, Schneeman BO. Plasma cholecystokinin is associated with subjective measures of satiety in women. Am J Clin Nutr. 2002;76:659-667.

4. Flint A, Raben A, Astrup A, Holst J. Glucagon-like peptide 1 promotes satiety and suppresses energy intake in humans. J Clin Invest. 1998;101:515-520.

5. Gutzwiller JP, Goke B, Drewe J, Hildebrand P, Ketterer S, Handschin D, Winterhalder R, Conen D, Beglinger C. Glucagon-like peptide-1: a potent regulator of food intake in humans. Gut. 1999;44:81-86.

6. Feltrin KL, Little TJ, Meyer JH, Horowitz M, Smout AJPM, Wishart J, Pilichiewicz AN, Rades $\mathrm{T}$, Chapman IM, Feinle-Bisset C. Effects of intraduodenal fatty acids on appetite, antropyloroduodenal motility, and plasma CCK and GLP-1 in humans vary with their chain length. Am J Physiol Regul Integr Comp Physiol. 2004;287:R524-533.

7. Matzinger D, Degen L, Drewe J, Meuli J, Duebendorfer R, Ruckstuhl N, D'Amato M, Rovati $\mathrm{L}$, Beglinger $\mathrm{C}$. The role of long chain fatty acids in regulating food intake and cholecystokinin release in humans. Gut. 2000;46:689-694.

8. Lawton C, Delargy H, Brockman J, Smith F, Blundell J. The degree of saturation of fatty acids influences post-ingestive satiety. Br J Nutr. 2000;83:473-482. 
9. McLaughlin J, Lucł MG, Jones MN, D'Amato M, Dockray GJ, Thompson DG. Fatty acid chain length determines cholecystokinin secretion and effect on human gastric motility. Gastroenterology. 1999;116:46-53.

10. Wolff R, Bayard C. Fatty acid composition of some pine seed oils. Journal of the American Oil Chemists' Society. 1995;72:1043-1046.

11. Pasman W, Heimerikx J, Rubingh C, van den Berg R, O'Shea M, Gambelli L, Hendriks H, Einerhand A, Scott C, Keizer H, Mennen L. The effect of Korean pine nut oil on in vitro CCK release, on appetite sensations and on gut hormones in post-menopausal overweight women. Lipids in Health and Disease. 2008;7:10.

12. Hughes G, Boyland E, Williams N, Mennen L, Scott C, Kirkham T, Harrold J, Keizer H, Halford $\mathrm{J}$. The effect of Korean pine nut oil (PinnoThinTM) on food intake, feeding behaviour and appetite: A double-blind placebo-controlled trial. Lipids in Health and Disease. 2008;7:6.

13. Stunkard A, Messick S. The three-factor eating questionnaire to measure dietary restraint, disinhibition and hunger. J Psychosom Res. 1985;29:71-83.

14. Flint A, Raben A, Blundell J, Astrup A. Reproducibility, power and validity of visual analogue scales in assessment of appetite sensations in single test meal studies. Int $\mathrm{J}$ Obes Relat Metab Disord. 2000;24:38-48.

15. Stubbs R, Hughes D, Johnstone A, Rowley E, Reid C, Elia M, Stratton R, Delargy H, King N, Blundell $\mathrm{J}$. The use of visual analogue scales to assess motivation to eat in human subjects: a review of their reliability and validity with an evaluation of new hand-held computerized systems for temporal tracking of appetite ratings. Br J Nutr. 2000;84:405-415.

16. Harris J, Benedict F. A Biometric Study of Human Basal Metabolism in Man. Carnegie institution of Washington: Washington, DC. 1919.

17. Little TJ, Russo A, Meyer JH, Horowitz M, Smyth DR, Bellon M, Wishart JM, Jones KL, Feinle-Bisset C. Free Fatty Acids Have More Potent Effects on Gastric Emptying, Gut Hormones, and Appetite Than Triacylglycerides. Gastroenterology. 2007;133:1124-1131.

18. Meyer JH, Hlinka M, Kao D, Lake R, McLaughlin E, Graham L, Elashoff L. Gastric emptying of oil from solid and liquid meals. Effect of human pancreatic insufficiency. Dig Dis Sci. 1996;41:1691-1699. 


\section{Chapter 4 Genetic predisposition, dietary restraint and disinhibition in relation to weight loss and maintenance}

Verhoef SPM, Camps SGJA, Bouwman FG, Mariman ECM, Westerterp KR Submitted for publication 


\begin{abstract}
Interindividual differences in response to weight loss and maintenance thereafter are ascribed to genetic predisposition and behavioural changes. To examine whether body weight and short and long-term body weight loss were affected by candidate single nucleotide polymophisms (SNPs) and changes in eating behaviour or by an interaction between these genetic and behavioural factors. 150 healthy subjects (39 males, 111 females) aged $20-50$ y with a BMI of $27-38 \mathrm{~kg} / \mathrm{m}^{2}$ followed a very low energy diet for 8-weeks, followed by a 3-month weight maintenance period. SNPs were selected from six candidate genes: ADRB2, FTO, MC4R, PPARG, PPARD, and $P P A R G C 1 A$. Changes in eating behaviour were determined with the Three Factor Eating Questionnaire. A high genetic predisposition score was associated with a high body weight at baseline and more short-term weight loss. From the six selected obesity-related SNPS, FTO was associated with increased body weight at baseline, and the effect allele of PPARGC1A was positively associated with short-term weight loss, when assessed for each SNP separately. Long-term weight loss was associated with a larger increase in dietary restraint and larger decrease in disinhibition. During longterm weight loss, genetic effects are dominated by changes in eating behaviour.
\end{abstract}




\section{Introduction}

Obesity results from a chronic imbalance between energy intake and expenditure [1]. The increasing prevalence of obesity coincides with changes in dietary habits due to high availability of energy-dense foods, suggesting a causal link [2]. However, some individuals seem resistant to become overweight or obese. Inter-individual variation in the susceptibility to develop obesity can be partly explained by genetics. Family and twin studies have shown that the genetic contribution can be 40-70\% [3, 4]. Genomewide association studies (GWAS), already identified 52 genetic loci to be unequivocally associated with obesity related-traits [5]. However, the effects of the loci on obesity-susceptibility are small and explain only a small fraction of the total variation with a poor predictive ability [5-7]. Studying the GWAS-identified loci in longitudinal cohort studies can contribute to elucidating new physiological pathways that underlie obesitysusceptibility.

Most association studies focus on single nucleotide polymorphisms (SNPs) in relation to body weight, instead of changes in body weight. Successfully maintaining weight loss, defined as "keeping off an intentional loss of at least $10 \%$ body weight for at least one year" is only achieved in around $20 \%$ of the cases [8, 9]. Individual differences in weight loss and regain may in part be caused by a genetic predisposition to resist weight loss or promoting weight gain [10]. Twin studies on the response to longterm negative energy balance have demonstrated a much larger variability between pairs than within pairs $[11,12]$, suggesting that there is also a genetic contribution in the resistance for body weight loss and maintenance.

In this study, we tested the combined and individual effect of six genetic variants, which had shown associations with obesity-related traits: rs9939609 of fat mass and obesity associated (FTO) gene; rs 17782313 of melanocortin 4 receptor (MC4R) gene; rs1042713 of $\beta 2$-adrenergic receptor (ADRB2) gene; rs1801282 of peroxisome proliferator-activated receptory2 (PPAR 2 ) gene; rs8192678 of peroxisome proliferatoractivated receptor $\gamma$ coactivator-1 $\alpha$ (PPARGC1 $\alpha)$ gene; rs2076168 of peroxisome proliferator-activated receptor $(P P A R \delta)$ gene. The aim of the study was to examine whether body weight changes during an 8-week weight loss period and subsequent follow-up of 3-months were affected by the six selected SNPs and by changes in eating behaviour, or by an interaction between these genetic and behavioural factors.

\section{Material and methods}

\section{Subjects}

150 healthy subjects (39 males, 111 females) aged 20-50 y with a BMI of $27-38 \mathrm{~kg} / \mathrm{m}^{2}$ participated in the study, which started in February 2010. The weight loss diet consisted of 8 weeks very low energy diet providing 2.1 MJ/day (Modifast; Nutrition et Santé Benelux, Breda, The Netherlands). This diet was a protein-enriched formula diet 
that provided $50 \mathrm{~g}$ carbohydrates, $52 \mathrm{~g}$ protein, $7 \mathrm{~g}$ fat and a micronutrient content, which meets the Dutch recommended daily allowance. Vegetables were allowed in addition to the diet. The weight loss period was followed by a weight maintenance period of 3 months, in which subjects were instructed to maintain their newly achieved body weight. Measurements were done at rest and following an overnight fast at three time points; before weight loss, after weight loss and after 3 months follow-up. The study was conducted according to the guidelines laid down in the Declaration of Helsinki and all procedures involving human subjects were approved by the Central Committee on Human Research and by the Medical Ethical Committee of Maastricht University. Written informed consent was obtained from all subjects. The study was registered in ClinicalTrials.gov (registration number: NCT01015508).

\section{Anthropometry}

Height was measured at screening to the nearest $0.1 \mathrm{~cm}$ with the use of a wallmounted stadiometer (model 220; Seca, Hamburg, Germany). Body weight was measured with subjects in underwear after an overnight fast using a calibrated scale of the BodPod $^{\circledR}$. Body mass index (BMI) was calculated by dividing body weight by height squared $\left(\mathrm{kg} / \mathrm{m}^{2}\right)$.

Body composition was calculated from body volume (BodPod $^{\circledR}$, Life measurement, Concord, CA, USA) [13] and total body water (TBW) [14] as assessed with the deuterium dilution technique, using Siri's three-compartment model [15]. The dilution of the deuterium isotope $\left({ }^{2} \mathrm{H}_{2} \mathrm{O}\right)$ is a measure for total body water. Subjects wore tightly fitting bathing suits and a swim cap during the volume-measurements in the BodPod $^{\circledR}$, and had not engaged in exercise at least 1 hour prior to the test.

\section{Questionnaires}

To determine whether attitude toward food intake changed during weight loss and maintenance, a validated Dutch translation of the three-factor eating questionnaire (TFEQ) was used [16]. Changes in dietary restraint and disinhibtion scores were used as indicators for changes in eating behaviour and different disinhibition and restraint ouctomes have been associated with distinct weight and behaviour outcomes [17].

\section{DNA isolation and genotyping}

Blood was collected in an EDTA tube during screening and the buffy coat was stored at $-80^{\circ} \mathrm{C}$. Genomic DNA was isolated from the buffy coat using the QIAamp mini blood kit (Qiagen, Amsterdam, The Netherlands). Six SNPs were selected based on GWAS and intervention studies, which associated them to obesity (table 1). Genotypes were coded 0,1 or 2 according to the number of risk alleles for each SNP. From these codes a genetic predisposition score (GPS) was constructed for each individual by summing the risk alleles across the six SNPs, as previously done by other authors [5, $18,19]$.

Genotyping of five SNPs was performed using commercially available TaqMan SNP genotyping assays from Applied Biosystems (Foster City, California, USA). The 
procedure was performed according to the manufacturer's protocol and measured on an Applied Biosystems 7900 HT Fast Real-Time PCR system. Allelic calls were determined semi-automatically using the allelic discrimination software of Applied Biosystems. The Pro12Ala polymorphism of the PPAR $\gamma 2$ gene was characterized using the polymerase chain reaction-restriction fragment length polymorphism (PCR-RFLP) assay. The primers used were 5'-GCCAATTCAAGCCCAGTC-3' and 5'GATATGTTTGCAGACAGTGTATCAGTGAAGGAATCGCTTTCCG-3'. The cycling conditions were $95^{\circ} \mathrm{C}$ for $5 \mathrm{~min}, 30$ cycles of $95^{\circ} \mathrm{C} / 30 \mathrm{~s}, 56^{\circ} \mathrm{C} / 45 \mathrm{~s}, 68^{\circ} \mathrm{C} / 45 \mathrm{~s}$ and followed by $68^{\circ} \mathrm{C}$ for $7 \mathrm{~min}$. The restriction enzym BstU-I was used, which generated the following fragments: 270bp (Pro12Pro); 270, 227, 43bp (Pro12Ala) and 227, 43bp (Ala12Ala).

\section{Statistical analysis}

Data are presented as mean and their standard deviations, unless otherwise indicated. A Chi-square test was used to check whether the allele frequencies were in Hardy Weinberg equilibrium. ANOVA repeated measures was carried out to determine changes over time. Mean baseline values and changes in weight during weight loss and follow-up periods were compared between groups with ANOVA. Corrections for multiple testing were performed by using Bonferroni correction. Each SNP was tested individually, with age, sex and baseline value for that particular dependent variable as covariates. Linear regressions were used to test for associations. Significance was defined as $\mathrm{P}<0.05$. All of the statistical analyses were executed with SPSS version 16.0 for Macintosh OS X (SPSS Inc, Chicago, IL).

\section{Results}

Body weight, BMI, fat mass, percentage fat mass, waist and hip circumference decreased significantly during weight loss and remained significantly lower after 3-month follow-up compared to baseline (table 1). Dietary restraint increased and disinhibition and hunger decreased significantly during weight loss and remained significantly below baseline values during follow-up.

Table 1: Subject characteristics (mean \pm SD) on baseline (t0), after weight loss (t2), after 3month (t5) and 10-month follow-up (t12).

\begin{tabular}{lllll}
\hline & t0 & t2 & t5 & P-value $^{\#}$ \\
\cline { 2 - 5 } Body weight $(\mathrm{kg})$ & $92.6 \pm 12.3$ & $83.2 \pm 10.9^{*}$ & $84.7 \pm 11.7^{*}$ & $<0.001$ \\
BMI $\left(\mathrm{kg} / \mathrm{m}^{2}\right)$ & $32.0 \pm 3.1$ & $28.7 \pm 3.0^{*}$ & $29.2 \pm 3.2^{*}$ & $<0.001$ \\
Fat mass $(\mathrm{kg})$ & $38.6 \pm 7.8$ & $31.2 \pm 7.8^{*}$ & $30.9 \pm 8.6^{*}$ & $<0.001$ \\
Percentage fat mass (\%) & $41.6 \pm 6.6$ & $37.4 \pm 7.4^{*}$ & $33.5 \pm 8.5^{*}$ & $<0.001$ \\
Dietary restraint & $7.5 \pm 3.8$ & $12.4 \pm 4.2^{*}$ & $12.0 \pm 4.2^{*}$ & $<0.001$ \\
Disinhibition & $6.5 \pm 2.7$ & $4.9 \pm 2.6^{*}$ & $5.3 \pm 2.8^{*}$ & $<0.001$ \\
Hunger & $5.1 \pm 3.0$ & $3.7 \pm 3.0^{*}$ & $3.4 \pm 2.9^{*}$ & $<0.001$ \\
BMI; Body Mass Index & & \\
\# Difference over time (repeated measures ANOVA) \\
"Significantly different from baseline, P<0.01
\end{tabular}




\section{Genetic predisposition}

All SNPs were in Hardy Weinberg equilibrium (table 2). To determine the genetic contribution of the selected SNPs, differences in body weight at baseline and body weight changes during short and long-term weight loss were compared between the different genotypes (table 3). Furthermore, a GPS was calculated by summing the risk alleles across the six SNPs. Multiple regression showed a positive association between GPS and body weight at baseline (table 4), with a higher GPS associated with a higher body weight at baseline. There was no unifying effect on body weight as the GPS might have suggested when the effect of the SNPs separately was assessed (table 3). There was a significant difference in body weight at baseline between FTO genotypes, with a higher body weight with the effect allele. More weight loss during energy restriction was associated with a high GPS (table 4). Subjects with the effect allele for PPARGC1A had more short-term weight loss. During long-term weight loss there were no significant associations with GPS. Long-term weight loss was significantly different between $M C 4 R$ genotypes, with less weight loss after 3-month followup compared to baseline in subjects with the effect allele.

Additionally, results for differences in fat mass and percentage fat mass between genotypes were comparable to those for body weight as reported above (data not shown). For dietary restraint, disinhibition and hunger scores, there were no significant differences between genotypes.

Table 2: Genotypic and allelic distributions per single nucleotide polymorphism

\begin{tabular}{|c|c|c|c|c|c|c|c|}
\hline Gene & SNP & $\bar{G}$ & $F(N)$ & $F(\%)$ & Allele & $F(\%)$ & HWE \\
\hline \multirow[t]{3}{*}{ FTO } & rs9936909 & AA & 25 & 16.9 & A & 38.9 & 0.65 \\
\hline & & AT & 65 & 43.9 & $\mathrm{~T}$ & 61.1 & \\
\hline & & TT & 58 & 39.2 & & & \\
\hline \multirow[t]{3}{*}{$M C 4 R$} & rs 17782313 & $\mathrm{CC}$ & 15 & 10.1 & C & 24.1 & 0.19 \\
\hline & & CT & 46 & 31.1 & $\mathrm{~T}$ & 75.9 & \\
\hline & & TT & 87 & 58.8 & & & \\
\hline \multirow[t]{3}{*}{ ADRB2 } & rs1042713 & GG & 56 & 37.8 & G & 62.3 & 0.92 \\
\hline & & GA & 71 & 48.0 & A & 37.7 & \\
\hline & & AA & 21 & 14.2 & & & \\
\hline \multirow[t]{3}{*}{ PPARD } & rs2076168 & GG & 16 & 10.9 & G & 28.1 & 0.33 \\
\hline & & GT & 52 & 35.4 & $\mathrm{~T}$ & 71.9 & \\
\hline & & TT & 79 & 53.7 & & & \\
\hline \multirow[t]{3}{*}{ PPARGC1A } & rs8192678 & $\mathrm{AA}$ & 20 & 13.6 & A & 37.2 & 0.95 \\
\hline & & $A G$ & 70 & 47.6 & G & 62.8 & \\
\hline & & GG & 57 & 38.8 & & & \\
\hline \multirow[t]{3}{*}{ PPARG2 } & rs1801282 & Ala12Ala & 1 & 0.7 & Ala & 10.7 & 0.83 \\
\hline & (Pro12Ala) & Pro12Ala & 30 & 20.1 & Pro & 89.3 & \\
\hline & & Pro12Pro & 118 & 79.2 & & & \\
\hline
\end{tabular}


Table 3: Baseline and changes in body weight $(\mathrm{kg})$ during short and long-term weight loss.

\begin{tabular}{|c|c|c|c|c|c|c|c|c|}
\hline \multirow[t]{2}{*}{ Gene } & \multirow[t]{2}{*}{ Effect allele } & \multirow[t]{2}{*}{ Genotype } & \multicolumn{2}{|c|}{ Baseline Weight (t0) } & \multicolumn{2}{|c|}{ Short-term weight loss (t2-0) } & \multicolumn{2}{|c|}{ Long-term weight loss (t5-0) } \\
\hline & & & Mean \pm SE & P-value & Change \pm SE & P-value & Change \pm SE & P-value \\
\hline \multirow[t]{3}{*}{ FTO } & $A$ & AA & $96.0 \pm 2.4$ & 0.017 & $-9.9 \pm 0.8$ & 0.333 & $-8.8 \pm 0.6$ & 0.411 \\
\hline & & AT & $93.9 \pm 1.3$ & & $-9.7 \pm 0.4$ & & $-8.0 \pm 0.4$ & \\
\hline & & TT & $90.5 \pm 1.3$ & & $-8.9 \pm 0.4$ & & $-7.8 \pm 0.4$ & \\
\hline \multirow[t]{3}{*}{ MC4R } & C & $\mathrm{CC}$ & $96.6 \pm 3.1$ & 0.353 & $-8.2 \pm 1.0$ & 0.422 & $-7.5 \pm 0.9$ & 0.049 \\
\hline & & CT & $91.3 \pm 1.6$ & & $-9.6 \pm 0.5$ & & $-7.2 \pm 0.4$ & \\
\hline & & TT & $92.6 \pm 1.2$ & & $-9.5 \pm 0.4$ & & $-8.6 \pm 0.3$ & \\
\hline \multirow{2}{*}{$A D R B 2$} & & GA & $93.1 \pm 1.3$ & & $-9.0 \pm 0.4$ & & $-8.1 \pm 0.4$ & \\
\hline & & AA & $89.4 \pm 2.2$ & & $-8.8 \pm 0.7$ & & $-8.6 \pm 0.6$ & \\
\hline \multirow[t]{3}{*}{$P P A R D$} & G & GG & $91.8 \pm 2.8$ & 0.530 & $-9.9 \pm 0.9$ & 0.525 & $-8.4 \pm 0.8$ & 0.385 \\
\hline & & GT & $91.4 \pm 1.6$ & & $-9.5 \pm 0.5$ & & $-7.4 \pm 0.4$ & \\
\hline & & TT & $93.7 \pm 1.2$ & & $-9.0 \pm 0.4$ & & $-8.1 \pm 0.3$ & \\
\hline \multirow[t]{2}{*}{ PPARGC1A } & $A$ & $A A$ & $92.9 \pm 2.6$ & 0.112 & $-10.7 \pm 0.8$ & 0.023 & $-9.1 \pm 0.7$ & 0.290 \\
\hline & & $A G$ & $94.2 \pm 1.3$ & & $-9.8 \pm 0.4$ & & $-7.9 \pm 0.4$ & \\
\hline \multirow[t]{2}{*}{ PPARG2 } & Ala & Pro12Ala & $93.8 \pm 2.1$ & 0.725 & $-10.1 \pm 0.7$ & 0.189 & $-7.6 \pm 0.6$ & 0.525 \\
\hline & & Pro12Pro & $92.3 \pm 1.0$ & & $-9.2 \pm 0.3$ & & $-8.0 \pm 0.3$ & \\
\hline
\end{tabular}

Adjusted for age and sex

Adjusted for age, sex and baseline weight

${ }^{* \star *}$ Adjusted for age, sex, baseline weight and weight loss (t2-0) 
Table 4: Multiple regression between body weight and body weight changes with GPS.

\begin{tabular}{lllll}
\hline Response & Parameter & $\mathrm{B} \pm \mathrm{SE}$ & $\beta$ & P-value \\
\cline { 2 - 5 } Baseline weight (t0) & GPS & $1.14 \pm 0.57$ & 0.15 & 0.049 \\
& Gender & $-15.38 \pm 2.28$ & -0.52 & 0.000 \\
Short-term weight loss (t2-0) & Gge & $-0.03 \pm 0.11$ & -0.02 & 0.821 \\
& Gender & $-0.52 \pm 0.18$ & -0.21 & 0.004 \\
& Baseline weight (t0) & $2.86 \pm 0.82$ & 0.30 & 0.000 \\
& Age & $0.04 \pm 0.04$ & 0.07 & 0.317 \\
\hline Response; dependent variable & & & \\
Parameter; independent variable & & & \\
B; unstandardized regression coefficient & & & \\
$\beta ;$ standardized regression coefficient & & &
\end{tabular}

\section{Eating behaviour}

Changes in dietary restraint were inversely correlated with changes in disinhibition during both short and long-term weight loss (respectively $R^{2}=0.044 P=0.011$ and $\left.R^{2}=0.082 P<0.001\right)$. Body weight at baseline was significantly correlated with dietary restraint and disinhibition, but did not reach significance after adjusting for age and gender (table 5). In a multiple regression together with SNPs that showed a significant effect, body weight at baseline was associated with gender and FTO. Short-term weight loss was associated with body weight at baseline, gender and PPARGC1A. Long-term weight loss was associated with the amount of weight lost during energy restriction, gender and the change in dietary restraint and disinhibition after 3-month follow-up.

\section{Discussion}

A high GPS was associated with a high body weight at baseline and more short-term weight loss. From the six selected obesity-related SNPs in this study, FTO was associated with increased body weight at baseline. The effect allele of PPARGC1A was associated with short-term weight loss when assessed for each SNP separately. Long-term weight loss was associated with a larger increase in dietary restraint and larger decrease in disinhibition.

Based on literature six SNPs were selected as being related to obesity associated-traits, and thus suggested to be candidates for associations with body weight changes. The correlations with GPS indicate that the SNPs have a negative effect on body weight, but a positive effect on short-term weight loss, with subjects with the most effect alleles losing more weight during energy restriction. However, when assessed for each SNP separately merely FTO and body weight and PPARGC1A and short-term weight loss were significantly associated. For FTO rs9936909, body weight at baseline was higher in A-allele carriers, while there were no differences in weight loss consistent with previous studies [20-22]. During short-term weight loss subjects with the A-allele of PPARGC1A rs8192678 lost more weight, but this effect was lost 
Table 5: Multiple regression between body weight at baseline and body weight changes with SNPs, dietary restraint and disinhibition.

\begin{tabular}{lllll}
\hline Response & Parameter & $\mathrm{B} \pm \mathrm{SE}$ & $\beta$ & P-value \\
\cline { 2 - 5 } Body weight (t0) & Age & $0.01 \pm 0.10$ & 0.00 & 0.959 \\
& Gender & $-13.69 \pm 2.17$ & -0.49 & 0.000 \\
& FTO & $3.26 \pm 1.29$ & 0.18 & 0.012 \\
& Dietary restraint (t0) & $0.11 \pm 0.24$ & 0.03 & 0.654 \\
Short-term weight loss (t2-0) & Disinhibition (t0) & $-0.48 \pm 0.33$ & -0.11 & 0.156 \\
& Age & $0.03 \pm 0.03$ & 0.06 & 0.410 \\
& Gender & $2.70 \pm 0.78$ & 0.29 & 0.001 \\
& PPARGC1A & $-1.15 \pm 0.42$ & -0.20 & 0.008 \\
& Body weight (t0) & $-0.11 \pm 0.03$ & -0.33 & 0.000 \\
& Dietary restraint (t2-0) & $-0.06 \pm 0.06$ & -0.07 & 0.346 \\
& Disinhibition (t2-0) & $0.01 \pm 0.12$ & 0.01 & 0.912 \\
Long-term weight loss (t5-0) & Age & $-0.05 \pm 0.03$ & -0.08 & 0.077 \\
& Gender & $-1.94 \pm 0.61$ & -0.17 & 0.002 \\
& MC4R & $0.57 \pm 0.37$ & 0.07 & 0.123 \\
& Weight loss (t2-0) & $1.02 \pm 0.07$ & 0.82 & 0.000 \\
& Dietary restraint (t5-0) & $-0.23 \pm 0.07$ & -0.18 & 0.001 \\
& Disinhibition (t5-0) & $0.25 \pm 0.11$ & 0.12 & 0.024 \\
\hline
\end{tabular}

Response; dependent variable

Parameter; independent variable

$B$; unstandardized regression coefficient

$\beta$; standardized regression coefficient

during long-term weight loss. There were also no differences in baseline body weight between PPARGC1A genotypes. These results were in contrast with previous studies, which showed associations with body weight and not with weight changes [23, 24]. Long-term weight loss was significantly lower in subjects with the C-allele of MC4R rs17782313, while others have shown that this SNP was associated with body weight and not weight changes [25, 26]. In contrast to what we expected from the literature, there were in addition to PPARGC1A and MC4R also no significant differences in body weight for the ADRB2 rs1042713 and PPARD rs2076168 [27, 28]. Although not many studies determined the relation between SNPs and weight changes, most associations were found with PPARG2 rs1801282 [29-33], but our results could not confirm this. Many explanations for the inconsistent results in the literature have already been proposed, like low sample size, limitations of study populations and different study designs. However, a probably more important factor is the largely unknown gene-environment interactions that can mask the effect of a genetic variant, as described by Andreasen et al. [34]. Especially during a period of conscious weight loss, behavioural changes might dominate genetic effects. Furthermore, comparing studies using GPS is difficult, because a calculated GPS is not a constant variable and is different in each study depending on the different SNPs selected.

Dietary restraint and disinhibition have emerged from the literature as important indicators for eating behaviour and different disinhibition and restraint outcomes have been associated with distinct weight and behaviour outcomes [17]. Here, changes in dietary restraint and disinhibition were inversely correlated with each other consistent with previous studies [35-38]. Both changes in dietary restraint and disinhibition were correlated with long-term weight loss, emphasizing the importance of both factors 
during periods of weight maintenance. These results confirm findings of previous studies that already have shown that the increase in dietary restraint was associated with more success in weight maintenance [37, 39, 40]. There was no effect of the SNPs on dietary restraint and disinhibition or changes in these factors, so changes in eating behavior independently predict success in long-term weight loss.

From these results we cannot exclude whether there were gene-environment interactions masking effects of a genetic variant. In turn, dietary restraint and disinhibition not fully cover behavioural factors, though widely used to characterize eating behavior. In addition, six SNPs as measured in 150 subjects are low compared to other genetic studies. However, this is a consequence of the design of our study, since accurate assessment of short and long-term weight loss were limiting factors. Since these measurements are part of a larger intervention study, the selection of the SNPs comprised those previously associated with obesity-related traits in general and not specifically personality traits.

In conclusion, long-term weight loss is mainly determined by changes in eating behaviour.

\section{Acknowledgements}

K.R. Westerterp and S.P.M. Verhoef designed the study. S.P.M. Verhoef, S.G.J.A. Camps and F.G. Bouwman collected the data. S.P.M. Verhoef analyzed the data and wrote the manuscript. K.R. Westerterp and E.C.M. Mariman contributed to the interpretation of the data and reviewed the manuscript. The study was executed under supervision of K.R. Westerterp. All authors read and approved the final manuscript. None of the authors had any conflict of interest.

\section{References}

1. Tremblay A, Perusse L, Bouchard C. Energy balance and body-weight stability: impact of gene-environment interactions. The British journal of nutrition 2004; 92 Suppl 1:S63-66

2. Hill JO, Wyatt HR, Reed GW, Peters JC. Obesity and the Environment: Where Do We Go from Here? Science 2003; 299:853-855

3. Loos RJ, Bouchard C. Obesity--is it a genetic disorder? Journal of internal medicine 2003; 254:401-425

4. Maes HH, Neale MC, Eaves LJ. Genetic and environmental factors in relative body weight and human adiposity. Behavior genetics 1997; 27:325-351

5. Li S, Zhao JH, Luan J, Luben RN, Rodwell SA, Khaw KT et al. Cumulative effects and predictive value of common obesity-susceptibility variants identified by genome-wide association studies. Am J Clin Nutr 2010; 91:184-190

6. Loos RJ. Genetic determinants of common obesity and their value in prediction. Best practice \& research 2012; 26:211-226

7. Speliotes EK, Willer CJ, Berndt SI, Monda KL, Thorleifsson G, Jackson AU et al. Association analyses of 249,796 individuals reveal 18 new loci associated with body mass index. Nature genetics 2010; 42:937-948

8. Wing RR, Hill JO. Successful weight loss maintenance. Annu Rev Nutr 2001; 21:323-341 
9. Wing RR, Phelan S. Long-term weight loss maintenance. Am J Clin Nutr 2005; 82:222S225S

10. Mariman E. Human Biology of Weight Maintenance after Weight Loss. Journal of nutrigenetics and nutrigenomics 2012; 5:13-38

11. Bouchard C, Tremblay A, Despres JP, Theriault G, Nadeau A, Lupien PJ et al. The response to exercise with constant energy intake in identical twins. Obes Res 1994; 2:400-410

12. Hainer V, Stunkard AJ, Kunesova M, Parizkova J, Stich V, Allison DB. Intrapair resemblance in very low calorie diet-induced weight loss in female obese identical twins. Int $\mathrm{J}$ Obes Relat Metab Disord 2000; 24:1051-1057

13. Dempster $P$, Aitkens $S$. A new air displacement method for the determination of human body composition. Medicine and science in sports and exercise 1995; 27:1692-1697

14. Westerterp KR, Wouters L, van Marken Lichtenbelt WD. The Maastricht protocol for the measurement of body composition and energy expenditure with labeled water. Obes Res 1995; 3 Suppl 1:49-57

15. Siri W. Body composition from fluid spaces and density: analysis of methods. In: Brozek J, Henschel A (eds). Techniques for measuring body composition. National Academy of Science: Washington DC. 1961; 223-244

16. Stunkard A, Messick $S$. The three-factor eating questionnaire to measure dietary restraint, disinhibition and hunger. J Psychosom Res 1985; 29:71-83

17. Bryant EJ, King NA, Blundell JE. Disinhibition: its effects on appetite and weight regulation. Obes Rev 2008; 9:409-419

18. den Hoed M, Ekelund U, Brage S, Grontved A, Zhao JH, Sharp SJ et al. Genetic susceptibility to obesity and related traits in childhood and adolescence: influence of loci identified by genome-wide association studies. Diabetes 2010; 59:2980-2988

19. Peterson RE, Maes HH, Holmans P, Sanders AR, Levinson DF, Shi J et al. Genetic risk sum score comprised of common polygenic variation is associated with body mass index. Human genetics $2011 ; 129: 221-230$

20. Franks PW, Jablonski KA, Delahanty LM, McAteer JB, Kahn SE, Knowler WC et al. Assessing gene-treatment interactions at the FTO and INSIG2 loci on obesity-related traits in the Diabetes Prevention Program. Diabetologia 2008; 51:2214-2223

21. Grau K, Hansen T, Holst C, Astrup A, Saris WH, Arner P et al. Macronutrient-specific effect of FTO rs9939609 in response to a 10-week randomized hypo-energetic diet among obese Europeans. International journal of obesity (2005) 2009; 33:1227-1234

22. Lappalainen TJ, Tolppanen AM, Kolehmainen M, Schwab U, Lindstrom J, Tuomilehto J et al. The common variant in the FTO gene did not modify the effect of lifestyle changes on body weight: the Finnish Diabetes Prevention Study. Obesity (Silver Spring, Md 2009; 17:832-836

23. Goyenechea E, Crujeiras AB, Abete I, Parra D, Martinez JA. Enhanced short-term improvement of insulin response to a low-caloric diet in obese carriers the Gly482Ser variant of the PGC-1alpha gene. Diabetes research and clinical practice 2008; 82:190-196

24. Mirzaei K, Hossein-Nezhad A, Emamgholipour S, Ansar H, Khosrofar M, Tootee A et al. An Exonic Peroxisome Proliferator-Activated Receptor- gamma Coactivator-1 alpha Variation May Mediate the Resting Energy Expenditure through a Potential Regulatory Role on Important Gene Expression in This Pathway. Journal of nutrigenetics and nutrigenomics 2012; 5:59-71

25. Haupt A, Thamer C, Heni M, Tschritter O, Machann J, Schick F et al. Impact of variation near MC4R on whole-body fat distribution, liver fat, and weight loss. Obesity (Silver Spring, Md 2009; 17:1942-1945

26. Kring SI, Holst C, Toubro S, Astrup A, Hansen T, Pedersen $\mathrm{O}$ et al. Common variants near MC4R in relation to body fat, body fat distribution, metabolic traits and energy expenditure. International journal of obesity (2005) 2010; 34:182-189 
27. Masuo K, Katsuya T, Kawaguchi H, Fu Y, Rakugi H, Ogihara T et al. Rebound Weight Gain as Associated With High Plasma Norepinephrine Levels That Are Mediated Through Polymorphisms in the [beta]2-Adrenoceptor. American Journal of Hypertension 2005; 18:15081516

28. Ruiz JR, Larrarte E, Margareto J, Ares R, Labayen I. Role of beta(2)-adrenergic receptor polymorphisms on body weight and body composition response to energy restriction in obese women: preliminary results. Obesity (Silver Spring, Md 2011; 19:212-215

29. Goyenechea E, Dolores Parra M, Alfredo Martinez J. Weight regain after slimming induced by an energy-restricted diet depends on interleukin- 6 and peroxisome-proliferator-activatedreceptor-gamma2 gene polymorphisms. The British journal of nutrition 2006; 96:965-972

30. Lindi VI, Uusitupa MI, Lindstrom J, Louheranta A, Eriksson JG, Valle TT et al. Association of the Pro12Ala polymorphism in the PPAR-gamma2 gene with 3-year incidence of type 2 diabetes and body weight change in the Finnish Diabetes Prevention Study. Diabetes 2002; 51:2581-2586

31. Nicklas BJ, van Rossum EFC, Berman DM, Ryan AS, Dennis KE, Shuldiner AR. Genetic Variation in the Peroxisome Proliferator,ÄìActivated Receptor-CE $\geq 2$ Gene (Pro12Ala) Affects Metabolic Responses to Weight Loss and Subsequent Weight Regain. Diabetes 2001; 50:2172-2176

32. Rosmond R, Chagnon M, Bouchard C. The Pro12Ala PPARgamma2 gene missense mutation is associated with obesity and insulin resistance in Swedish middle-aged men. Diabetes/metabolism research and reviews 2003; 19:159-163

33. Vogels N, Mariman ECM, Bouwman FG, Kester ADM, Diepvens K, Westerterp-Plantenga MS. Relation of weight maintenance and dietary restraint to peroxisome proliferator-activated receptor \{gamma\}2, glucocorticoid receptor, and ciliary neurotrophic factor polymorphisms. Am J Clin Nutr 2005; 82:740-746

34. Andreasen $\mathrm{CH}$, Andersen G. Gene-environment interactions and obesity--further aspects of genomewide association studies. Nutrition (Burbank, Los Angeles County, Calif 2009; 25:998-1003

35. Dykes J, Brunner EJ, Martikainen PT, Wardle J. Socioeconomic gradient in body size and obesity among women: the role of dietary restraint, disinhibition and hunger in the Whitehall II study. Int J Obes Relat Metab Disord 2004; 28:262-268

36. Hays NP, Bathalon GP, McCrory MA, Roubenoff R, Lipman R, Roberts SB. Eating behavior correlates of adult weight gain and obesity in healthy women aged 55-65 y. Am J Clin Nutr 2002; 75:476-483

37. Vogels N, Westerterp-Plantenga MS. Successful long-term weight maintenance: a 2-year follow-up. Obesity (Silver Spring, Md 2007; 15:1258-1266

38. Williamson DA, Lawson OJ, Brooks ER, Wozniak PJ, Ryan DH, Bray GA et al. Association of body mass with dietary restraint and disinhibition. Appetite 1995; 25:31-41

39. Lejeune MP, Van Aggel-Leijssen DP, Van Baak MA, Westerterp-Plantenga MS. Effects of dietary restraint vs exercise during weight maintenance in obese men. European journal of clinical nutrition 2003; 57:1338-1344

40. Westerterp-Plantenga MS, Kempen KP, Saris WH. Determinants of weight maintenance in women after diet-induced weight reduction. Int J Obes Relat Metab Disord 1998; 22:1-6 


\section{Chapter 5 Relative shrinkage of adipocytes by paraffin in proportion to plastic embedding in human adipose tissue before and after weight loss}

Verhoef SPM, van Dijk P, Westerterp KR Obes Res \& Clin Prac , 2013; 7(1): e8-e13 


\begin{abstract}
Adipocyte size is a major modulator of endocrine functioning of adipose tissue and methods allowing accurate determination of adipocyte size are important to study energy metabolism. The aim of this study was to assess the relative shrinkage of adipocytes before and after weight loss by comparing adipose tissue from the same subjects embedded in paraffin and plastic. 18 healthy subjects ( 5 males, 13 females) aged $20-50$ y with a BMI of 28-38 kg/m² followed a very low energy diet for 8 weeks. Adipose tissue biopsies were taken prior to and after weight loss and were processed for paraffin and plastic sections. Parameters of adipocyte size were determined with computer image analysis. Mean adipocyte size was smaller in paraffin compared to plastic embedded tissue both before $(66 \pm 4$ vs $103 \pm 5 \mu \mathrm{m}, \mathrm{P}<0.001)$ as after weight loss $(62 \pm 4$ vs $91 \pm 5 \mu \mathrm{m}, \mathrm{P}<0.001)$. Relative shrinkage of adipocytes in paraffin embedded tissue in proportion to plastic embedded tissue was not significantly different before and after weight loss (73 and 69\%, respectively). Shrinkage due to the type of embedding of the adipose tissue can be ignored when comparing before and after weight loss. Plastic embedding of adipose tissue provides more accurate and sensitive results.
\end{abstract}




\section{Introduction}

A major function of adipose tissue is storage and release of energy. Additionally, adipose tissue functions as an endocrine organ regulating energy expenditure, food intake and glucose metabolism. The extent of regulation, through secretion of hormones by the adipocytes, depends on the adipocyte size. Accordingly, adipocyte hypertrophy, a characteristic of obesity, leads to functional changes like increased inflammation and is hypothesized to thereby cause insulin resistance $(1,2)$. Therefore, it is important to determine adipocyte size and that methods used are accurate.

Many methods are described for determining adipocyte size, each with its advantages and disadvantages (3). Measurements of triglyceride content per DNA content of adipose tissue as an estimation for adipocyte size is a relatively easy method, although prone to underestimation since DNA content also reflects other cell types. Another technique is fixation in osmium tetroxide combined with direct electronically counting of adipocyte number. Dividing lipid weight of a comparable sample by the electronically determined cell number is used to calculate mean adipocyte size. Disadvantages of this technique are the toxicity of osmium tetroxide and the overestimation of cell size due to the cell swelling caused by osmium. These methods also do not provide information on adipocyte size distribution. In contrast, collagenase treatment does separate adipocytes from stromal-vascular cells and followed by microscopic determination of cell size, adipocyte size distribution can be determined. One major disadvantage of this method is that large adipocytes break by the treatment, leading to underestimation of cell size. Measurements should be performed immediately after the collagenase treatment, because the cells cannot be stored without affecting cell morphology. On the contrary, fixed histological sections can be stored until analysis and cell size distribution is maintained.

Beside the techniques used to process the tissue, the method of measuring cell size is also important. Manually measuring adipocyte size is a tedious and timeconsuming process. In contrast, computerized determination of adipocyte size allows measuring a large number of adipocytes in a rapid and reliable manner. Introducing a minimum and maximum value, below and above which cells are excluded from the analysis, prevents inclusion of artifacts. In addition, such cut off points help to exclude other cell types, like pre-adipocytes, from the analysis.

Fixation, embedding and cutting cause shrinkage and compression of the tissue. Paraffin is commonly used as embedding, whereas plastic embedding allows cutting thinner sections and gives better support to the cellular components, thereby improving morphology and minimizing cell shrinking. Shrinkage in paraffin-embedded tissue from various organs was reported to be $10-50 \%$, while shrinkage in plastic-embedded tissues was reported to range from 3-13\% (4-6). Especially adipose tissue is susceptible to cell shrinking because of the large lipid droplet comprising the largest part of adipocytes. This high lipid content in adipose tissue also results in a strong anti-freeze feature, and consequently we were unsuccessful in preparing cryostat sections from our human adipose tissue samples. In the present study, paraffin and plastic (Tech- 
novit 8100 ) embedded human adipose tissue derived prior to and after weight loss were compared to assess relative shrinkage of adipocytes.

\section{Material and methods}

\section{Subjects}

Subjects were 4 males and 9 females aged 20-50 y with a BMI of $28-38 \mathrm{~kg} / \mathrm{m}^{2}$, who participated in a weight loss study. The weight loss diet consisted of 8 weeks very low energy diet providing 2.1 MJ/day (Modifast; Nutrition et Santé Benelux, Breda, The Netherlands). Biopsies were taken and body weight was determined at rest and following an overnight fast, both before and after weight loss. The study was conducted according to the guidelines laid down in the Declaration of Helsinki and procedures involving human subjects were approved by the Central Committee on Human Research and by the Medical Ethical Committee of the Maastricht University. Written informed consent was obtained from all subjects.

\section{Biopsy}

An abdominal subcutaneous adipose tissue sample was obtained by needle aspiration under local anaesthesia ( $2 \%$ lidocaine). Samples were rinsed in sterile cold saline and stored in $4 \%$ formaldehyde. Part of the sample was dehydrated and embedded in paraffin, the other part of the sample was dehydrated with $100 \%$ acetone and embedded in Technovit 8100 (Heraeus Kulzer GmbH, Germany). Sections of $5 \mu \mathrm{m}$ were cut and stained with hematoxylin and eosin.

\section{Image analysis}

The sections were viewed with a Leica DMRE microscope, objective 20X, Leica camera DC500 and images were obtained with Leica Image Manager (IM50), version 1.20 (Leica Microsystems AG, Switzerland). An image analysis computer programme (Leica QWin V3) was used to determine diameter $(\mu \mathrm{m})$ and area $\left(\mu \mathrm{m}^{2}\right)$ of the adipocytes based on the method of Chen and Farese (3). Results were directly loaded into a spreadsheet program (Excel; Microsoft Inc.) for analysis. Diameters $<40 \mu \mathrm{m}$ were assumed to represent artifacts or types of cells other than adipocytes and were excluded from analysis. Further analyses were done on results per subject. Adipocyte volume was calculated with the Goldrick formula (7). Relative shrinkage of paraffinembedded tissue in relation to plastic-embedded tissue was estimated by: 1- (volumeparaffin $/$ volume plastic . A minimum of 250 cells was measured per subject per time point.

\section{Statistical analysis}

Data are presented as mean with the standard deviations, unless otherwise indicated. A paired t-test (two-tailed distribution) was carried out to determine possible differen- 
ces between mean values. All frequency distributions were normally distributed. Significance was defined as $P<0.05$. All of the statistical analyses were executed with SPSS version 16.0 for Macintosh OS X (SPSS Inc, Chicago, IL).

\section{Results}

After weight loss mean adipocyte diameter and area were decreased in both paraffin and plastic embedded tissues (figure 1). This is visualized by a shift in the frequency distribution of the adipocyte diameter for both paraffin and plastic embedded tissue (figure 2). Comparing paraffin and plastic, mean adipocyte diameter (66 \pm 4 vs $103 \pm 5$ $\mu \mathrm{m}, \mathrm{P}<0.001$ before weight loss and $62 \pm 4$ vs $91 \pm 5 \mu \mathrm{m}, \mathrm{P}<0.001$ after weight loss), area $\left(3621 \pm 434\right.$ vs $8746 \pm 802 \mu \mathrm{m}^{2}, \mathrm{P}<0.001$ before weight loss and $3160 \pm 401$ vs $6883 \pm 832 \mu \mathrm{m}^{2}, \quad \mathrm{P}<0.001$ after weight loss) and volume $(174990 \pm 31505 \mathrm{vs}$ $662751 \pm 90039 \mu^{3}, \quad P<0.001$ before weight loss and $142625 \pm 27657$ vs $466669 \pm 87273 \mu \mathrm{m}^{3}, \mathrm{P}<0.001$ after weight loss) were smaller in paraffin embedded tissue both before and after weight loss. Hence, adipocytes shrink due to weight loss as well as embedding, with paraffin causing more shrinkage. However, the percentage decrease in diameter and area due to weight loss was not significantly different in plastic compared to paraffin embedded tissue. In addition, relative shrinkage of adipocytes in paraffin embedded tissue in proportion to plastic embedded tissue was $0.73 \pm$ 0.05 before weight loss and $0.69 \pm 0.05$ after weight loss (range 0.58 to 0.82 ) (figure 3). This difference was not statistically significant.

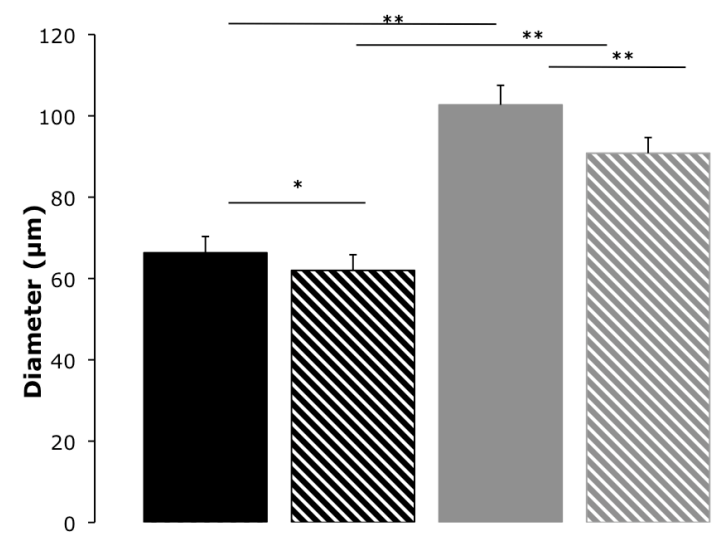

Figure 1. Mean $( \pm S D$ ) adipocyte diameter $(\mu \mathrm{m})$ both pre (solid) and post (dashed) weight loss in paraffin (black) and plastic (grey) embedded tissue. Significant differences; ${ }^{*} \mathrm{P}<0.01$, ** $\mathrm{P}<0.001$ (paired t-test). 


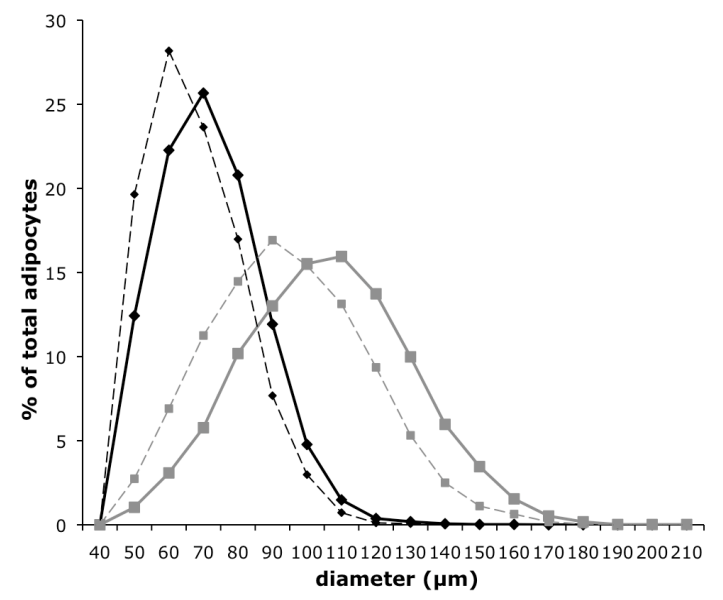

Figure 2. Frequency distribution of adipocyte diameter $(\mu \mathrm{m})$ both pre (solid) and post (dashed) weight loss in paraffin (black) and plastic (grey) embedded tissue.

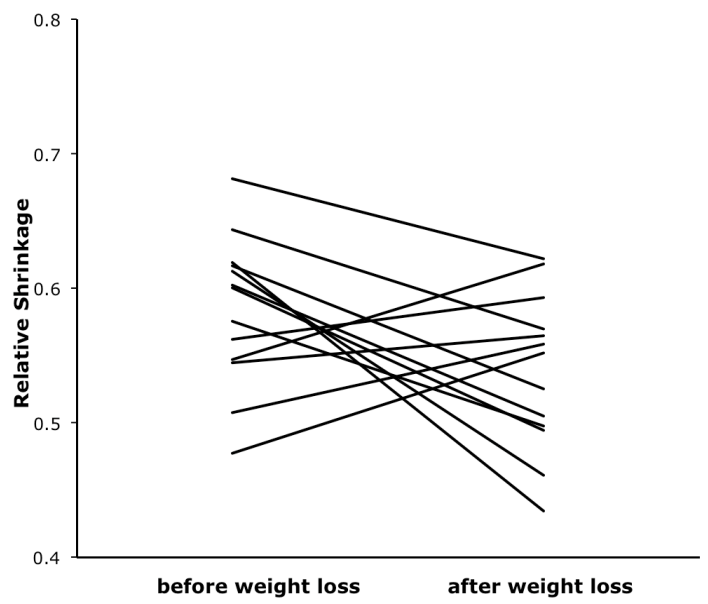

Figure 3. Relative shrinkage of adipose tissue in paraffin embedded tissue in proportion to plastic embedded tissue estimated by: 1 - (volume paraffin $/$ volume $_{\text {plastic }}$ ).

In plastic embedded tissue adipocytes were more round after weight loss $(2.00 \pm$ 0.10 vs $2.12 \pm 0.13, P<0.05$ ), but there was no difference in roundness in paraffin embedded tissue before and after weight loss. However, before weight loss adipocytes had a higher roundness in paraffin compared to plastic embedded tissue (1.82 \pm 0.17 vs $2.12 \pm 0.13, \mathrm{P}<0.01$ ). Possibly due to cell shrinking the cell membrane loosens and the extracellular space increases, which results in rounder adipocytes. In plastic the original cell structure is more preserved and therefore shrinking due to weight loss might cause the change in roundness of adipocytes in plastic and not in paraffin embedded tissue. The difference in roundness between paraffin and plastic before weight loss is probably caused by cell shrinking due to paraffin embedding. After weight loss this difference in roundness did not reached significance $(P=0.09)$. 


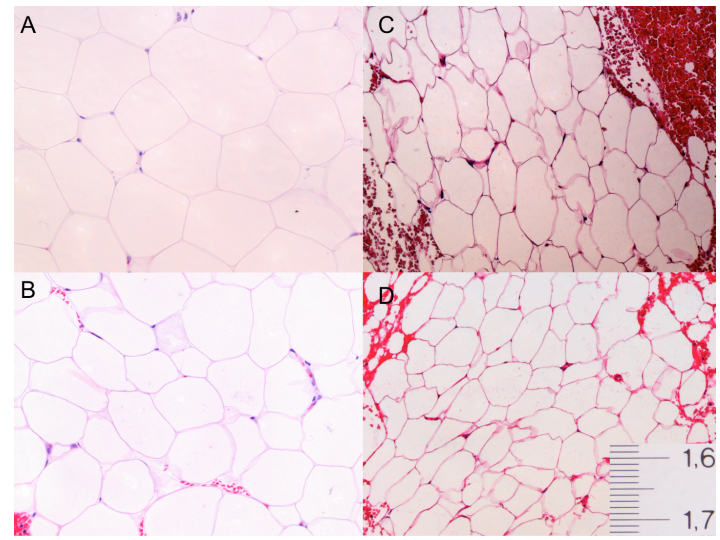

Figure 4. Microscopic picture of plastic (A-B) and paraffin (C-D) embedded adipose tissue before (A-C) and after (B-D) weight loss in one subject with a 20x magnification (scale in $\mathrm{mm}$ ).

Differences in overall morphology in plastic and paraffin embedded tissue can be seen in the microscopic pictures shown in figure 4.

\section{Discussion}

Adipocytes in paraffin embedded adipose tissue had a lower mean cell diameter and area before and after weight loss. Mean relative shrinkage of adipocytes in paraffin embedded tissue in proportion to plastic embedded tissue was 73 and $69 \%$ before and after weight loss, respectively.

Already in 1974 Fletcher compared plastic embedded avian tissues with the more conventional paraffin method and found that cell shrinkage was lower and fewer sectioning artifacts were present in plastic embedded tissue (8). Recently, advantages of plastic embedding over paraffin in human bone tissue have been reported $(9,10)$. One disadvantage is that sectioning of plastic embedded tissue is more time consuming compared to paraffin. However, the advantages outweigh the disadvantages, since artifacts and cell shrinking do influence results that are based on morphological features.

The majority of studies using paraffin or plastic embedding to evaluate morphological characteristics of tissues do not include measurements of shrinkage. However, interpretation of quantitative parameters or density and size estimations may be very difficult without knowledge of the degree of shrinkage. Here, we defined relative shrinkage of paraffin embedded adipose tissue in proportion to plastic embedded adipose tissue, since plastic is suggested to virtually remove shrinkage (6). Paraffin embedding caused a relative shrinkage of about $70 \%$ in proportion to plastic embedding. This is high compared to findings from other studies, which reported shrinkage from $10-50 \%$ in different organs (4-6). The use of adipose tissue in this study probably caused this high relative shrinkage, since adipose tissue is susceptible to cell shrinking because of the large lipid droplet comprising the largest part of adipocytes. Alt- 
hough the high relative shrinkage, paraffin embedding produced consistent results in the different tissues. Relative shrinkage was not significantly different in adipose tissue before and after weight loss. Therefore, the shrinkage of adipose tissue due to embedding in this study can be ignored.

High cell shrinking due to paraffin embedding might have consequences for interpretation of results. The degree of cell shrinkage might be important for defining cut off points, in order to exclude cells other than adipocytes. Beside some studies that do not even take into account such cut off points $(2,11-15)$, the values that are used as cut off point vary greatly $(16,17)$. In this study a diameter of $40 \mu \mathrm{m}$ was used as a cut off point for both paraffin and plastic embedded tissues. Since several methods of processing result in different degrees of cell shrinking, therefore the use of the same cut off points for different methods might be questioned. Another consequence of higher cell shrinking in paraffin embedded tissue is a lower sensitivity to detect significant differences in cell size measurements.

One explanation for the continuous use of paraffin embedded tissue is immunohistochemical staining, since the effectiveness largely depends on the type of fixation, preparation and embedding. The advantage of paraffin embedding for immunohistochemical staining is the lack of chemical interaction with the tissue. Recently, immunohistochemical staining of bone tissue embedded with Technovit 9100 New showed a stronger immunostaining for several markers and a better preservation of trabecular bone morphology compared to paraffin embedding $(9,10)$. Because of the continuous use of paraffin, most protocols for immunohistochemical staining are optimized for this type of embedding. However, when protocols would be optimized for plastic embedded tissues, the morphological advantages of this technique could also be exploited when immunohistological staining is required. One disadvantage is the higher costs associated with plastic embedding.

A limitation of our study is the small sample size of our population with both male and females and a relatively large variation in age and BMI. Age, BMI and sex could have an effect on adipocyte size. However, by comparing both techniques by defining relative shrinkage of paraffin-embedded tissue in relation to plastic-embedded tissue within the same subjects before and after weight loss, we believe that a possible effect of age, BMI and sex on adipocyte size would not influence our conclusion.

In conclusion, shrinkage of adipose tissue due to the type of embedding in this study can be ignored, since relative shrinkage was not significantly different in adipose tissue before and after weight loss. However, paraffin embedded tissue resulted in higher cell shrinkage and has the disadvantage of poorer morphology. Therefore, plastic embedding is more accurate and susceptible to detect differences in adipocyte size caused by weight loss.

\section{Acknowledgements}

K.R. Westerterp and S.P.M. Verhoef designed the study. S.P.M. Verhoef collected and analyzed the data and wrote the manuscript. W.H. Lamers and K.R. Westerterp contributed to the interpretation of the data and reviewed the manuscript. The study was executed under supervision of K.R. Westerterp. Thanks to Paul van Dijk for his 
excellent assistance of histological methods, Jack Cleutjens for his assistance of the image analysis computer programme and Stefan Camps for his assistance in data collection. All authors read and approved the final manuscript. None of the authors had any conflict of interest.

\section{References}

1. Gauthier MS, Ruderman NB. Adipose tissue inflammation and insulin resistance: all obese humans are not created equal. Biochem J.430:e1-4.

2. He ML, Sharma R, Mir PS, Okine E, Dodson MV. Feed withdrawal abate regimens lipodystrophy and metabolic syndrome symptoms, such as glucose tolerance, are associated with the diameter of retroperitoneal adipocytes in rats. Nutr Res.30:125-133.

3. Chen HC, Farese RV, Jr. Determination of adipocyte size by computer image analysis. J Lipid Res. 2002;43:986-989.

4. Hanstede JG, Gerrits PO. The effects of embedding in water-soluble plastics on the final dimensions of liver sections. J Microsc. 1983;131:79-86.

5. Helander KG. Thickness variations within individual paraffin and glycol methacrylate sections. J Microsc. 1983;132:223-227.

6. Nielsen KK, Andersen CB, Kromann-Andersen B. A comparison between the effects of paraffin and plastic embedding of the normal and obstructed minipig detrusor muscle using the optical dissector. J Urol. 1995;154:2170-2173.

7. Goldrick RB. Morphological changes in the adipocyte during fat deposition and mobilization. Am J Physiol. 1967;212:777-782.

8. Fletcher OJ. Research Note: Plastic Embedding of Avian Tissues for Diagnostic Histopathology. Avian Diseases. 1975;19:201-208.

9. Willbold E, Witte F. Histology and research at the hard tissue-implant interface using Technovit 9100 New embedding technique. Acta Biomater.6:4447-4455.

10. Wittenburg G, Volkel C, Mai R, Lauer G. Immunohistochemical comparison of differentiation markers on paraffin and plastic embedded human bone samples. J Physiol Pharmacol. 2009;60 Suppl 8:43-49.

11. Bambace C, Telesca M, Zoico E, Sepe A, Olioso D, Rossi A, Corzato F, Di Francesco V, Mazzucco A, Santini F, Zamboni M. Adiponectin gene expression and adipocyte diameter: a comparison between epicardial and subcutaneous adipose tissue in men. Cardiovasc $\mathrm{Pa}$ thol.

12. Farnier C, Krief S, Blache M, Diot-Dupuy F, Mory G, Ferre P, Bazin R. Adipocyte functions are modulated by cell size change: potential involvement of an integrin/ERK signalling pathway. Int J Obes Relat Metab Disord. 2003;27:1178-1186.

13. Garaulet M, Hernandez-Morante JJ, Lujan J, Tebar FJ, Zamora S. Relationship between fat cell size and number and fatty acid composition in adipose tissue from different fat depots in overweight/obese humans. Int J Obes (Lond). 2006;30:899-905.

14. Miyazaki S, Izawa T, Ogasawara JE, Sakurai T, Nomura S, Kizaki T, Ohno H, Komabayashi T. Effect of exercise training on adipocyte-size-dependent expression of leptin and adiponectin. Life Sci.86:691-698.

15. Varady KA, Tussing L, Bhutani S, Braunschweig CL. Degree of weight loss required to improve adipokine concentrations and decrease fat cell size in severely obese women. Metabolism. 2009;58:1096-1101.

16. DeMartinis FD, Francendese A. Very small fat cell populations: mammalian occurrence and effect of age. Journal of Lipid Research. 1982;23:1107-1120.

17. Tchoukalova YD, Harteneck DA, Karwoski RA, Tarara J, Jensen MD. A quick, reliable, and automated method for fat cell sizing. J Lipid Res. 2003;44:1795-1801 



\section{Chapter 6 Physiological response of adipocytes to weight loss and maintenance}

Verhoef SPM, Camps SGJA, Bouwman FG, Mariman ECM, Westerterp KR PloSOne, 2013; 8(3): e58011 


\begin{abstract}
Metabolic processes in adipose tissue are dysregulated in obese subjects and, in response to weight loss, either normalize or change in favor of weight regain. To determine changes in adipocyte glucose and fatty acid metabolism in relation to changes in adipocyte size during weight loss and maintenance. Twenty-eight healthy subjects (12 males), age $20-50 y$, and BMI $28-35 \mathrm{~kg} / \mathrm{m}^{2}$, followed a very low energy diet for 2 months, followed by a 10-month period of weight maintenance. Body weight, body composition (deuterium dilution and BodPod), protein levels (Western blot) and adipocyte size were assessed prior to and after weight loss and after the 10-month followup. A $10 \%$ weight loss resulted in a $16 \%$ decrease in adipocyte size. A marker for glycolysis decreased (AldoC) during weight loss in association with adipocyte shrinking, and remained decreased during follow-up in association with weight maintenance. A marker for fatty acid transport increased (FABP4) during weight loss and remained increased during follow-up. Markers for mitochondrial beta-oxidation (HADHsc) and lipolysis (ATGL) were only increased after the 10-month follow-up. During weight loss HADHsc and ATGL were coordinately regulated, which became weaker during follow-up due to adipocyte size-related changes in HADHsc expression. AldoC was the major denominator of adipocyte size and body weight, whereas changes in ATGL during weight loss contributed to body weight during follow-up. Upregulation of ATGL and HADHsc occured in the absence of a negative energy balance and was triggered by adipocyte shrinkage or indicated preadipocyte differentiation. Markers for adipocyte glucose and fatty acid metabolism are changed in response to weight loss in line with normalization from a dysregulated obese status to an improved metabolic status.
\end{abstract}




\section{Introduction}

Adipose tissue is a major energy-storing tissue and to fulfill this role adipocytes need to respond rapidly to alterations in nutrient deprivation and excess by metabolic regulation. Many studies found evidence for involvement of metabolic processes in the development of obesity, like a reduced fat oxidation in obese humans (1-3). But also inside the adipocyte these metabolic processes are linked to obesity. Walewski et al. showed that an increased uptake and reduced metabolism of long chain fatty acids contribute to the accumulation of these long chain fatty acids in obese adipocytes (4). Furthermore, an impaired hormone-sensitive lipase protein expression in adipose tissue of obese subjects suggests a decreased lipolysis in obesity (5). Studies on weight loss indicate that caloric restriction results in changes in the expression of genes involved in lipid, carbohydrate and energy metabolism in adipose tissue (6) and proteins regulating adipose tissue growth (7). Also the endocannabinoid system is dysregulated in adipose tissue in the obese state, but is normalized after weight loss (8).

However, successfully maintaining weight loss, defined as "keeping off an intentional loss of at least $10 \%$ body weight for at least one year" (9), is difficult and is only achieved in around $20 \%$ of the cases (10). The biological response to weight loss is causing the susceptibility to weight regain as reviewed by MacLean et al. (11). This response is a network of adaptations with an energy gap promoting regain and physiological changes resulting in resistance for further weight loss as was summarized by Mariman (12). Few studies assessed the effect of weight loss maintenance on gene expression in subcutaneous adipose tissue (13-15). Genes involved in processes like fatty acid metabolism, citric acid cycle, oxidative phosphorylation and apoptosis were differentially expressed during weight loss and maintenance thereafter (1315). Mutch et al. showed that the regulation of these genes by weight loss was different between weight maintainers and weight regainers, which was suggested to predict successful short-term weight maintenance (15).

Our objective was to determined changes in markers for adipocyte glucose and fatty acid metabolism during weight loss and maintenance by measuring protein levels before and after an 8-week very low energy diet and after a 10-month follow-up in order to find out whether these changes are associated with adipocyte size and are in line with weight regain or maintenance.

\section{Methods}

\section{Ethics statement}

All procedures were carried out with the adequate understanding and written informed consent of the subjects. The study was conducted according to the guidelines laid down in the Declaration of Helsinki and was approved by the Central Committee on Human Research and by the Medical Ethical Committee of the University of Maa- 
stricht. The study was registered in ClinicalTrials.gov (registration number: NCT01015508). The protocol described here in this study deviates from the trial protocol approved by the Medical Ethical Committee of the University of Maastricht (adipocyte size is determined differently and protein levels measurements are not explicitly described) as it comprises only a part of the approved trial protocol.

\section{Subjects}

Thirty-one healthy subjects (13 males, 18 pre-menopausal females) aged 20-50 y with a BMI of $28-35 \mathrm{~kg} / \mathrm{m}^{2}$ were recruited by advertisements in local newspapers and on notice boards at the university. Subjects underwent a screening and all were in good health, nonsmokers, not using medication (except for oral contraception) and moderate alcohol users. None of the subjects gained or lost more than $5 \mathrm{~kg}$ in three months prior to the study. The weight loss diet consisted of 8 weeks very low energy diet providing 2.1 MJ/day (Modifast; Nutrition et Santé Benelux, Breda, The Netherlands). This diet was a protein-enriched formula diet that provided $50 \mathrm{~g}$ carbohydrates, $52 \mathrm{~g}$ protein, $7 \mathrm{~g}$ fat and a micronutrient content, which meets the Dutch recommended daily allowance. Vegetables were allowed in addition to the diet. The weight loss period was followed by a follow-up period of 10 months, in which subjects were instructed to maintain their newly achieved body weight without a prescribed diet. Subjects did receive advise on how to monitor and limit their food intake concerning both quantity as well as quality at all test days after weight loss. Measurements were done at rest and following an overnight fast at three time points; before weight loss (t0), after weight loss (t2) and after 10 months follow-up (t12).

\section{Anthropometry}

Height was measured at screening to the nearest $0.1 \mathrm{~cm}$ with the use of a wallmounted stadiometer (model 220; Seca, Hamburg, Germany). Body weight was measured with subjects in underwear after an overnight fast using a calibrated scale of the BodPod $^{\circledR}$. Body mass index (BMI) was calculated by dividing body weight by height squared $\left(\mathrm{kg} / \mathrm{m}^{2}\right)$. Fat distribution was assessed by measuring the waist circumference at the site of the smallest circumference between the rib cage and the ileac crest, with the subjects in standing position. Hip circumference was measured at the site of the largest circumference between waist and thighs.

Body composition was calculated from body volume of the BodPod ${ }^{\circledR}$ (Life measurement, Concord, CA, USA) (16) and total body water (TBW) (17) of the deuterium dilution technique, using Siri's three-compartment model (18). The dilution of the deuterium isotope $\left({ }^{2} \mathrm{H}_{2} \mathrm{O}\right)$ is a measure for total body water. Subjects wore tightly fitting bathing suits and a swim cap during the volume-measurements in the $\operatorname{BodPod}^{\circledR}$, and had not engaged in exercise at least 1 hour prior to the test.

\section{Blood parameters}

Fasted blood samples were taken and collected in EDTA containing tubes to prevent clotting. Plasma was obtained by centrifugation and stored at $-80^{\circ} \mathrm{C}$ until further ana- 
lysis. Leptin, insulin and adiponectin concentrations were measured with the use of the human RIA kit (respectively, Millipore, St Charles, MO, USA, Kabi-Pharmacia, Uppsala, Sweden and Millipore, St Charles, MO, USA).

\section{Western blot analysis}

Five proteins involved in glucose and fatty acid metabolisms were selected and measured in adipose tissue by Western blotting. Fructose-bisphosphate aldolase $\mathrm{C}$ (Al$\mathrm{doC}$ ) is an enzyme of the glycolysis and involved in the formation of triglycerides. Fatty acid binding protein 4 (FABP4) is an indicator for fatty acid handling inside the adipocyte by facilitating the intracellular transport of fatty acids. Adipose triglyceride lipase (ATGL) and short chain 3-hydroxyacyl-CoA dehydrogenase (HADHsc) are ratelimiting enzymes of respectively lipolysis and mitochondrial beta-oxidation. Finally catalase represents peroxisomal beta-oxidation because it is responsible for converting the harmful product of this reaction, hydrogen peroxide.

Abdominal subcutaneous adipose tissue biopsies (approximately $1.5 \mathrm{~g}$ ) were obtained by needle liposuction under local anaesthesia ( $2 \%$ lidocaine, Fresenius Kabi BV, The Netherlands) after an overnight fast, before and after the diet. Samples were rinsed in sterile cold saline, frozen in liquid nitrogen and stored at $-80^{\circ} \mathrm{C}$ until protein isolation.

Frozen adipose tissue was grinded in a mortar and the powder was dissolved in $200 \mu \mathrm{l}$ of $8 \mathrm{M}$ urea, $2 \%$ CHAPS, $65 \mathrm{mM}$ DTT per $100 \mathrm{mg}$ powder. The homogenate was vortexed for $5 \mathrm{~min}$ and centrifuged for $30 \mathrm{~min}$ at $14000 \mathrm{rpm}$ and $10^{\circ} \mathrm{C}$. The supernatant containing the adipose tissue proteome was carefully collected and aliquots were stored at $-80^{\circ} \mathrm{C}$. Protein concentrations were determined by a Biorad Bradfort-based protein assay (19).

Samples with equal amount of protein were run on a $12 \%$ SDS polyacrylamide gel $(180 \mathrm{~V}$, Criterion Cell; Biorad, Hercules, CA) and then transferred (90 min, $100 \mathrm{~V}$, Criterion blotter; Biorad) to $0.45-\mathrm{mm}$ nitrocellulose membranes. After Ponceau S staining and destaining, membranes were blocked in $5 \%$ bovine serum albumin (BSA) in Tris-buffered saline containing $0.1 \%$ Tween 20 (TBST) for AldoC and 5\% nonfat dry milk powder in TBST for catalase, FABP4, ATGL and HADHsc for $1 \mathrm{~h}$. Thereafter, the blots were incubated with the primary antibodies against AldoC (1:250 dilution, Santa Cruz sc-12066), catalase (1:500 dilution, Santa Cruz sc69762), FABP4 (1:1000 dilution, Cayman 10004944), ATGL (1:250 dilution, Cell Signaling 2138) and HADHsc (1:500 dilution, Santa Cruz sc-74650) in 5\% BSA-TBST (AldoC), 0.5\% nonfat dry milk powder TBST (ATGL) or $5 \%$ nonfat dry milk powder TBST (catalase, FABP4, HADHsc) overnight at $4^{\circ} \mathrm{C}$ on a shaker. Thereafter, the blots were washed three times for 10 min in TBST, and then incubated with 1:10000 dilution of the horseradish peroxidaseconjugated secondary antibody (DAKO) in 5\% BSA-TBST, $0.5 \%$ nonfat dry milk powder TBST or $5 \%$ nonfat dry milk powder TBST for $1 \mathrm{~h}$. The blots were washed three times for $10 \mathrm{~min}$ in TBST. A CCD camera (XRS-system, Biorad) was used to detect immunoreactive bands using chemiluminescent substrate (SuperSignal CL; Pierce). The quantification was performed with the program Quantity One version 4.6.5 (Biorad). Blots were normalized to $\beta$-actin (1:1000 dilution, Santa Cruz sc-47778) to correct for differences in protein loading. 


\section{Adipocyte size}

Part of the biopsies was rinsed in sterile cold saline and stored in $4 \%$ paraformaldehyde. Tissues were dehydrated and embedded in paraffin. Section of $5 \mu \mathrm{m}$ were cut and stained with hematoxylin and eosin. The sections were viewed at 20x magnification, and images were obtained with Leica Image Manager (IM50), version 1.20 (Leica Microsystems AG, Switzerland). An image analysis computer programme (Leica QWin V3) was used to determine adipocyte area $\left(\mu \mathrm{m}^{2}\right)$ and diameter $(\mu \mathrm{m})$ based on the method of Chen and Farese (20). Results were directly loaded into a spreadsheet program (Excel; Microsoft Inc.) for analysis. Diameters $<40 \mu \mathrm{m}$ were assumed to represent artifacts or types of cells other than adipocytes and were excluded from analysis. Volume was calculated with the Goldrick formula (21). A minimum of 250 cells was measured per subject per time point.

\section{Statistical analysis}

Data are presented as mean and their standard errors, unless otherwise indicated. A paired t-test (two-tailed distribution) was carried out to determine possible differences between mean values. Spearman Rho's correlation coefficients were calculated for associations between parameters. ANOVA repeated measures was carried out to determine possible differences over time with gender as covariate. Significance was defined as $\mathrm{P}<0.05$. The power calculation was based on a weight loss study, in which a significant 3-fold increase in ATGL and a 2-fold increase in HADHsc levels was measured with Western blotting during weight loss in 8 obese subjects (submitted, Bouwman et al.). With an $\alpha$ of $0.05, \beta$ of 0.10 , mean change of respectively 0.177 and 0.285 , and standard deviations of respectively 0.180 and 0.223 for ATGL and HADHsc, and taking into account an expected success-rate of $20 \%$ during weight maintenance and a dropout rate of $15 \%$, at least 29 subjects needed to be included at the start of the study. All of the statistical analyses were executed with SPSS version 16.0 for Macintosh OS X (SPSS Inc, Chicago, IL).

\section{Results}

\section{Subject characteristics}

Three subjects dropped out during follow-up, thus 28 subjects (12 males, 16 females) aged $39 \pm 2$ y completed the study and from those biopsies were taken at the three time points. Blood samples were available from 13 subjects ( 7 males and 6 females), with no significant differences in weight loss and weight maintenance thereafter between these 13 subjects and the other 15 subjects.

Subject characteristics at t0, t2 and $\mathrm{t} 12$ are shown in table 1. Average weight loss was $10 \pm 0.6 \%$ (range $4-17 \%$ ) and $82 \%$ of this lost weight was fat mass. This was accompanied by a decrease in adipocyte volume of $16 \pm 0.1 \%$. Weight loss was also accompanied by a decrease in leptin and a trend towards a decrease in insulin levels $(P=0.106)$. During follow-up BMI significantly increased, although there was a large 
Table 1. Anthropometric parameters (mean \pm SEM) at t0, t2 and $t 12(n=28)$.

\begin{tabular}{lllll}
\hline & t0 & t2 & t12 & P-value \\
\cline { 2 - 5 } Body weight $(\mathrm{kg})$ & $96.9 \pm 2.7$ & $87.2 \pm 2.3$ & $91.7 \pm 2.6$ & $<0.001$ \\
BMI $\left(\mathrm{kg} / \mathrm{m}^{2}\right)$ & $31.8 \pm 0.5$ & $28.6 \pm 0.5$ & $30.1 \pm 0.6$ & $<0.001$ \\
Waist circumference $(\mathrm{cm})$ & $97.8 \pm 2.1$ & $89.2 \pm 1.6$ & $92.6 \pm 1.8$ & $<0.001$ \\
Hip circumference $(\mathrm{cm})$ & $113.6 \pm 1.6$ & $107.5 \pm 1.5$ & $109.2 \pm 1.6$ & $<0.001$ \\
Fat mass $(\mathrm{kg})$ & $38.9 \pm 1.4$ & $30.9 \pm 1.4$ & $34.4 \pm 1.5$ & $<0.001$ \\
Percentage fat mass $(\%)$ & $40.2 \pm 1.0$ & $35.5 \pm 1.3$ & $37.4 \pm 1.2$ & $<0.001$ \\
Adipocyte diameter $(\mu \mathrm{m})$ & $66.9 \pm 0.6$ & $63.2 \pm 1.0$ & $65.2 \pm 1.0$ & 0.005 \\
Adipocyte volume $\left({ }^{*} 10^{5} \mu \mathrm{m}^{3}\right)$ & $1.8 \pm 0.0$ & $1.5 \pm 0.1$ & $1.7 \pm 0.1$ & 0.013 \\
Leptin" $(\mu \mathrm{g} / \mathrm{L})$ & $20.3 \pm 2.9$ & $13.1 \pm 3.4$ & $17.8 \pm 4.6$ & 0.005 \\
Insulin ${ }^{*}(\mathrm{mU} / \mathrm{L})$ & $18.4 \pm 2.2$ & $14.7 \pm 2.1$ & $19.6 \pm 5.4$ & $\mathrm{NS}$ \\
Adiponectin" $(\mu \mathrm{g} / \mathrm{L})$ & $17.0 \pm 2.1$ & $18.0 \pm 2.6$ & $17.0 \pm 3.5$ & $\mathrm{NS}$ \\
\hline ANOVA repeated measures & & & & \\
${ }^{\#} \mathrm{n}=13$ & & & & \\
BMI, Body Mass Index & & & &
\end{tabular}

variation. As expected, only $18 \%$ of the subjects were successful in maintaining their reduced weight or even continued to lose weight during the 10-month follow-up (10). Average adipocyte volume did not change significantly during follow-up, but the changes in adipocyte volume were positively correlated with changes in body weight between t0 and t12 ( $P=0.007, r=0.519)$.

\section{Proteins}

Protein levels are depicted in figure 1. Correlation analysis between the changes in protein levels and changes in adiposity parameters are depicted in table 2. No significant correlations were found with changes in adiponectin levels. Fructosebisphosphate aldolase $\mathrm{C}$ (AldoC) decreased during weight loss and remained decreased during follow-up (figure $1 \mathrm{~A}$ ). Changes in AldoC were positively correlated with changes in body weight and adipocyte size.

Fatty acid binding protein 4 (FABP4) increased during weight loss and remained increased during follow-up, with a trend towards an additional increase between 2 and $\mathrm{t} 12(\mathrm{P}=0.058)$ (figure 1B). During follow-up changes in FABP4 were positively correlated with changes in body weight, whereas changes in FABP4 during weight loss were inversely correlated with changes in body weight during follow-up. Short chain 3hydroxyacyl-CoA dehydrogenase (HADHsc) increased during follow-up (figure 1C). Changes in adipocyte size during weight loss were inversely correlated with changes in HADHsc during follow-up. Adipose triglyceride lipase (ATGL) also increased during follow-up (figure 1D). Changes in ATGL during weight loss were positively correlated with changes in body weight during follow-up. Catalase on average did not significantly change over time (figure 1E). However, there was a trend towards an inverse correlation between changes in catalase and changes in body weight and adipocyte size during follow-up. In addition there was a trend towards a positive correlation between changes in catalase during weight loss and changes in adipocyte size during follow-up. 
A

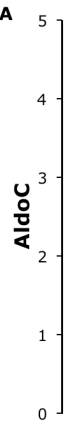

B

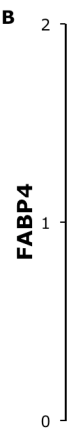

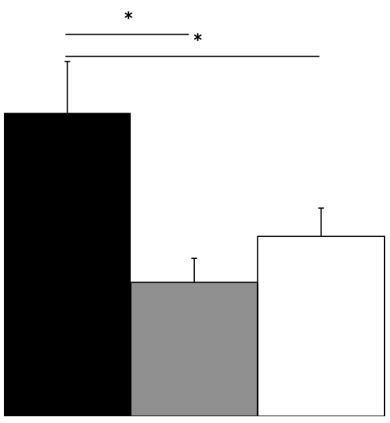

D

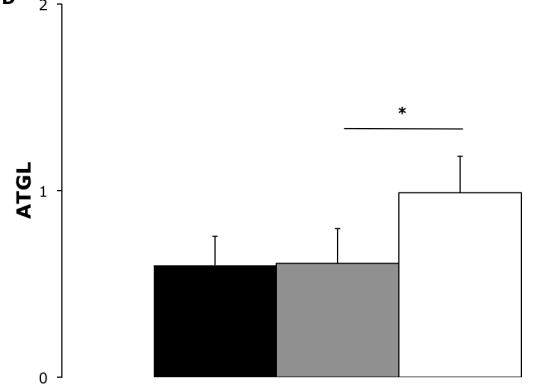

$\mathbf{E}$

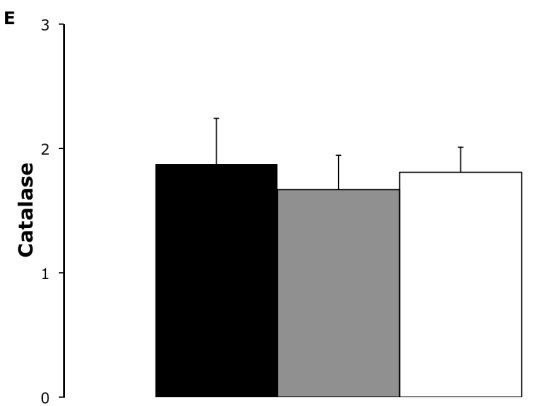

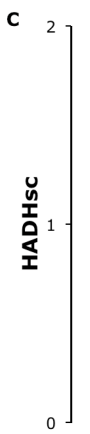
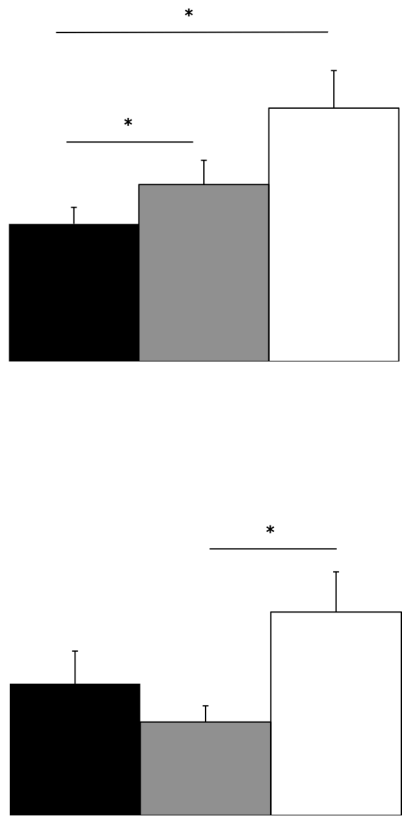

Figure 1. Protein levels measured with Western blots over time. AldoC (A), FABP4 (B), HADHsc (C), ATGL (D) and Catalase (E) levels (arbitrary units) at to (black), t2 (grey) and t12 (white) (mean \pm SEM). ${ }^{*} \mathrm{P}<0.05$ with repeated measures ANOVA.

The correlations between the changes in protein levels are listed in table 3 . Changes in AldoC, HADHsc and catalase during weight loss were inversely correlated with changes during follow-up. Changes in FABP4 are positively correlated with changes in both HADHsc and ATGL. In turn, changes in ATGL and HADHsc during weight loss are positively correlated, whereas changes in ATGL during weight loss are inversely correlated with changes in HADHsc during follow-up. Changes in catalase are inversely correlated with changes in HADHsc, but positively correlated with changes in AldoC. Changes in AldoC and changes in HADHsc between to and $\mathrm{t} 12$ were inversely correlated. 


\section{Discussion}

Measuring proteins involved in glucose and fatty acid metabolism before and after an 8-week very low energy diet and after a 10-month follow-up revealed a decreased marker for glycolysis (decreased AldoC) and increased marker for fatty acid transport (increased FABP4) after weight loss sustained during weight maintenance. There was a delayed response in fatty acid metabolism with increased markers for lipolysis (increased ATGL) and mitochondrial beta-oxidation (increased HADHsc) during followup.

The changes in catalase, HADHsc and AldoC during weight loss were inversely correlated with the changes of these proteins during follow-up. These correlations remained significant in a multiple regression analysis taking into account body weight loss (data not shown). The transition from weight loss to follow-up seems to have a major impact on markers for beta-oxidation and glycolysis. This is probably due to switching from a negative energy balance after the 8-week very low energy diet to a normal diet during the follow-up. Results here are in line with previous research that did take into account a 3-week maintenance interval to remove possible immediate effects of a negative energy balance (22).

The increase in FABP4 during weight loss, which was sustained during the 10month follow-up, indicates an increased marker for intracellular trafficking of fatty acids. Together with the decrease in adipocyte size this suggests that there would be an increased lipolysis. However, against our expectations we found no significant increase of ATGL during weight loss. This could be due to a sufficient lipolytic capacity or that a decrease in lipid content is the result of another mechanism like autophagia $(23,24)$. Despite the lack of an increase in ATGL during weight loss, correlations between changes in protein levels demonstrate a coordinated regulation of ATGL, HADHsc and CAT indicating cross-talk between markers for lipolysis and mitochondrial and peroxisomal $\beta$-oxidation. There was an inverse correlation between changes in ATGL during weight loss and changes in HADHsc during the follow up (figure 2). This correlation remained significant in a multiple regression analysis taking into account body weight loss (data not shown), but may be simply the consequence of other correlations. Nevertheless, the coordination between those processes of FA-handling becomes weaker during follow-up. According to the correlation analysis, the weakening of the coordination between FA-handling processes may be related to changes in adipocyte size during weight loss, which may influence the HADHsc expression during follow-up. Shrinking of adipocytes during weight loss has been reported to generate cellular stress $(22,25,26)$ and the more they shrink, the higher will be the resistance against increasing mitochondrial beta-oxidation via HADHsc during follow-up.

During development of obesity, the capacity of lipolysis and beta-oxidation decrease (1-3). In this respect, the increase of both ATGL and HADHsc suggest that weight loss induces an improved homeostasis. The fact that this process only starts after the end of the weight loss period indicates that it is inhibited by a negative energy balance. The increase in ATGL and HADHsc may be triggered by the shrinking of the adipocytes, but may also be the result of differentiation of preadipocytes, which in the rat has been observed after weight loss $(5,11)$. Newly differentiated adipocytes are metabolically active, which will contribute to an improved physiological status. 
Table 2. Spearman Rho's correlation coefficients of changes in protein levels with changes in adiposity parameters.

\begin{tabular}{|c|c|c|c|c|c|c|c|c|c|c|c|c|c|c|c|c|}
\hline \multirow[b]{2}{*}{ Parameter } & & \multicolumn{3}{|c|}{ Aldolase C } & \multicolumn{3}{|l|}{ FABP4 } & \multicolumn{3}{|c|}{ HADHsc } & \multicolumn{3}{|l|}{ ATGL } & \multicolumn{3}{|c|}{ Catalase } \\
\hline & & $\mathrm{t} 2-0$ & t12-2 & $t 12-0$ & t2-0 & t12-2 & $\mathrm{t} 12-0$ & t2-0 & t12-2 & t12-0 & t2-0 & t12-2 & $t 12-0$ & t2-0 & $\mathrm{t} 12-2$ & $t 12-0$ \\
\hline Body weight & t2-0 & & & & & & & & & & & & & & & \\
\hline \multirow[t]{2}{*}{$(\mathrm{kg})$} & $\mathrm{t} 12-2$ & & $0.483^{b}$ & & $-0.405^{\mathrm{a}}$ & $0.414^{\mathrm{a}}$ & & & & & $0.561^{b}$ & & $0.532^{b}$ & & & $-0.399^{a}$ \\
\hline & $t 12-0$ & & & $0.450^{b}$ & & $0.635^{\mathrm{c}}$ & & & & & & & & & & \\
\hline \multirow{3}{*}{$\begin{array}{l}\text { Adipocyte size } \\
\left({ }^{*} 10^{5} \mu \mathrm{m}^{3}\right)\end{array}$} & $\mathrm{t} 2-0$ & $0.562^{\mathrm{b}}$ & & & & & & & $-0.462^{b}$ & & & & & & & \\
\hline & $\mathrm{t} 12-2$ & & $0.372^{\mathrm{a}}$ & & & & & & & & & & & $0.398^{\mathrm{a}}$ & $-0.388^{a}$ & \\
\hline & $\mathrm{t} 12-0$ & & & $0.411^{a}$ & & & & & & & & & & & & \\
\hline Leptin ${ }^{\#}$ & t2-0 & & & $-0.667^{b}$ & & & & & & & & & & & & \\
\hline \multirow[t]{2}{*}{ ( $\mu \mathrm{g} / \mathrm{L})$} & $\mathrm{t} 12-2$ & & & & & & & & & & & & & & & \\
\hline & $\mathrm{t} 12-0$ & & & & & & & & & & & & & & & \\
\hline Insulin ${ }^{\#}$ & $\mathrm{t} 2-0$ & & & $-0.700^{b}$ & $0.576^{a}$ & & & & & & & & & & & \\
\hline \multirow[t]{2}{*}{$(\mathrm{mU} / \mathrm{L})$} & $\mathrm{t} 12-2$ & & & & $-0.886^{b}$ & $0.829^{b}$ & & & & & & & & & & \\
\hline & $\mathrm{t} 12-0$ & & & & & & & & & & & & & & & \\
\hline
\end{tabular}

${ }^{\#} \mathrm{n}=13$

${ }^{a} \mathrm{P}<0.1$

${ }^{b} \mathrm{P}<0.05$

${ }^{\mathrm{C}} \mathrm{P}<0.01$

BMI, Body Mass Index 
Table 3. Spearman Rho's correlation coefficients of changes in protein levels with each other.

\begin{tabular}{|c|c|c|c|c|c|c|c|c|c|c|c|c|c|c|c|c|}
\hline & & Aldola & & & FABP & & & HADHs & & & ATGL & & & Catala & & \\
\hline & & $\overline{t 2-0}$ & t12-2 & t12-0 & $\mathrm{t} 2-0$ & t12-2 & t12-0 & t2-0 & t12-2 & $\mathrm{t} 12-0$ & t2-0 & t12-2 & t12-0 & $\mathrm{t} 2-0$ & t12-2 & t12-0 \\
\hline Aldolase C & t2-0 & & & & & & & & & & & & & & & \\
\hline & $\mathrm{t} 12-2$ & $-0.488^{b}$ & & & & & & & & & & & & & & \\
\hline & $\mathrm{t} 12-0$ & $0.564^{\circ}$ & & & & & & & & & & & & & & \\
\hline FABP4 & $\mathrm{t} 2-0$ & & & & & & & & & & & & & & & \\
\hline & $\mathrm{t} 12-2$ & & & & & & & & & & & & & & & \\
\hline & $\mathrm{t} 12-0$ & & & & $0.396^{a}$ & $0.739^{c}$ & & & & & & & & & & \\
\hline HADHsc & $\mathrm{t} 2-0$ & & & & & & & & & & & & & & & \\
\hline & t12-2 & & & & & & & $-0.542^{c}$ & & & & & & & & \\
\hline & $\mathrm{t} 12-0$ & & & $-0.461^{b}$ & & $0.481^{b}$ & $0.458^{\mathrm{b}}$ & & $0.583^{c}$ & & & & & & & \\
\hline ATGL & t2- 0 & & $0.545^{\mathrm{a}}$ & & & & & $0.618^{b}$ & $-0.618^{b}$ & & & & & & & \\
\hline & t12-2 & & & & & $0.500^{\mathrm{a}}$ & $0.643^{b}$ & & & & & & & & & \\
\hline & t12-0 & & & & & & $0.516^{\mathrm{a}}$ & & & & $0.689^{c}$ & $0.889^{\circ}$ & & & & \\
\hline Catalase & t2-0 & & & & & & & $-0.740^{\circ}$ & & & & & & & & \\
\hline & t12-2 & & & & & & & & & & & $-0.564^{a}$ & & $-0.697^{\circ}$ & & \\
\hline & $t 12-0$ & & & $0.500^{\mathrm{b}}$ & & & & $-0.482^{b}$ & & $-0.552^{b}$ & & & & $0.571^{\circ}$ & & \\
\hline
\end{tabular}

$$
{ }^{b} \mathrm{P}<0.05
$$

${ }^{\mathrm{c}} \mathrm{P}<0.01$ 
Changes in parameters of adiposity were correlated with changes in AldoC. This indicates that successful weight maintainers sustain their decreased AldoC levels, whereas AldoC increases again with weight regain (figure 3A). Furthermore, a large sustained decrease in adipocyte size was associated with success during follow-up (figure 3B). This is in line with the model proposed by MacLean, which argues that adipocyte size and functioning are returned to baseline levels only when body weight is fully regained (11). Although not defined as groups, these results are in line with the study of Mutch et al., which showed that genes regulating fatty acid metabolism were differently regulated by weight loss in weight maintainers and weight regainers (15). In addition, these results suggest that glycolysis is a major denominator of adipocyte size and contributes to body weight during follow-up. The amount of stored fat is a resultant of storage and lipolysis and raising the production of glycerolphosphate from glucose, which is necessary for the formation and storage of triglycerides, may therefore shift the balance towards growing of the adipocytes and gain of body weight. Change in body weight during follow-up is not only related to AldoC, but also to changes in ATGL during weight loss (figure 4). This correlation remained significant in a multiple regression analysis taking into account body weight loss (data not shown), and suggests that the amount of fat you lose from the adipose tissue during the weight loss phase determines what happens to the body weight afterwards. This is in line with the model of adipocyte cellular stress for weight regain $(11,22,25,26)$.

A limitation of this study is that diet and physical activity were not standardized during the 10-month follow-up. On the other hand, due to the absence of an advise on diet and physical activity, this study truly reflects achievements in free-living conditions. Another limitation is the use of total adipose tissue biopsy material for Western blotting. Furthermore, $\beta$-actin showed no significant changes and was chosen as a housekeeping control to be able to compare the present results with those of other studies. Although the selected proteins are involved in the major steps of the glucose and fatty acid metabolism and may reflect the capacity of metabolic pathways, it should be noted that protein levels do not represent the actual flux through the pathways. The 10-month follow-up is a major advantage with regard to previous studies and indicates that the cellular response to weight loss persists during follow-up until body weight is regained. Another advantage is that previous findings are now confirmed in a larger population and in combination with measurements on adipocyte size.

In conclusion, these data show a coordinated regulation of markers for lipolysis and beta-oxidation during weight loss, which seems weaker during follow-up due to adipocyte size-related changes in HADHsc expression. AldoC as a marker for glycolysis is the major denominator of adipocyte size and body weight, whereas the marker for lipolysis during weight loss contributes to body weight during follow-up. Upregulation of ATGL and HADHsc occur in the absence of a negative energy balance and are triggered by adipocyte shrinkage or indicate preadipocyte differentiation. Overall, our findings are in line with normalization from a dysregulated obese status to an improved metabolic status. 

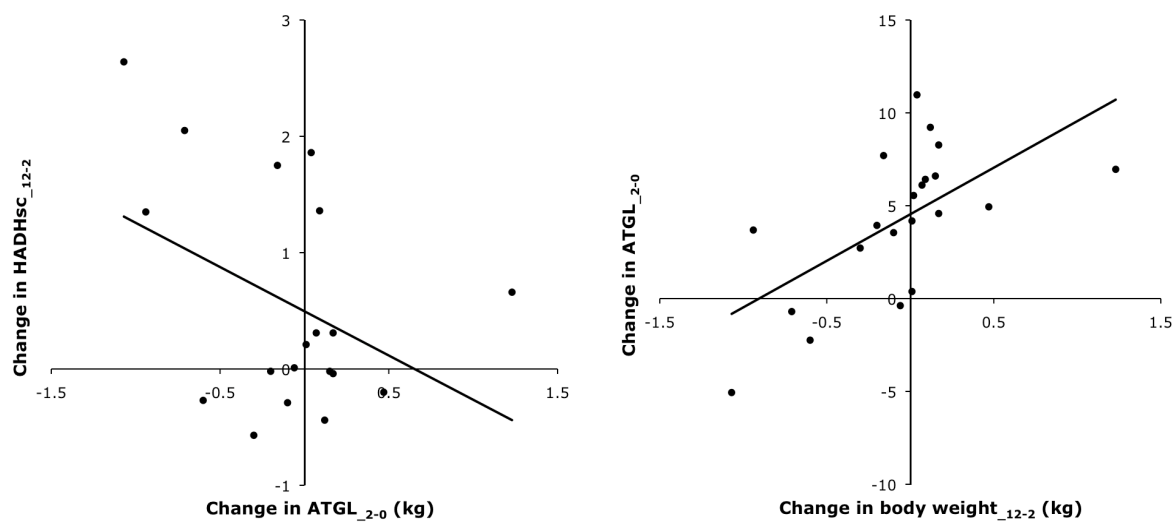

Figure 2. Change in ATGL levels during weight Figure 4. Change in ATGL levels during weight loss as a function of the change in HADHsc loss as a function of the change in body weight levels during follow-up. (kg) during follow-up.
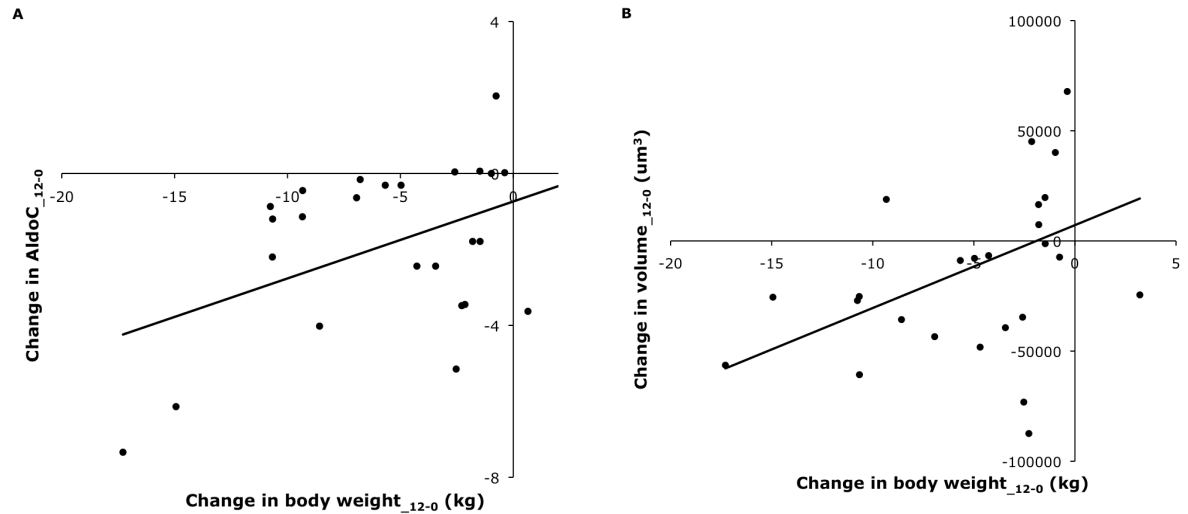

Figure 3. Change in Aldolase $C$ levels and change in adipocyte volume as a function of the change in body weight $(\mathrm{kg})$ after 10-month follow-up compared to baseline. Aldolase C (A), adipocyte volume $\left(\mu \mathrm{m}^{3}\right)(\mathrm{B})$.

\section{Acknowledgements}

Thanks to Paul van Dijk, Loek Wouters and Jos Stegen for their assistance.

\section{References}

1. Blaak EE, Hul G, Verdich C, Stich V, Martinez A, et al. (2006) Fat oxidation before and after a high fat load in the obese insulin-resistant state. J Clin Endocrinol Metab 91: 1462-1469. 
2. Frisancho AR. (2003) Reduced rate of fat oxidation: a metabolic pathway to obesity in the developing nations. Am J Hum Biol 15: 522-532.

3. Westerterp KR, Smeets A, Lejeune MP, Wouters-Adriaens MPE, Westerterp-Plantenga MS. (2008) Dietary fat oxidation as a function of body fat. Am J Clin Nutr 87: 132-135.

4. Walewski JL, Ge F, Gagner M, Inabnet WB, Pomp A, et al. (2010) Adipocyte accumulation of long-chain fatty acids in obesity is multifactorial, resulting from increased fatty acid uptake and decreased activity of genes involved in fat utilization. Obes Surg 20: 93-107.

5. Langin D, Dicker A, Tavernier G, Hoffstedt J, Mairal A, et al. (2005) Adipocyte lipases and defect of lipolysis in human obesity. Diabetes 54: 3190-3197.

6. Capel F, Viguerie N, Vega N, Dejean S, Arner P, et al. (2008) Contribution of energy restriction and macronutrient composition to changes in adipose tissue gene expression during dietary weight-loss programs in obese women. J Clin Endocrinol Metab 93: 4315-4322.

7. Aubin D, Gagnon A, Grunder L, Dent R, Allen M, et al. (2004) Adipogenic and antiapoptotic protein levels in human adipose stromal cells after weight loss. Obes Res 12: 1231-1234.

8. Bennetzen MF, Wellner N, Ahmed SS, Ahmed SM, Diep TA, et al. (2005) Investigations of the human endocannabinoid system in two subcutaneous adipose tissue depots in lean subjects and in obese subjects before and after weight loss. Int $J$ Obes (Lond) 35: 1377-1384.

9. Wing RR, Hill JO. (2001) Successful weight loss maintenance. Annu Rev Nutr 21: 323-341.

10. Wing RR, Phelan S. (2005) Long-term weight loss maintenance. Am J Clin Nutr 82: 222S225S.

11. Maclean P, Bergouignan A, Cornier M-A, Jackman M. (2011) Biology's response to dieting: the impetus for weight regain. American journal of physiology. Regulatory, integrative and comparative physiology 301: 581-600.

12. Mariman E. (2012) Human Biology of Weight Maintenance after Weight Loss. Journal of nutrigenetics and nutrigenomics 5: 13-38.

13. Johansson LE, Danielsson AP, Parikh H, Klintenberg M, Norstrom F, et al. (2012) Differential gene expression in adipose tissue from obese human subjects during weight loss and weight maintenance. Am J Clin Nutr 96: 196-207.

14. Marquez-Quinones A, Mutch DM, Debard C, Wang P, Combes M, et al. (2010) Adipose tissue transcriptome reflects variations between subjects with continued weight loss and subjects regaining weight 6 mo after caloric restriction independent of energy intake. Am J Clin Nutr 92: 975-984.

15. Mutch DM, Pers TH, Temanni MR, Pelloux V, Marquez-Quinones A, et al. (2011) A distinct adipose tissue gene expression response to caloric restriction predicts 6-mo weight maintenance in obese subjects. Am J Clin Nutr 94: 1399-1409.

16. Dempster P, Aitkens S. (1995) A new air displacement method for the determination of human body composition. Med Sci Sports Exerc 27: 1692-1697.

17. Westerterp KR, Wouters L, van Marken Lichtenbelt WD. (1995) The Maastricht protocol for the measurement of body composition and energy expenditure with labeled water. Obes Res 3 Suppl 1: 49-57.

18. Siri W. (1961) Body composition from fluid spaces and density: analysis of methods. In: Brozek J, Henschel A (eds). Techniques for measuring body composition. National Academy of Science: Washington DC. 223-244.

19. Bradford MM. (1976) A rapid and sensitive method for the quantitation of microgram quantities of protein utilizing the principle of protein-dye binding. Analytical Biochemistry 72: 248254.

20. Chen HC, Farese RV, Jr. (2002) Determination of adipocyte size by computer image analysis. J Lipid Res 43: 986-989.

21. Goldrick RB. (1967) Morphological changes in the adipocyte during fat deposition and mobilization. Am J Physiol 212: 777-782. 
22. Bouwman FG, Claessens M, van Baak MA, Noben JP, Wang P, et al. (2009) The physiologic effects of caloric restriction are reflected in the in vivo adipocyte-enriched proteome of overweight/obese subjects. J Proteome Res 8: 5532-5540.

23. Kovsan J, Bashan N, Greenberg AS, Rudich A. (2010) Potential role of autophagy in modulation of lipid metabolism. Am J Physiol Endocrinol Metab 298: E1-7.

24. Kovsan J, Bluher M, Tarnovscki T, Kloting N, Kirshtein B, et al. (2011) Altered autophagy in human adipose tissues in obesity. J Clin Endocrinol Metab 96: E268-277.

25. Mariman EC, Wang P. (2010) Adipocyte extracellular matrix composition, dynamics and role in obesity. Cell Mol Life Sci 67: 1277-1292.

26. Wang P, Bouwman FG, Mariman EC. (2009) Generally detected proteins in comparative proteomics--a matter of cellular stress response? Proteomics 9: 2955-2966. 



\section{Chapter 7 Concomitant changes in sleep duration and body- weight and body-composition during weight-loss and 3- month weight-maintenance}

Verhoef SPM, Camps SGJA, Gonnissen HKJ, Westerterp KR, Westerterp-Plantenga MS Am J Clin Nutr, 2013; in press 


\begin{abstract}
An inverse relationship between sleep duration and body mass index (BMI) has been shown. Assessing the relationship between changes in sleep duration and changes in body-weight and body-composition during weight loss. 98 healthy subjects (25males), age $20-50 \mathrm{y}$, and BMI $28-35 \mathrm{~kg} / \mathrm{m}^{2}$, followed a 2-month very low energy diet, followed by a 10-month period of weight maintenance. Body weight, body composition (deuterium dilution and air-displacement plethysmography), eating behaviour (Three Factor Eating Questionnaire), physical activity (Baecke) and sleep (questionnaire, Epworth Sleepiness Scale) were assessed prior to and immediately after weight loss and after 3 and 10 months follow-up. Average weight loss was $10 \%$ after 2-month dieting, and 9 and $6 \%$ after respectively 3 and 10 -month follow-up. Daytime sleepiness and time to fall asleep decreased during weight loss. Sleep duration increased in short- and average-sleepers during weight loss. This change in sleep duration was concomitantly negatively correlated with the change in BMI during weight loss and after 3-month follow-up, and with the change in fat mass after 3-month follow-up. Short $(\leq 7 \mathrm{~h})$ and average $(>7<9 \mathrm{~h})$ sleepers increased their sleep duration, while sleep duration in long sleepers $(\geq 9 \mathrm{~h}$ ) did not changed significantly during weight loss. Sleep duration benefits from weight loss, or vice versa. Successful weight loss, loss of body-fat and 3month weight maintenance in short and average sleepers are underscored by an increase in sleep duration, or vice versa.
\end{abstract}




\section{Introduction}

Parallel to the increase in the prevalence of obesity, a reduction in sleep duration is observed during the past decades $(1,2)$. Evidence is accumulating that short sleep duration is a risk factor for weight gain $(3,4)$. Consequently, it is suggested to add sleep duration to a growing panel of determinants that contribute to obesity (3).

Sleep deprivation may predispose to obesity via both energy intake, energy expenditure and substrate utilization (5-9). Short sleep duration can increase energy intake through alteration in the neuroendocrine control of appetite and reward $(6,7,9$ 12). Moreover, short sleep duration increases opportunities to eat, and in combination with highly available palatable foods, this can lead to an increase in energy intake (13). Energy expenditure can be decreased with short sleep duration by a decline in physical activity caused by an increased tiredness during waking hours (5) or by an altered thermogenesis (14). Although some studies do find an effect of short sleep duration on specific components of energy metabolism such as activity energy expenditure $(7)$, total daily energy expenditure does not seem to be affected $(7,15)$. Stress also may play a role, through the relationship between the activity of the hypothalamic-pituitary-adrenal axis, insulin sensitivity and substrate utilization (16).

The relatively short- or medium-term observational studies may elucidate mechanisms supposedly inducing continuous weight gain, but whether they lead to the development of obesity in the long-term remains questionable. Therefore, it is necessary to observe whether sleep duration and body-weight including body-composition are related to each other and change concomitantly over the longer term. A few studies have addressed this research question. Rat studies have shown a quantitative relationship between sleep and the energy status of the body $(17,18)$, and a qualitative relationship between sleep and lipid/protein synthesis and degradation (17). Nedeltcheva et al. showed that a combined energy and sleep restriction in humans resulted in decreased loss of fat mass and increased loss of fat free mass (14). This suggests that sleep plays a role in the preservation of human fat-free mass during periods of energy restriction. Another long-term study showed that shifting sleep duration from a short to a healthier length is associated with lower adiposity gain (19). Sleep duration and quality at baseline were both associated with body fat loss in a moderate caloric restriction intervention (20).

The studies suggest an inverse relationship between sleep duration and the development of body-weight. However, it is impossible to ascertain the temporal sequence from case-control and cross-sectional studies, since they assess sleep duration and body-weight concurrently. Only longitudinal study designs are suitable to investigate whether changes in sleep duration are followed by changes in body-weight or vice versa.

The purpose of this study was to assess the relationship between changes in sleep duration and changes in body-weight and body-composition during weight loss in the long-term. More specifically it was investigated whether a temporal sequence of changes in sleep duration and in body-weight and body-composition could be revealed. 


\section{Material and methods}

\section{Subjects}

150 healthy subjects aged $20-50$ y with a body mass index (BMI) of $28-35 \mathrm{~kg} / \mathrm{m}^{2}$ were recruited by advertisements in local newspapers and on notice boards at the university. Subjects underwent a screening and were in good health, nonsmokers, not using medication (except for oral contraception) and moderate alcohol users. None of the subjects gained or lost more than $5 \mathrm{~kg}$ in the three months prior to the study. 98 subjects (25 males, 73 females) completed the study. The weight loss diet consisted of 8 weeks very low energy diet (VLED) providing 2.1 MJ/day (Modifast; Nutrition et Santé Benelux, Breda, The Netherlands). This diet was a protein-enriched formula diet that provided $50 \mathrm{~g}$ carbohydrates, $52 \mathrm{~g}$ protein, $7 \mathrm{~g}$ fat and a micronutrient content, which meets the Dutch recommended daily allowance. Vegetables were allowed in addition to the diet. The weight loss period was followed by a weight maintenance period of 10 months, in which subjects were instructed to maintain their newly achieved bodyweight without specific dietary instructions. Measurements were performed at four time points; before weight loss (t0), after weight loss (t2) and after 3 (t5) and 10months (t12) follow-up. The study was conducted according to the guidelines laid down in the Declaration of Helsinki and all procedures involving human subjects were approved by the Central Committee on Human Research and by the Medical Ethical Committee of the University of Maastricht. Written informed consent was obtained from all subjects. The study was registered in ClinicalTrials.gov (registration number: NCT01015508).

\section{Anthropometry}

Height was measured at screening to the nearest $0.1 \mathrm{~cm}$ with the use of a wallmounted stadiometer (model 220; Seca, Hamburg, Germany). Body-weight was measured with subjects in underwear after an overnight fast using a calibrated scale. BMI was calculated by dividing body weight by height squared $\left(\mathrm{kg} / \mathrm{m}^{2}\right)$. The distribution of fat was investigated by measuring the waist circumference at the site of the smallest circumference between the rib cage and the ileac crest, with the subjects in standing position. Hip circumference was measured at the site of the largest circumference between waist and thighs. Body-composition was calculated from body volume with the use of air-displacement plethysmography (BodPod ${ }^{\circledR}$, Life measurement, Concord, CA, USA) (21) and total body water (22) as assessed with the deuterium dilution technique, using Siri's three-compartment model (23). The dilution of the deuterium isotope $\left({ }^{2} \mathrm{H}_{2} \mathrm{O}\right)$ is a measure for total body water. Subjects wore tightly fitting bathing suits and a swim cap during the volume-measurements of the air-displacement plethysmography, and had not engaged in exercise at least 1 hour prior to the test.

\section{Blood parameters}

Fasted blood samples were taken and collected in EDTA containing tubes to prevent clotting. Plasma was obtained by centrifugation and stored at $-80^{\circ} \mathrm{C}$ until further ana- 
lysis. Leptin concentrations were measured with the use of the human RIA kit (Millipore, St Charles, MO, USA).

\section{Questionnaires}

Subject characteristics were assessed at all visits through specific questionnaires. To determine whether attitude toward food intake changed during weight loss and followup, a validated Dutch translation of the three-factor eating questionnaire (TFEQ) was used (24). To determine the physical activity the validated Baecke-questionnaire was used $(24,25)$.

For sleep duration the question was: 'How many hours do you usually sleep per night during week days?' and 'How many hours do you usually sleep per night during weekend days?'. A total weekly sleep score was calculated as ((hours sleep week days $x$ 5) + (hours sleep weekend days x 2)) / 7 (5). Another question concerning sleep quality was: 'How long does it take to fall asleep'. Daytime sleepiness was assessed through the Epworth Sleepiness Scale (ESS). Subjects rated the likelihood of falling asleep in eight specific situations on a 0-3 scale, with 0 meaning no chance at all of falling asleep and 3 meaning a high chance of falling asleep. The total score can range from 0 to 24 , with a score of ten and higher suggesting excessive daytime sleepiness (26).

\section{Statistical analysis}

Data are presented as mean and their standard deviation (SD), unless otherwise indicated. ANOVA repeated measures was carried out to determine possible differences over time. Age and gender were used as covariates in all tests. Since subjects consisted of short sleepers ( $\leq 7$ hours of sleep), average sleepers ( $>7<9$ hours of sleep) and long sleepers ( $\geq 9$ hours of sleep) (3), changes in sleep duration were assessed for short- and average-sleepers separately from changes in long-sleepers. Linear regressions were carried out to determine relationships between dependent and independent variables. Significance was defined as $P<0.05$. All of the statistical analyses were executed with SPSS version 16.0 for Macintosh OS X (SPSS Inc, Chicago, IL).

\section{Results}

98 subjects ( 25 males, 73 females) completed the study, with an average weight loss of $10 \%$ after the VLED and $9 \%$ after 3-month follow-up and $6 \%$ after 10 -month followup compared to baseline. Body weight, BMI, fat mass, and hip circumference were decreased compared to baseline (table 1). Also leptin levels decreased (table 1), with a significant positive correlation between the change in leptin and the change in fat mass after 10-month follow-up $\left(P<0.01, R^{2}=0.32\right)$. Dietary restraint scores increased and disinhibition scores decreased (table 1). The change in dietary restraint scores was negatively correlated with the change in BMI and fat mass after 10-month followup (respectively $P<0.01, R^{2}=0.17$ and $P<0.01, R^{2}=0.15$ ). The change in disinhibition 
Table 1. Subject characteristics over time (mean $\pm S D$ ); at baseline (t0), after very low energy diet (VLED) (t2), after 3-month follow-up (t5) and after 10-month follow-up (t12) (n=98).

\begin{tabular}{llllll}
\hline & $\mathrm{t} 0$ & $\mathrm{t} 2$ & $\mathrm{t} 5$ & $\mathrm{t} 12$ & P-value \\
\cline { 2 - 6 } Body weight $(\mathrm{kg})$ & $92.5 \pm 12.7$ & $83.0 \pm 11.3^{*}$ & $84.4 \pm 12.4^{*}$ & $86.8 \pm 13.2$ & $<0.001$ \\
BMI $\left(\mathrm{kg} / \mathrm{m}^{2}\right)$ & $31.9 \pm 3.2$ & $28.7 \pm 3.1^{*}$ & $29.1 \pm 3.4^{*}$ & $29.9 \pm 3.7$ & $<0.001$ \\
Fat mass $(\mathrm{kg})$ & $38.7 \pm 7.6$ & $31.2 \pm 7.5^{*}$ & $30.9 \pm 8.3$ & $33.6 \pm 8.6$ & 0.021 \\
Percentage fat mass $(\%)$ & $41.8 \pm 6.6$ & $37.5 \pm 7.3$ & $36.5 \pm 7.7$ & $38.5 \pm 6.8$ & 0.196 \\
Waist circumference $(\mathrm{cm})$ & $96.9 \pm 9.6$ & $89.4 \pm 8.7$ & $89.7 \pm 9.3$ & $94.2 \pm 11.3$ & 0.089 \\
Hip circumference $(\mathrm{cm})$ & $112.7 \pm 7.5$ & $106.1 \pm 7.5^{*}$ & $106.3 \pm 7.7$ & $108.6 \pm 9.0$ & 0.010 \\
Leptin concentration $(\mu \mathrm{g} / \mathrm{L})$ & $27.5 \pm 16.0$ & $13.5 \pm 12.2^{*}$ & $21.4 \pm 18.5^{*}$ & $21.0 \pm 16.2$ & 0.004 \\
Dietary restraint & $7.1 \pm 3.7$ & $12.6 \pm 4.3^{*}$ & $12.1 \pm 4.4^{*}$ & $11.4 \pm 4.4^{*}$ & $<0.001$ \\
Disinhibition & $6.4 \pm 2.8$ & $4.9 \pm 2.7^{*}$ & $5.3 \pm 2.9^{*}$ & $5.7 \pm 2.7^{*}$ & 0.010 \\
Hunger & $5.2 \pm 3.0$ & $3.7 \pm 3.0$ & $3.4 \pm 2.9$ & $3.9 \pm 2.9$ & 0.098 \\
Work activity & $2.6 \pm 0.6$ & $2.6 \pm 0.6$ & $2.7 \pm 0.7$ & $2.7 \pm 0.7$ & 0.401 \\
Sport activity & $2.3 \pm 0.7$ & $2.4 \pm 0.6$ & $2.5 \pm 0.7$ & $2.4 \pm 0.7$ & 0.255 \\
Leisure activity & $2.9 \pm 0.6$ & $3.0 \pm 0.6$ & $3.0 \pm 0.6$ & $3.0 \pm 0.6$ & 0.624 \\
Sleep duration (h) & & & & & \\
Short and average sleepers & $7.6 \pm 0.9$ & $8.0 \pm 1.0^{*}$ & $7.8 \pm 1.0$ & $7.8 \pm 0.9$ & 0.005 \\
Long sleepers & $9.6 \pm 0.9$ & $8.9 \pm 1.3$ & $8.8 \pm 1.0$ & $8.7 \pm 1.3$ & 0.375 \\
ESS & $5.5 \pm 3.3$ & $5.2 \pm 3.4$ & $4.8 \pm 3.4$ & $5.0 \pm 3.5^{*}$ & 0.036 \\
Time to fall asleep (min) & $18.8 \pm 17.0$ & $15.5 \pm 14.9$ & $16.6 \pm 15.8$ & $17.1 \pm 16.6^{*}$ & 0.009 \\
\hline P-Value; diferences over time & Win ANOVA & & & &
\end{tabular}

$\mathrm{P}$-value; differences over time with ANOVA repeated measures

Significantly different from baseline $(P<0.05)$

BMI, body mass index

ESS, Epworth Sleepiness Scale

scores was positively correlated with the change in BMI and fat mass after 10-month follow-up (respectively $P<0.05, R^{2}=0.03$ and $P<0.05, R^{2}=0.03$ ). There were no significant differences in percentage fat mass, waist circumference, hunger scores and physical-activity levels over time after correcting for gender and age. ESS was decreased (table 1), indicating a decrease in daytime sleepiness. Furthermore, the time to fall asleep slightly but significantly decreased (table 1 ).

In short and average sleepers sleep duration increased during weight loss $(0.4 \pm$ $0.7 \mathrm{~h}, \mathrm{P}<0.01)$. To assess whether this change in sleep duration was associated with changes in body-weight and body-composition, linear regression analyses were performed. The change in sleep duration was negatively correlated with the change in BMI after weight loss and after 3-month follow-up (figure 2). After 10-month follow-up there was no significant correlation between the change in sleep duration and BMI. To assess the temporal sequence, a linear regression analysis was performed between the change in sleep duration during weight loss and the change in BMI after follow-up. These correlations were neither significant after 3, nor after 10-month follow-up. Also vice versa, the change in BMI during weight loss was not correlated with the change in sleep duration after follow-up, indicating that the changes in BMI and in sleep duration only occurred in parallel during weight loss.

To assess whether the change in sleep duration in short and average sleepers is associated with the change in fat mass, linear regression analyses were also performed with the change in fat mass. During weight loss this correlation was not significant. At 3-month follow-up the change in sleep duration was negatively correlated with the change in fat mass (figure 3). After 10-month follow-up there was no significant 


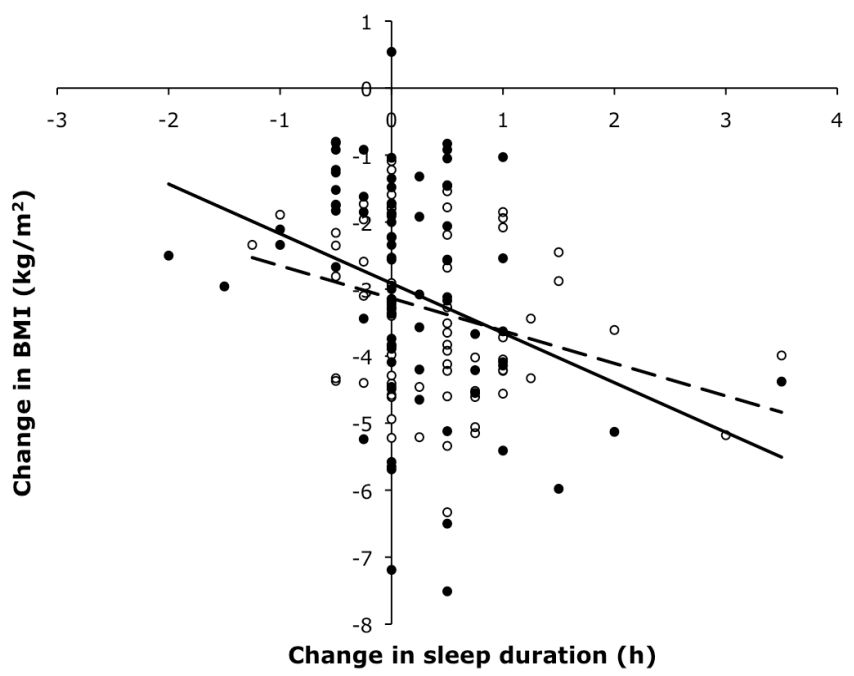

Figure 1. Change in body mass index $(\mathrm{BMI})\left(\mathrm{kg} / \mathrm{m}^{2}\right)$ as a function of the change in sleep duration (hours) during weight loss (changes over t2-0; white circles and dotted trend line) and after 3-month follow-up (changes over t5-0; black circles and black trend line) in short and average sleepers $(n=78)$. Linear regression $B_{12-0}$ vs sleep duration ${ }_{t 2-0} ; P<0.05, R^{2}=0.09(y=-$ $0.4857 x-3.137)$ and $B I_{t 5-0}$ vs sleep duration ${ }_{t 5-0} ; P<0.01, R^{2}=0.10(y=-0.7411 x-2.9135)$. Changes over t12-0 were not significantly correlated and therefore not depicted.

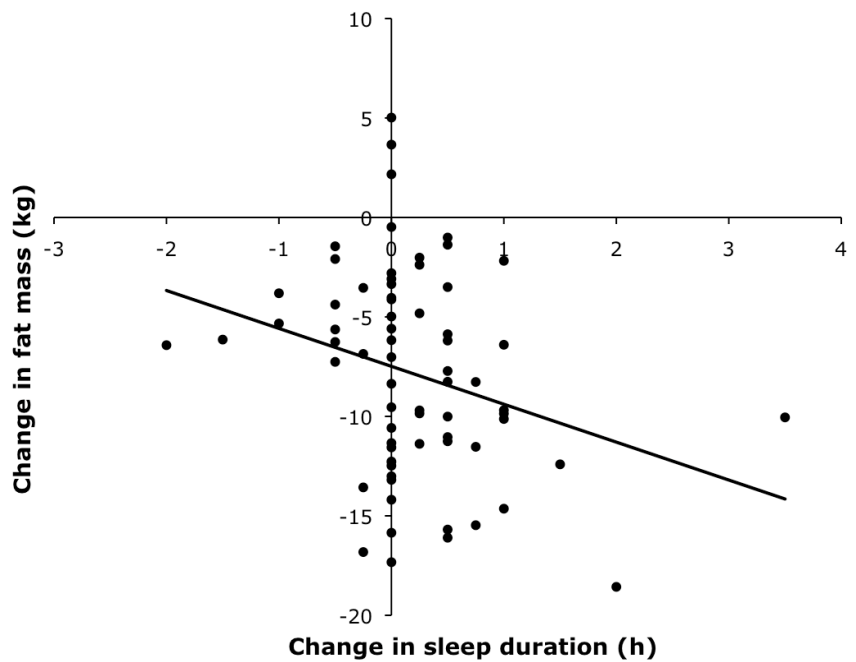

Figure 2. Change in fat mass $(\mathrm{kg})$ as a function of the change in sleep duration (hours) after 3month follow-up (changes over t5-0; black circles and black trend line) in short and average sleepers $(n=78)$. Linear regression Fat mass $_{t 5-0}$ vs sleep duration ${ }_{55-0} ; P<0.05, R^{2}=0.07(y=-$ $1.906 \mathrm{x}-7.4817)$. Changes over $\mathrm{t} 2-0$ and $\mathrm{t} 12-0$ were not significantly correlated and therefore not depicted. 
correlation between the change in sleep duration and the change in fat mass. As for $\mathrm{BMI}$, also for fat mass there was no significant correlation between the change in sleep duration during weight loss and the change in fat mass after follow-up or vice versa. This again indicates that the changes in fat mass and sleep duration occurred in parallel until 3-month after weight loss. A multiple regression analysis of changes in sleep duration and changes in BMI, respectively fat mass did not increase the explained variation of changes in BMI alone. Changes in body weight and fat mass both after weight loss and after 10-month follow-up were however not significantly different between groups.

Change in sleep duration was inversely correlated with sleep duration at baseline in the entire group (figure 4). At closer inspection of the data, it appeared that the variance in sleep duration had decreased remarkably after weight loss. Short and average sleepers increased their sleep duration during weight loss (respectively, $n=21$ $0.7 \pm 1.1 \mathrm{~h}, \mathrm{P}<0.01$ and $\mathrm{n}=570.2 \pm 0.5 \mathrm{~h}, \mathrm{P}<0.01$ ). Sleep duration in long sleepers did not significantly change during weight loss after including age and gender as covariates $(\mathrm{n}=20-0.7 \pm 1.0 \mathrm{~h}, \mathrm{P}=0.37)$.

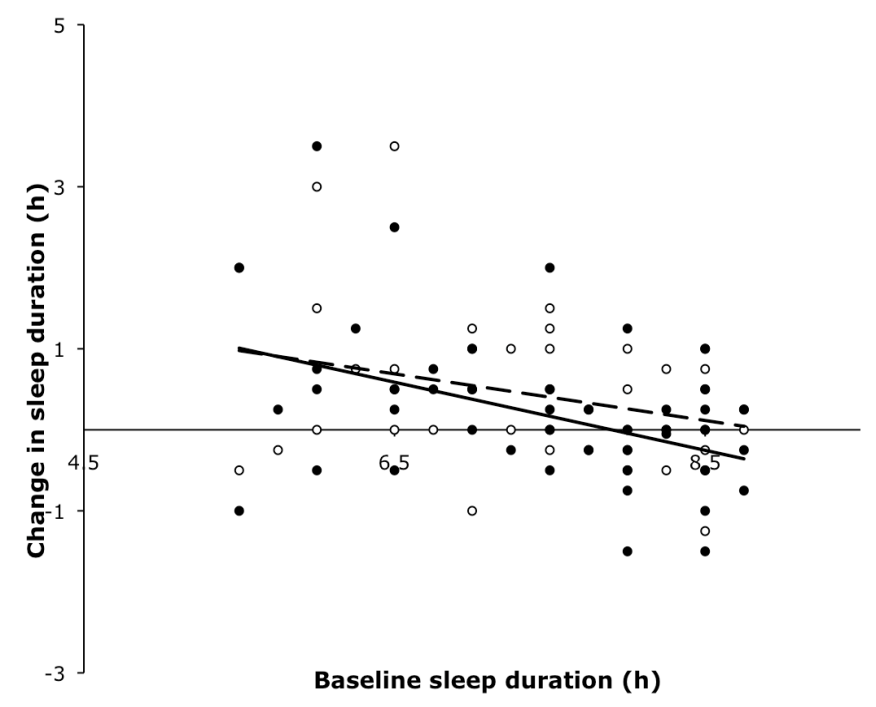

Figure 3. Change in sleep duration (hours) as a function of baseline sleep duration (hours) in short and average sleepers $(n=78)$ (changes over t2-0; white circles and dotted trend line, changes over t12-0; black circles and black trend line). Linear regression sleep duration $\mathrm{t}_{\mathrm{t} 2 \mathrm{o}} \mathrm{v}$ v sleep duration $_{\text {to }} P<0.01, R^{2}=0.11(y=-0.2876 x+2.5597)$ and sleep duration ${ }_{t 12-0}$ vs sleep duration ${ }_{t 0}$ $P<0.001, R^{2}=0.21(y=-0.4204 x+3.3209)$. Changes over t5-0 were not significantly correlated and therefore not depicted. 


\section{Discussion}

Average weight loss was $10 \%$ after 2 -month dieting $(\mathrm{P}<0.01)$, $9 \%$ after 3 -month follow-up $(\mathrm{P}<0.01)$ and a non-significant $6 \%$ after 10 -month follow-up $(\mathrm{P}=0.05)$. Sleep duration increased in short- and average-sleepers during weight loss. This change in sleep duration was concomitantly negatively correlated with the change in body weight during weight loss and after 3-month follow-up, and with the change in fat mass after 3-month follow-up. Short $(\leq 7 \mathrm{~h})$ and average $(>7<9 \mathrm{~h})$ sleepers increased their sleep duration during weight loss, while sleep duration in long sleepers $(\geq 9 \mathrm{~h})$ did not change significantly. This suggests that sleep duration in short and average sleepers benefits from weight loss, and vice versa.

The inverse correlations between changes in sleep duration and changes in BMI indicate that successful weight loss and maintenance occurs concomitantly with an increase in sleep duration. The slope coefficient of the correlation between the changes after 3-month follow-up was higher compared to the slope coefficient of the correlation between the changes after weight loss $\left(\right.$ beta $_{2-0}=-0.5$ and beta b- $\left._{0}=-0.7\right)$. The changes in BMI and in sleep duration appear to be the largest during weight loss, and they stabilize during the 3-month follow-up. However, after 10-month follow-up there was no significant correlation between the increase in sleep duration and decrease in $\mathrm{BMI}$ anymore. This might be due to the larger variation in weight maintenance, with some subjects regaining their lost weight, while some lost even more weight, while the newly achieved sleep duration was maintained overall. To assess whether an increase in sleep duration would precede a decrease in BMI or vice versa, the possible relationship between the change in sleep duration during weight loss and the change in BMI during follow-up was tested in a linear regression and vice versa. No significant correlations were found and therefore no conclusion can be drawn on the temporal sequence. Longitudinal cohort studies suggested that short sleep duration is associated with future weight gain $(27,28)$. However, the first study cannot be generalized since they included persons with a high risk for psychiatric disorders (27), while the other study cannot exclude the possibility of reverse causation since only sleep duration was assessed at one time point (28).

Moreover, it is impossible to disentangle cause and effect due to different study designs $(29,30)$. So far, only effects of sleep restriction have been investigated, because until now it is not known how to intervene using sleep improvement, while changes in body-weight mainly have been shown using diet-induced weight-loss. To our knowledge, so far no studies have shown spontaneous changes in body-weight and in sleep duration at the same time. From the presently available studies it seems that the parallel changes in sleep duration and BMI may have a common underlying cause, which can exert its effect in a parallel manner. For example, stress might act on sleep duration and on body-weight independently, possibly exerting a synergistic effect.

The second objective of this study was to assess whether an increase in sleep duration from short to normal sleep duration would be associated with a larger decrease in fat mass. Nedeltcheva et al. showed that a combined energy and sleep restriction in humans resulted in an increased loss of fat free mass (14). This suggests that sleep plays a role in the preservation of human fat-free mass during periods of energy 
restriction. However, no constructive conclusion can be drawn from studies restricting both energy intake and sleep duration as in the study of Nedeltcheva. Therefore, we assessed spontaneous changes in sleep duration during both energy restriction as well as a weight maintenance period. The inverse correlation between the change in sleep duration and the change in fat mass after 3-month follow-up suggests that in addition to a concomitant correlation between a change in sleep duration and weight loss and weight maintenance, also body-fat loss is concomitantly associated with a change in sleep duration or vice versa. However, adding the change in fat mass in a multiple regression does not strengthen the association between the change in BMI and the change in sleep duration. So, the association of the change in sleep duration with the change in fat mass might be included in the association with the change in BMI. Changes in body weight and fat mass during follow-up were not significantly different between groups, indicating that sleep duration habits did not influence body weight stability in the reduced obese state.

During weight loss, sleep quality was improved with a decrease in daytime sleepiness and a decrease in time to fall asleep. Previous studies have shown that there is an interaction between sleep quality and the lipid/protein synthesis and degradation (17). Minet-Ringuet et al. showed that sleep quality improved by re-feeding rats with alpha-lactalbumin (18). Such studies suggest that adjustments in the diet could be used to improve sleep in adults, while they also may improve body-weight regulation (31).

Sleep duration increased in short and average sleepers during weight loss, while sleep duration in long sleepers did not change significantly. This suggests that sleep duration in short and average sleepers benefits from weight loss, and vice versa. Chaput et al. concluded that shifting sleep duration from a short to a healthier length is associated with lower adiposity gain (19). However, it is still unclear what this healthier sleep duration would be. For clinical implications it is important to find the optimum sleep duration, and by which factors it is determined, to be able to use this in combination with changes in diet and exercise, to optimize weight loss.

A limitation of this study is the use of self-reported sleep durations, though previous studies showed good agreement between self-reported and measured sleep durations $(32,33)$. The time to fall asleep significantly decreased, however a decrease of only 1-2 min might not be clinically relevant. After 10 months follow up many anthropometric parameters, namely body weight, BMI, fat mass, waist and hip circumference had returned to baseline values in part of the subjects, so these parameters lost their statistical significance with respect to the difference shown at 3 months follow up. This is probably due to a large variation in body-weight regain of the subjects. This may indicate a transient effect of the negative energy balance during the VLED, in part of the subjects. During weight loss subjects were allowed to eat vegetables in addition to the diet and results indicated that subjects during weight loss consumed a total of $5.2 \mathrm{MJ} /$ day, including the diet. In addition, effects of potential behavioural and metabolical changes induced by the VLED of only $5.2 \mathrm{MJ} /$ day itself cannot be excluded.

This study differentiates from previous studies by its longitudinal design to investigate the relationship between spontaneous changes in sleep duration and changes in body-weight and body-composition due to energy restriction. In conclusion, sleep 
duration benefits from weight loss, or vice versa. Successful weight loss, loss of bodyfat and 3-month weight maintenance in short and average sleepers are underscored by an increase in sleep duration, or vice versa.

\section{Acknowledgements}

K.R. Westerterp and S.P.M. Verhoef designed the study. S.P.M. Verhoef and S.G.J.A. Camps collected the data. S.P.M. Verhoef analyzed the data and wrote the manuscript. M.S. Westerterp-Plantenga and H.K.J. Gonnissen contributed to the interpretation of the data and reviewed the manuscript. The study was executed under supervision of K.R. Westerterp. Thanks to Loek Wouters and Jos Stegen for their assistance. All authors read and approved the final manuscript. None of the authors had any conflict of interest.

\section{References}

1. Marshall NS, Glozier N, Grunstein RR. Is sleep duration related to obesity? A critical review of the epidemiological evidence. Sleep Med Rev 2008;12:289-98.

2. Patel SR, Hu FB. Short sleep duration and weight gain: a systematic review. Obesity (Silver Spring) 2008;16:643-53.

3. Chaput JP, Despres JP, Bouchard C, Tremblay A. The association between sleep duration and weight gain in adults: a 6-year prospective study from the Quebec Family Study. Sleep 2008;31:517-23.

4. Patel SR. Reduced sleep as an obesity risk factor. Obes Rev 2009;10 Suppl 2:61-8.

5. Garaulet M, Ortega FB, Ruiz JR, Rey-Lopez JP, Beghin L, Manios Y, Cuenca-Garcia M, Plada M, Diethelm K, Kafatos A, Molnar D, Al-Tahan J, Moreno LA. Short sleep duration is associated with increased obesity markers in European adolescents: effect of physical activity and dietary habits. The HELENA study. Int J Obes (Lond) 2011;35:1308-17.

6. Gonnissen HK, Rutters F, Mazuy C, Martens EA, Adam TC, Westerterp-Plantenga MS. Effect of a phase advance and phase delay of the 24-h cycle on energy metabolism, appetite, and related hormones. Am J Clin Nutr 2012;96:689-97.

7. Hursel R, Rutters F, Gonnissen HK, Martens EA, Westerterp-Plantenga MS. Effects of sleep fragmentation in healthy men on energy expenditure, substrate oxidation, physical activity, and exhaustion measured over $48 \mathrm{~h}$ in a respiratory chamber. Am J Clin Nutr 2011;94:804-8.

8. Penev PD. Sleep deprivation and energy metabolism: to sleep, perchance to eat? Curr Opin Endocrinol Diabetes Obes 2007;14:374-81.

9. Rutters F, Gonnissen HK, Hursel R, Lemmens SG, Martens EA, Westerterp-Plantenga MS Distinct associations between energy balance and the sleep characteristics slow wave sleep and rapid eye movement sleep. Int J Obes (Lond) 2012.

10. Gonnissen HK, Hursel R, Rutters F, Martens EA, Westerterp-Plantenga MS. Effects of sleep fragmentation on appetite and related hormone concentrations over $24 \mathrm{~h}$ in healthy men. $\mathrm{Br}$ J Nutr 2012:1-9.

11. Leproult R, Van Cauter E. Role of sleep and sleep loss in hormonal release and metabolism. Endocr Dev 2010;17:11-21.

12. Spiegel K, Tasali E, Penev P, Van Cauter E. Brief communication: Sleep curtailment in healthy young men is associated with decreased leptin levels, elevated ghrelin levels, and increased hunger and appetite. Ann Intern Med 2004;141:846-50. 
13. St-Onge MP, Roberts AL, Chen J, Kelleman M, O'Keeffe M, RoyChoudhury A, Jones PJ. Short sleep duration increases energy intakes but does not change energy expenditure in normal-weight individuals. Am J Clin Nutr 2011;94:410-6.

14. Nedeltcheva AV, Kilkus JM, Imperial J, Schoeller DA, Penev PD. Insufficient sleep undermines dietary efforts to reduce adiposity. Ann Intern Med 2010;153:435-41.

15. Klingenberg L, Sjodin A, Holmback U, Astrup A, Chaput JP. Short sleep duration and its association with energy metabolism. Obes Rev 2012;13:565-77.

16. Elder CR, Gullion CM, Funk KL, Debar LL, Lindberg NM, Stevens VJ. Impact of sleep, screen time, depression and stress on weight change in the intensive weight loss phase of the LIFE study. Int J Obes (Lond) 2012;36:86-92.

17. Guesdon B, Minet-Ringet J, Tome DG, Even PC. Restriction-refeeding of calories and protein induces changes to slow wave and paradoxical sleep that parallel changes in body lipid and protein levels in rats. Behav Brain Res 2005;164:156-64.

18. Minet-Ringuet J, Le Ruyet PM, Tome D, Even PC. A tryptophan-rich protein diet efficiently restores sleep after food deprivation in the rat. Behav Brain Res 2004;152:335-40.

19. Chaput JP, Despres JP, Bouchard C, Tremblay A. Longer sleep duration associates with lower adiposity gain in adult short sleepers. Int J Obes (Lond) 2012.

20. Chaput JP, Tremblay A. Sleeping habits predict the magnitude of fat loss in adults exposed to moderate caloric restriction. Obes Facts 2012;5:561-6.

21. Dempster P, Aitkens $S$. A new air displacement method for the determination of human body composition. Med Sci Sports Exerc 1995;27:1692-7.

22. Westerterp KR, Wouters L, van Marken Lichtenbelt WD. The Maastricht protocol for the measurement of body composition and energy expenditure with labeled water. Obes Res 1995;3 Suppl 1:49-57.

23. Siri W. Body composition from fluid spaces and density: analysis of methods. In: Brozek J, Henschel A (eds). Techniques for measuring body composition. National Academy of Science: Washington DC. 1961:223-244.

24. Stunkard A, Messick S. The three-factor eating questionnaire to measure dietary restraint, disinhibition and hunger. J Psychosom Res 1985;29:71-83.

25. Philippaerts RM, Westerterp KR, Lefevre J. Doubly labelled water validation of three physical activity questionnaires. Int J Sports Med 1999;20:284-9.

26. Johns MW. A new method for measuring daytime sleepiness: the Epworth sleepiness scale. Sleep 1991;14:540-5.

27. Hasler G, Buysse DJ, Klaghofer R, Gamma A, Ajdacic V, Eich D, Rossler W, Angst J. The association between short sleep duration and obesity in young adults: a 13-year prospective study. Sleep 2004;27:661-6.

28. Patel SR, Malhotra A, White DP, Gottlieb DJ, Hu FB. Association between reduced sleep and weight gain in women. Am J Epidemiol 2006;164:947-54.

29. Cappuccio FP, Taggart FM, Kandala NB, Currie A, Peile E, Stranges S, Miller MA. Metaanalysis of short sleep duration and obesity in children and adults. Sleep 2008;31:619-26.

30. Nielsen LS, Danielsen KV, Sorensen TI. Short sleep duration as a possible cause of obesity: critical analysis of the epidemiological evidence. Obes Rev 2011;12:78-92.

31. Soenen S, Hochstenbach-Waelen A, Westerterp-Plantenga MS. Efficacy of alphalactalbumin and milk protein on weight loss and body composition during energy restriction. Obesity (Silver Spring) 2011;19:370-9.

32. Hauri PJ, Wisbey J. Wrist actigraphy in insomnia. Sleep 1992;15:293-301.

33. Lockley SW, Skene DJ, Arendt J. Comparison between subjective and actigraphic measurement of sleep and sleep rhythms. J Sleep Res 1999;8:175-83. 


\section{CHAPTER 8 \\ General Discussion}


The subject of the thesis is body weight loss and weight maintenance as affected by environment and genetic predisposition. The first two studies focussed on food components, oligofructose and Korean pine nut oil, with the potential to prevent weight gain by decreasing the risk of overeating through suppression of appetite. It was shown that $16 \mathrm{~g} / \mathrm{d}$ oligofructose over 13 days can be effective to reduce energy intake in normal-weight and overweight men and women, probably by increasing satiety peptides. No evidence was found for appetite suppressing effects of Korean pine nut oil in human subjects in the dosages tested. The next study focussed on genetic, physiological and behavioural factors affecting body weight, weight loss and weight maintenance thereafter. A high genetic predisposition score was associated with a high body weight and more weight loss during an 8-week energy restricted diet. During subsequent weight maintenance, genetic effects were dominated by changes in eating behaviour. Adipocyte glucose and fatty acid metabolism changes in response to weight loss were in line with normalization from a dysregulated obese status to an improved metabolic status, and linked to changes in adipocyte size. Weight-loss induced increases in sleep duration underscored successful weight loss, weight maintenance and body-fat loss and vice versa.

\section{Decreasing the risk of overeating}

Oligofructose is an inulin-type fructan thought to suppress appetite through effects on satiety peptides, mediated by short chain fatty acids (SCFAs) generated during colonic fermentation (1). Human studies on inulin-type fructans have demonstrated acute effects on appetite ratings (2) and energy intake (2, 3), as well as long-term effects on appetite ratings (4-6), satiety peptides (7-9), energy intake $(5,8)$ and even body weight $(4,8)$. In contrast, some studies did not find an effect on appetite ratings $(3,7$, $8,10)$ or energy intake $(7,10,11)$. Assessing long-term effects of two dosages of oligofructose on appetite profile, satiety peptides and energy intake in normal-weight and overweight men and women indicated that the highest dosage oligofructose $(16 \mathrm{~g} / \mathrm{d})$ can be effective to reduce energy intake, probably by increasing the satiety peptides.

Korean pine nut oil is another potential appetite suppressing food component, although results from previous studies were contradictive. Human studies demonstrated acute effects on satiety peptides (12), while no effects on appetite ratings (12) or energy intake were found (13). Assessing acute effects of two dosages of Korean pine nut oil triacylglycerol (TAG) on appetite ratings and energy intake in normal to overweight women indicated that $6 \mathrm{~g}$ of Korean pine nut oil TAG is not sufficient to suppress appetite and energy intake.

The inconsistent results in the literature for both oligofructose and Korean pine nut oil studies are probably caused by differences in study designs. Dosage, timing of dosing regime, methods and study population influence results and need to be taken into account in designing a study. Type and texture determine the mechanism of action of the food component and thus timing of the dosing regime. Piloting can help ascertain the sensitive moment in time and is essential for optimizing timings within a study design. 
Although evidence for an effect of oligofructose on energy intake in a sufficiently powered and well-designed study is provided, this does not necessarily imply a decreased risk of overeating in real-world food environments. In addition to the physiological factors discussed above, also psychological and social factors are involved in meal termination and initiation. There is a large inter-individual variation in the risk of overeating due to the variability in the sensitivity to gut-peptide signals $(14,15)$, to modulators as circadian rhythm and sleep $(16,17)$ and feelings of appetite and dietary restraint $(18,19)$. Previous studies suggest that reward deficiency can lead to overconsumption $(20,21)$. Hence, the palatability of the food component and its control within a study should be equal. It is hypothesized that eating whatever an individual likes in the presence of hunger, prevents reward deficiency in the absence of hunger thereafter $(22,23)$. Since the palatability of most energy-controlled diets, like highprotein diets, is not high, a food component influencing energy intake and possibly body weight should additionally be as highly rewarding as possible. Other factors involved in food intake regulation can influence the effect of an appetite suppressing food component in a real-world environment.

A food component proven to have an effect on appetite and energy intake, does not necessarily affect body weight. It is questionable whether an appetite suppressing food component can affect body weight in the absence of energy restriction. There is a need to carefully draw conclusions about effectiveness from these studies and translate this to health claims. Most importantly, appetite suppressing food components might help consumers stick to a diet, especially in periods of weight maintenance after weight loss, when suppressing appetite may help overcome the weight-loss induced elevated appetite. Concerning the food components tested in this thesis, oligofructose can be effective as an appetite suppressing food component decreasing the risk of overeating, although effectiveness in real-world environments and an independent effect on body weight regulation remains questionable.

\section{Genetic predisposition}

A high genetic predisposition score (GPS) from six single nucleotide polymorphisms (SNPs), already associated with obesity-related traits, was associated with a high body weight. Focusing on weight loss, twin studies have demonstrated a larger variability between pairs than within pairs on the response to long-term negative energy balance $(24,25)$. Short-term weight loss success was associated with a high GPS from the six SNPs studied. It is thought that genes associated with obesity-related traits must have an effect on either energy intake or energy expenditure. However, genetic factors might influence body weight regulation indirectly as proposed in the dual intervention point model (26-28). Genetically determined upper and lower boundaries define the points at which active physiological regulation becomes dominant, and between which mainly behavioural factors determine body weight regulation. $A$ high GPS would result in individuals becoming heavier due to the wider boundaries and thus less strict body weight regulation. In addition, a high GPS would result in individuals losing more weight irrespective of baseline body weight, since more weight 
can be lost before boundaries are reached and physiology takes over. SNPs associated with body weight can also have an effect on weight loss success.

Genetic differences can explain $40-70 \%$ of the inter-individual variation in obesity susceptibility (29), although only a small fraction is explained by the obesityassociated loci identified so far (30-32). The indirect influence of genetic factors as suggested in the dual intervention point model might explain why only a small fraction of the variation can be explained by the loci found so far. Elucidating genetic variants is further complicated by gene-gene and gene-environment interactions that can mask the effect of a genetic variant (33). Thus, it is important to study identified loci in longitudinal studies, to elucidate the pathways underlying the association between genetic factors and body weight and weight loss, in order to understand the genetic contribution.

Effects of both six SNPs as well as changes in eating behaviour on long-term weight loss maintenance were assessed in the long-term weight loss study. Previous studies have shown that an increased dietary restraint is associated with success in weight maintenance (34-36). Results from the weight loss study showed that longterm weight loss maintenance is associated with a large increase in dietary restraint and a large decrease in disinhibition. These changes in eating behaviour were independent of and dominated genetic effects during long-term weight loss maintenance.

To conclude, during a negative energy balance weight loss success is determined by genetic factors that are also associated with body weight. However, during weight maintenance thereafter success is mainly determined by changes in eating behaviour.

\section{Adipose tissue metabolism}

Weight loss results in nutrient deprivation at which adipocytes need to respond rapidly, and has indeed shown to result in changes in metabolic processes within adipocytes (37-40). The results from the weight loss study showed that changes in adipocyte size and glucose and fatty acid metabolism in response to weight loss are in line with normalization from a dysregulated obese status to an improved metabolic status. In contrast, other studies found preferential trafficking of dietary fat to adipose tissue at whole-body level in a weight-reduced state $(41,42)$, supported by the formation of new adipocytes (41), thereby favoring weight regain. Changes in adipocyte lipolysis and fatty acid trafficking in response to weight loss were associated with weight loss maintenance. Changes in adipocyte size as well as metabolism were sustained during weight maintenance until weight was regained, as previous literature suggested (43). The cellular stress model suggests that weight-loss induced adipocyte shrinking results in cellular stress that activates processes to increase adipocyte volume back to original levels, thereby resulting in weight regain. This suggests that a less intensive energy restriction might be more effective in the long-term, since it induces less cell shrinking, therefore less cellular stress, thus less weight regain.

Glycolysis was shown to be the major denominator of adipocyte size, and changes in adipocyte metabolism were correlated with changes in adipocyte size as previously proposed in the cellular stress model (44-46). This link between adipocyte size and metabolism highlights the importance of measuring adipocytes size in addition to 
adipocyte metabolism. Results show that shrinkage due to the type of embedding of the adipose tissue can be ignored when comparing before and after weight loss. Furthermore, plastic embedding of adipose tissue provides more accurate and sensitive results.

\section{Sleep}

Literature has shown inverse associations between sleep duration and body weight in adults $(47,48)$. During puberty changes in body weight were associated with changes in sleep duration (49). Focusing on weight loss, it has been shown that sleep duration influences success of an energy-restricted weight loss intervention $(50,51)$. Spontaneous changes in sleep duration throughout the weight loss study indicated that sleep duration normalizes during energy-restricted induced weight loss. Shifting sleep duration from a short to a healthier length is associated with lower adiposity gain during a long-term follow-up (52). However, it is still unclear what this healthier sleep duration would be and how to improve sleep duration and quality other than by weight loss. Animal studies have shown an interaction between sleep quality and diet $(53,54)$, suggesting that adjustments in the diet could be used to improve sleep in adults (55).

Successful weight loss, weight maintenance and body-fat loss was underscored by an increase in sleep duration and vice versa, in line with previous studies $(50,51)$. Longitudinal cohort studies suggest that short sleep duration is associated with future weight gain $(56,57)$. Sleep duration was assessed throughout the study, but no significant results revealing a temporal sequence were found. Interpretation of results should be done carefully, since cause and effect cannot be disentangled $(58,59)$. Sleep duration might have an indirect effect on body weight, or the parallel changes observed have a common underlying cause.

\section{Conclusions}

- $\quad$ Consumption of $16 \mathrm{~g} / \mathrm{d}$ oligofructose over 13 days reduces energy intake in normal-weight and overweight men and women, probably by increasing the satiety peptides.

- $\quad$ Addition of $6 \mathrm{~g}$ Korean pine nut oil to a meal is not sufficient to suppress appetite and energy intake.

- Weight-loss success is determined by genetic factors that are also associated with body weight.

- $\quad$ Changes in eating behaviour dominate genetic effects during long-term weight loss.

- Embedding related shrinkage of adipose tissue can be ignored when comparing adipocytes before and after weight loss.

- $\quad$ Plastic embedding of adipose tissue provides more accurate and sensitive results for fat cell size.

- $\quad$ Glycolysis is associated with adipocyte size and body weight.

- $\quad$ Changes in adipocyte lipolysis during weight loss are associated with changes in body weight during follow-up. 
- Changes in adipocyte glucose and fatty acid metabolism in response to weight loss are in line with normalization from a dysregulated obese status to an improved metabolic status.

- $\quad$ Sleep duration normalizes during weight loss.

- Weight-loss induced increases in sleep duration underscore successful weight loss, weight maintenance and body-fat loss and vice versa.

\section{Future perspectives}

Appetite suppressing food components might help consumers adhere to changes in eating behaviour necessary for successful weight loss maintenance. There are several points that need to be addressed when designing a study investigating potential appetite suppressing food components. The type, form and dosage of the food component can be tested in a pilot study to determine the proper timing of dosing regime and methods used. Furthermore, factors influencing the inter-individual variability in risk of overeating might be taken into account when defining the study population. Future research could focus on understanding the supposed mechanism of the food component, as well as the influence of other processes involved in food intake regulation.

There is a need to control statements and health claims concerning the effects of food components investigated in studies. Consumers should be made aware of the broader context of weight control, instead of a too simplistic promise that an appetite suppressing food component can improve their weight control. Food components shown to suppress appetite and reduce energy intake in the short-term can be further investigated on the long-term and for effects on body weight regulation. The European Food Safety Authority (EFSA) suggests that effects on appetite should be accompanied by corresponding reductions in energy intake. The effects should be sustainable, proving the absence of compensation and be continuous during repeated dosing over a minimum of 28 days (60). For claims regarding weight loss, significant changes in body weight need to be of appropriate duration, a minimum 3 months, and under specified conditions (60). These specific conditions are important to differentiate whether a product helps sustaining a diet, rather than having a positive effect in a diet, contributing to a proper definition of a claim. Studies taking into account EFSA criteria will result in scientifically based food claims and more transparency in research as well as industries and governments, thereby improving awareness of consumers.

Concerning the understanding of the genetic contribution to body weight as well as weight loss and maintenance, it is important to investigate gene-gene and geneenvironment interactions. Loci already associated with obesity by genome-wide association studies $(31,32)$, should be investigated in longitudinal cohort studies to elucidate the pathways that underlie the obesity-susceptibility.

With regard to adipocyte metabolism, future research should further investigate cellular stress involved in the response of adipocytes to weight loss (61). Whether a less intensive energy restriction is more effective with regard to weight loss success, possibly via lowering cellular stress, could be important for clinical implication. The link found between cell size and functioning emphasizes the need to include adipocyte size measurements in studies investigating adipocyte metabolism. Techniques used 
to measure cell size, need to be carefully selected taken into account the possibilities as well as sensitivity and accuracy. Cell size distribution and turnover are already part of the literature $(62,63)$, but deserve further investigations.

Research concerning sleep might focus on understanding the mechanisms correlating sleep and body weight. Investigating ways to improve sleep other than weight loss is important as well as to disentangle cause and effect, whether such an improvement of sleep also induces spontaneous body-weight loss and successive weight maintenance. Furthermore, finding the optimum sleep duration, if existing, could be of particular importance for clinical implications.

To put the current knowledge in a broader context of clinical implications for obesity treatments, successfulness of weight loss achieved by dieting and weight maintenance thereafter depends on both quantitative as well as qualitative changes in energy intake. Qualitative changes might be reached by the addition of appetite suppressing food components as discussed above, but also changes in macronutrient composition. High protein diets have shown to contribute to successfulness of weight loss and maintenance thereafter by increasing satiety as well as by a fat-free mass sparing effect, stimulating a sustained basal energy expenditure (64). In addition, psychological guidance and behavioural therapy might improve weight loss maintenance, although it has a risk of being time-consuming and costly. Optimizing factors as discussed in this thesis might contribute to success. Beside energy restriction, there are also other strategies to lose weight with each different success rates. So far no drug has been found that produces significant and sustained weight loss without side effects. Bariatric surgery is often more effective, but very radical. Another strategy is increasing levels of exercise, but the level of activity required to be effective is beyond the ability of most individuals to sustain. Next to optimizing weight-loss success rates, it is essential to put more focus on prevention of obesity.

\section{References}

1. Darzi J, Frost GS, Robertson MD. Do SCFA have a role in appetite regulation? Proc Nutr Soc. 2011;70:119-28.

2. Perrigue MM, Monsivais $P$, Drewnowski $A$. Added soluble fiber enhances the satiating power of low-energy-density liquid yogurts. J Am Diet Assoc. 2009;109:1862-8.

3. Archer BJ, Johnson SK, Devereux HM, Baxter AL. Effect of fat replacement by inulin or lupin-kernel fibre on sausage patty acceptability, post-meal perceptions of satiety and food intake in men. Br J Nutr. 2004;91:591-9.

4. Antal M, Regoly-Merei A, Biro L, Arato G, Schmidt J, Nagy K, et al. Effects of oligofructose containing diet in obese persons. Orv Hetil. 2008;149:1989-95.

5. Cani PD, Joly E, Horsmans Y, Delzenne NM. Oligofructose promotes satiety in healthy human: a pilot study. Eur J Clin Nutr. 2006;60:567-72.

6. Whelan K, Efthymiou L, Judd PA, Preedy VR, Taylor MA. Appetite during consumption of enteral formula as a sole source of nutrition: the effect of supplementing pea-fibre and fructooligosaccharides. Br J Nutr. 2006;96:350-6.

7. Cani PD, Lecourt E, Dewulf EM, Sohet FM, Pachikian BD, Naslain D, et al. Gut microbiota fermentation of prebiotics increases satietogenic and incretin gut peptide production with consequences for appetite sensation and glucose response after a meal. Am J Clin Nutr. 2009;90:1236-1243. 
8. Parnell JA, Reimer RA. Weight loss during oligofructose supplementation is associated with decreased ghrelin and increased peptide YY in overweight and obese adults. Am J Clin Nutr. 2009;89:1751-9.

9. Piche T, des Varannes SB, Sacher-Huvelin S, Holst JJ, Cuber JC, Galmiche JP. Colonic fermentation influences lower esophageal sphincter function in gastroesophageal reflux disease. Gastroenterology. 2003;124:894-902.

10. Peters HP, Boers HM, Haddeman E, Melnikov SM, Qvyjt F. No effect of added beta-glucan or of fructooligosaccharide on appetite or energy intake. Am J Clin Nutr. 2009;89:58-63.

11. Karalus M, Clark M, Greaves KA, Thomas W, Vickers Z, Kuyama M, et al. Fermentable fibers do not affect satiety or food intake by women who do not practice restrained eating. $J$ Acad Nutr Diet. 2012;112:1356-62.

12. Pasman W, Heimerikx J, Rubingh C, van den Berg R, O'Shea M, Gambelli L, et al. The effect of Korean pine nut oil on in vitro CCK release, on appetite sensations and on gut hormones in post-menopausal overweight women. Lipids in Health and Disease. 2008;7:10.

13. Hughes G, Boyland E, Williams N, Mennen L, Scott C, Kirkham T, et al. The effect of Korean pine nut oil (PinnoThinTM) on food intake, feeding behaviour and appetite: A double-blind placebo-controlled trial. Lipids in Health and Disease. 2008;7:6.

14. Adam TC, Jocken J, Westerterp-Plantenga MS. Decreased glucagon-like peptide 1 release after weight loss in overweight/obese subjects. Obes Res. 2005;13:710-6.

15. Adam TC, Westerterp-Plantenga MS. Glucagon-like peptide-1 release and satiety after a nutrient challenge in normal-weight and obese subjects. Br J Nutr. 2005;93:845-51.

16. Hursel R, Rutters F, Gonnissen HK, Martens EA, Westerterp-Plantenga MS. Effects of sleep fragmentation in healthy men on energy expenditure, substrate oxidation, physical activity, and exhaustion measured over $48 \mathrm{~h}$ in a respiratory chamber. Am J Clin Nutr. 2011;94:8048.

17. Rutters F, Gonnissen HK, Hursel R, Lemmens SG, Martens EA, Westerterp-Plantenga MS. Distinct associations between energy balance and the sleep characteristics slow wave sleep and rapid eye movement sleep. Int J Obes (Lond). 2012;

18. den Hoed M, Smeets AJPG, Veldhorst MAB, Mariman ECM, Westerterp-Plantenga MS, Westerterp KR. SNP analyses of postprandial responses in (an)orexigenic hormones and feelings of hunger reveal long-term physiological adaptations to facilitate homeostasis. Appetite. 2008;51:362-362.

19. den Hoed M, Westerterp-Plantenga MS, Bouwman FG, Mariman ECM, Westerterp KR. Postprandial responses in hunger and satiety are associated with the rs9939609 single nucleotide polymorphism in FTO. Am J Clin Nutr. 2009;90:1426-1432.

20. Born JM, Lemmens SG, Rutters F, Nieuwenhuizen AG, Formisano E, Goebel R, et al. Acute stress and food-related reward activation in the brain during food choice during eating in the absence of hunger. Int J Obes (Lond). 2010;34:172-81.

21. Born JM, Lemmens SG, Martens MJ, Formisano E, Goebel R, Westerterp-Plantenga MS. Differences between liking and wanting signals in the human brain and relations with cognitive dietary restraint and body mass index. Am J Clin Nutr. 2011;94:392-403.

22. Lemmens SG, Born JM, Rutters F, Schoffelen PF, Wouters L, Westerterp-Plantenga MS. Dietary restraint and control over "wanting" following consumption of "forbidden" food. Obesity (Silver Spring). 2010;18:1926-31.

23. Lemmens SG, Schoffelen PF, Wouters L, Born JM, Martens MJ, Rutters F, et al. Eating what you like induces a stronger decrease of 'wanting' to eat. Physiol Behav. 2009;98:318-25.

24. Bouchard C, Tremblay A, Despres JP, Theriault G, Nadeau A, Lupien PJ, et al. The response to exercise with constant energy intake in identical twins. Obes Res. 1994;2:40010.

25. Hainer V, Stunkard AJ, Kunesova M, Parizkova J, Stich V, Allison DB. Intrapair resemblance in very low calorie diet-induced weight loss in female obese identical twins. Int $\mathrm{J}$ Obes Relat Metab Disord. 2000;24:1051-7. 
26. Herman CP, Polivy J. A boundary model for the regulation of eating. Res Publ Assoc Res Nerv Ment Dis. 1984;62:141-56.

27. Levitsky DA. Putting behavior back into feeding behavior: a tribute to George Collier. Appetite. 2002;38:143-8.

28. Speakman JR. A nonadaptive scenario explaining the genetic predisposition to obesity: the "predation release" hypothesis. Cell Metab. 2007;6:5-12.

29. Maes HH, Neale MC, Eaves LJ. Genetic and environmental factors in relative body weight and human adiposity. Behav Genet. 1997;27:325-51.

30. Li S, Zhao JH, Luan J, Luben RN, Rodwell SA, Khaw KT, et al. Cumulative effects and predictive value of common obesity-susceptibility variants identified by genome-wide association studies. Am J Clin Nutr. 2010;91:184-90.

31. Loos RJ. Genetic determinants of common obesity and their value in prediction. Best Pract Res Clin Endocrinol Metab. 2012;26:211-26.

32. Speliotes EK, Willer CJ, Berndt SI, Monda KL, Thorleifsson G, Jackson AU, et al. Association analyses of 249,796 individuals reveal 18 new loci associated with body mass index. Nat Genet. 2010;42:937-48.

33. Andreasen $\mathrm{CH}$, Andersen G. Gene-environment interactions and obesity--further aspects of genomewide association studies. Nutrition. 2009;25:998-1003.

34. Lejeune MP, Van Aggel-Leijssen DP, Van Baak MA, Westerterp-Plantenga MS. Effects of dietary restraint vs exercise during weight maintenance in obese men. Eur $\mathrm{J}$ Clin Nutr. 2003;57:1338-44.

35. Vogels N, Westerterp-Plantenga MS. Successful long-term weight maintenance: a 2-year follow-up. Obesity (Silver Spring). 2007;15:1258-66.

36. Westerterp-Plantenga MS, Kempen KP, Saris WH. Determinants of weight maintenance in women after diet-induced weight reduction. Int J Obes Relat Metab Disord. 1998;22:1-6.

37. Aubin D, Gagnon A, Grunder L, Dent R, Allen M, Sorisky A. Adipogenic and antiapoptotic protein levels in human adipose stromal cells after weight loss. Obes Res. 2004;12:1231-4.

38. Bennetzen MF, Wellner N, Ahmed SS, Ahmed SM, Diep TA, Hansen HS, et al. Investigations of the human endocannabinoid system in two subcutaneous adipose tissue depots in lean subjects and in obese subjects before and after weight loss. Int $\mathrm{J}$ Obes (Lond). 2005;35:1377-84.

39. Bouwman FG, Claessens M, van Baak MA, Noben JP, Wang P, Saris WH, et al. The physiologic effects of caloric restriction are reflected in the in vivo adipocyte-enriched proteome of overweight/obese subjects. J Proteome Res. 2009;8:5532-40.

40. Capel F, Viguerie N, Vega N, Dejean S, Arner P, Klimcakova E, et al. Contribution of energy restriction and macronutrient composition to changes in adipose tissue gene expression during dietary weight-loss programs in obese women. J Clin Endocrinol Metab. 2008;93:4315-22.

41. Jackman MR, Steig A, Higgins JA, Johnson GC, Fleming-Elder BK, Bessesen DH, et al. Weight regain after sustained weight reduction is accompanied by suppressed oxidation of dietary fat and adipocyte hyperplasia. Am J Physiol Regul Integr Comp Physiol. 2008;294:R1117-1129.

42. Summermatter S, Mainieri D, Russell AP, Seydoux J, Montani JP, Buchala A, et al. Thrifty metabolism that favors fat storage after caloric restriction: a role for skeletal muscle phosphatidylinositol-3-kinase activity and AMP-activated protein kinase. Faseb J. 2008;22:774-85.

43. Maclean P, Bergouignan A, Cornier M-A, Jackman M. Biology's response to dieting: the impetus for weight regain. American journal of physiology. Regulatory, integrative and comparative physiology. 2011;301:581-600.

44. Eastman Q. Very low calorie diet makes adipocytes "scream". Journal of proteome research. $2009 ; 8: 5408$. 
45. Mariman EC, Wang P. Adipocyte extracellular matrix composition, dynamics and role in obesity. Cell Mol Life Sci. 2010;67:1277-92.

46. Wang P, Bouwman FG, Mariman EC. Generally detected proteins in comparative proteomics--a matter of cellular stress response? Proteomics. 2009;9:2955-66.

47. Patel SR, Blackwell T, Redline S, Ancoli-Israel S, Cauley JA, Hillier TA, et al. The association between sleep duration and obesity in older adults. Int J Obes (Lond). 2008;32:1825-34.

48. Horne J. The end of sleep: 'sleep debt' versus biological adaptation of human sleep to waking needs. Biol Psychol. 2011;87:1-14.

49. Rutters F, Gerver WJ, Nieuwenhuizen AG, Verhoef SP, Westerterp-Plantenga MS. Sleep duration and body-weight development during puberty in a Dutch children cohort. Int $\mathrm{J}$ Obes (Lond). 2010;34:1508-14.

50. Chaput JP, Tremblay A. Sleeping habits predict the magnitude of fat loss in adults exposed to moderate caloric restriction. Obes Facts. 2012;5:561-6.

51. Nedeltcheva AV, Kilkus JM, Imperial J, Schoeller DA, Penev PD. Insufficient sleep undermines dietary efforts to reduce adiposity. Ann Intern Med. 2010;153:435-41.

52. Chaput JP, Despres JP, Bouchard C, Tremblay A. Longer sleep duration associates with lower adiposity gain in adult short sleepers. Int J Obes (Lond). 2012;

53. Guesdon B, Minet-Ringet J, Tome DG, Even PC. Restriction-refeeding of calories and protein induces changes to slow wave and paradoxical sleep that parallel changes in body lipid and protein levels in rats. Behav Brain Res. 2005;164:156-64.

54. Minet-Ringuet J, Le Ruyet PM, Tome D, Even PC. A tryptophan-rich protein diet efficiently restores sleep after food deprivation in the rat. Behav Brain Res. 2004;152:335-40.

55. Soenen S, Hochstenbach-Waelen A, Westerterp-Plantenga MS. Efficacy of alphalactalbumin and milk protein on weight loss and body composition during energy restriction. Obesity (Silver Spring). 2011;19:370-9.

56. Hasler G, Buysse DJ, Klaghofer R, Gamma A, Ajdacic V, Eich D, et al. The association between short sleep duration and obesity in young adults: a 13-year prospective study. Sleep. 2004;27:661-6.

57. Patel SR, Malhotra A, White DP, Gottlieb DJ, Hu FB. Association between reduced sleep and weight gain in women. Am J Epidemiol. 2006;164:947-54.

58. Cappuccio FP, Taggart FM, Kandala NB, Currie A, Peile E, Stranges S, et al. Meta-analysis of short sleep duration and obesity in children and adults. Sleep. 2008;31:619-26.

59. Nielsen LS, Danielsen KV, Sorensen TI. Short sleep duration as a possible cause of obesity: critical analysis of the epidemiological evidence. Obes Rev. 2011;12:78-92.

60. EFSA Panel on Dietetic Products NaAN. DRAFT SCIENTIFIC OPINION 1. Guidance on the scientific requirements for health claims related to appetite ratings, weight management, and blood glucose concentrations. EFSA Journal. 2012;10:2604-2615.

61. Mariman E. Human Biology of Weight Maintenance after Weight Loss. Journal of nutrigenetics and nutrigenomics. 2012;5:13-38.

62. Arner P, Spalding KL. Fat cell turnover in humans. Biochem Biophys Res Commun. 2010;396:101-4.

63. Spalding KL, Arner E, Westermark PO, Bernard S, Buchholz BA, Bergmann O, et al. Dynamics of fat cell turnover in humans. Nature. 2008;453:783-7.

64. Westerterp-Plantenga MS, Lemmens SG, Westerterp KR. Dietary protein - its role in satiety, energetics, weight loss and health. Br J Nutr. 108 Suppl 2:S105-12. 


\section{Summary}


Obesity results from a positive energy balance over time and can be reversed by weight loss. Weight loss is most commonly achieved by energy restriction resulting in a negative energy balance. However, successful long-term weight loss is counteracted by homeostatic adaptations in response to weight loss, creating an elevated appetite and suppressed energy expenditure promoting weight regain. Moreover, there are large inter-individual differences in the susceptibility to become obese as well as the success rates for weight loss and maintenance. This thesis addresses food components that might help decreasing the risk of overeating by suppressing appetite and addresses genetic, physiological and behavioural factors involved in weight loss and weight maintenance thereafter.

The effects of two potential appetite suppressing food components, oligofructose and Korean pine nut oil, were investigated in study designs considering dosage and time of dose regime. Consumption of $16 \mathrm{~g} / \mathrm{d}$ oligofructose, the highest dosage tested, reduced energy intake in normal-weight and overweight men and women, probably by increasing the satiety peptides. Dosages of 3 and $6 \mathrm{~g}$ Korean pine nut oil were not sufficient to suppress appetite and energy intake. Thus, oligofructose is a potential appetite suppressing food component to decrease the risk of overeating. The effectiveness of appetite suppressing food components in reducing energy intake and body weight in real-world food environments, without being in the context of an energyrestricted diet is questionable. However, appetite suppressing food components might help consumers stick to a diet, especially in periods of weight maintenance after weight loss, when suppressing appetite may help overcome the weight-loss induced elevated appetite.

In the weight loss study it was examined whether body-weight and short and longterm weight loss were affected by six candidate single nucleotide polymorphisms (SNPs) and by changes in eating behaviour, or by an interaction between these genetic and behavioural factors. A high genetic predisposition score from the six SNPs was associated with a high body weight and more short-term weight loss. Further research is needed to elucidate the pathways underlying the genetic contribution to obesity-susceptibility. Long-term weight loss was associated with a large increase in dietary restraint and a decrease in disinhibition. During long-term weight loss, genetic effects were dominated by changes in eating behaviour. The latter emphasizes the importance behavioural changes for weight maintenance.

During weight loss and maintenance, changes in ALDOC as a marker of the glycolysis were associated with adipocyte size and body weight, whereas changes in body weight during follow-up were associated with changes in ATGL as a marker of lipolysis during weight loss. Changes in adipocyte glucose and fatty acid metabolism in response to weight loss were in line with normalization from a dysregulated obese status to an improved metabolic status. Changes in adipocyte size as well as metabolism in response to weight loss were sustained during weight maintenance until weight was regained. Studies investigating adipose tissue metabolism should include methods to determine adipocyte size as a major determinant of endocrine functioning of adipocytes. Shrinkage due to the type of embedding of the adipose tissue can be ignored when comparing before and after weight loss. Plastic embedding of adipose tissue provides more accurate results than paraffin embedding. 
Literature indicated associations between sleep duration and body weight, initiating sleep as a study parameter in weight loss maintenance interventions. Changes in sleep duration showed that sleep duration normalizes during weight loss. Successful weight loss, weight maintenance and body-fat loss was underscored by an increase in sleep duration and vice versa, without elucidating the temporal sequence. Future research might disentangle cause and effect and investigate ways to improve sleep, and whether such an improvement of sleep also induces spontaneous body-weight loss and successive weight maintenance.

In conclusion, appetite suppressing food components like oligofructose can decrease the risk of overeating and might help individuals to stick to an energy-restricted diet. Optimizing factors like eating behaviour, changes in adipocyte metabolism and sleep as discussed in this thesis might contribute to success of body weight loss and maintenance. 



\section{Samenvatting}


Overgewicht is het gevolg van een positieve energiebalans gedurende een langere periode en is omkeerbaar door gewichtsverlies. Gewichtsverlies wordt meestal bereikt door het verlagen van de energie-inname, resulterend in een negatieve energiebalans. Handhaving van gewichtsverlies wordt echter bemoeilijkt door homeostatische aanpassingen als gevolg van gewichtsverlies zoals verhoging van de eetlust en verlaging van het energiegebruik. Verschillen tussen individuen duiden er op dat ook aanleg hierbij een rol speelt. Dit proefschrift richt zich op voedingscomponenten die de eetlust kunnen beperken en op erfelijke, fysiologische en gedragsmatige factoren die betrokken zijn bij gewichtsverlies en gewichtsbehoud na gewichtsverlies.

De eetlust-onderdrukkende voedingscomponenten die werden onderzocht waren oligofructose en olie uit de pitten van de Koreaanse pijnboom. Het tijdstip van toediening en dosering werden gebaseerd op een voorstudie. Een dosis van $8 \mathrm{~g}$ oligofructose bij het ontbijt en bij de lunch verlaagde de energie-inname bij het diner, waarschijnlijk door het verhogen van verzadigingshormonen. Een dosis van 3 en $6 \mathrm{~g}$ olie uit de Koreaanse pijnboompitten was niet toereikend om eetlust en energie-inname te onderdrukken. Oligofructose is dus een eetlust-onderdrukkende voedingscomponent die het risico op overmatige energie-inname mogelijk kan verminderen. De effectiviteit van eetlust-onderdrukkende voedingscomponenten in het verlagen van de energieinname en lichaamsgewicht in het dagelijks leven vereist nog nader onderzoek. Eetlust-onderdrukkende voedingscomponenten kunnen consumenten mogelijk ondersteunen bij het volhouden van een dieet tijdens gewichtsbehoud na gewichtsverlies door onderdrukking van de door het gewichtsverlies geïnduceerde toename in eetlust.

In de studie naar gewichtsverlies is onderzocht of gewicht en gewichtsverlies over een korte en lange periode beïnvloed werden door variatie in de basenvolgorde van het erfelijk materiaal (single nucleotide polymorphisms; SNPs), door veranderingen in eetgedrag, of door een interactie tussen deze erfelijke en gedragsmatige factoren. Op basis van 6 erfelijke variaties kon een score worden berekend voor de erfelijke belasting en het bleek dat er een verband bestond tussen een hoge score en een hoog lichaamsgewicht en meer gewichtsverlies over een korte periode. Verder onderzoek is nodig om uit te zoeken hoe het verband tussen de erfelijke belasting en de kans op het ontwikkelen van overgewicht kan worden verklaard. Gewichtsverlies over een langere periode bleek in verband te staan met een grote toename in geremd eetgedrag en een afname in ontremd eetgedrag. Tijdens gewichtsverlies over langere termijn werd de invloed van de erfelijke variatie overschaduwd door de veranderingen in eetgedrag. Dit laatste benadrukt het belang van gedragsmatige veranderingen voor gewichtsbehoud na gewichtsverlies.

Tijdens de fasen van gewichtsverlies en gewichtsbehoud werd de concentratie van diverse eiwitten in het vetweefsel gemeten. Er bleek een duidelijk verband te bestaan tussen veranderingen in ALDOC als marker voor de glycolyse en vetcelgrootte en lichaamsgewicht. Veranderingen in lichaamsgewicht tijdens de fase van gewichtsbehoud vertoonden een verband met veranderingen in ATGL als marker voor de lipolyse gedurende gewichtsverlies. Veranderingen in het glucose- en vetzuurmetabolisme van de vetcel in reactie op gewichtsverlies waren in overeenstemming met de overgang van een ontregelde naar een verbeterde metabole status. Veranderingen in zowel vetcel-grootte als -metabolisme in reactie op gewichtsverlies bleven tijdens gewichtsbehoud gehandhaafd totdat het lichaamsgewicht weer toe ging nemen. Deze 
resultaten geven aan dat in studies naar de rol van het vetmetabolisme bij gewichtsregulatie, metingen van de vetcelgrootte als een bepalende factor voor het endocriene functioneren van vetweefsel, meegenomen dienen te worden. Onze ervaring heeft geleerd, dat bij het vergelijken van vetcelgrootte voor en na gewichtsverlies krimp als gevolg van de manier van inbedden van het vetweefsel verwaarloosd kan worden. Het inbedden van vetweefsel met behulp van plastic levert nauwkeurigere resultaten op dan inbedden met behulp van paraffine.

Recente literatuur duidt op een verband tussen lichaamsgewicht en slaapduur. Het hier beschreven onderzoek liet zien dat gewichtsverlies en verlies van lichaamsvet gepaard gaan met een toename in slaapduur en omgekeerd zonder oorzaak en gevolg te kunnen verklaren. Hiervoor is nader onderzoek nodig. Verbetering van slaap zou hiermee een bijdrage leveren aan het succes van gewichtsverlies en gewichtsbehoud.

Concluderend, oligofructose kan als eetlust-onderdrukkende voedingscomponent het risico op overmatige energie-inname verlagen en een ondersteunende rol spelen bij het handhaven van een energieverlaagd dieet. Het optimaliseren van factoren als eetgedrag, veranderingen in vetcelmetabolisme en slaap, zoals besproken in dit proefschrift, kunnen bijdragen aan succesvol gewichtsverlies en gewichtsbehoud. 



\section{Dankwoord}


Het proefschrift waarmee ik met trots en voldoening een mooie tijd kan afsluiten is af. $\mathrm{Nu}$ is een dankwoord er niet voor om jezelf te bedanken, maar juist de vele mensen die aan dit proefschrift hebben bijgedragen op welke manier dan ook. Bedankt!

Allereerst wil ik mijn promotoren bedanken voor de steun die ik in de afgelopen jaren van hen heb gekregen. Klaas, bedankt om mij de kans te geven om te promoveren door mij te "adopteren". Ik ben zeer dankbaar voor de vrijheid die je me hebt gegeven om mijn eigen interesses te volgen. Door je daadkrachtige manier van werken werden de grote lijn en de tijd toch nooit uit het oog verloren. Edwin, bedankt voor de rust en het geduld waarmee je me alles (soms meerdere keren) hebt uitgelegd. Jouw bijdrage zorgde ervoor dat er met een andere blik naar onze data gekeken werd. Je was altijd geïnteresseerd en je deur stond altijd open, wat ik zeer waardeer.

De leden van de beoordelingscommissie, Prof. dr. W.H. Lamers, Prof. dr. R.A.H. Adan, Prof. dr. R.P. Mensink, Dr. A.G. Nieuwenhuizen en Prof. dr. M.P. Zeegers, wil ik graag bedanken voor de beoordeling van mijn proefschrift.

Prof. dr. Margriet Westerterp-Plantenga, Margriet, graag wil ik u bedanken voor de vele momenten waarop ik op uw expertises mocht terugvallen. Dit waren zeer leerzame momenten. De manier waarop u zowel eigen als andere promovendi met al uw enthousiasme begeleidt bewonder ik zeer. Dr. A.G. Nieuwenhuizen, Arie, onze samenwerking was helaas slechts van korte duur, maar desondanks ben ik je zeer dankbaar voor de kans die je me gegeven hebt.

De vele proefpersonen die aan mijn studies hebben deelgenomen, jullie hebben veel voor mij gedaan, van vragenlijsten tot vetbiopten, dank daarvoor. Ook dank aan de stagiaires die mij hierbij geholpen hebben, Natascha, Cleo, Stefan, Elena, Vera, Geert, Nathalie en Rim.

Prof. dr. Wout Lamers, bedankt voor alle hulp die ik heb gekregen bij het meten van de vele vetcellen. Paul, zonder jou was het me nooit gelukt om die cellen mooi in beeld te krijgen, maar ook bedankt voor de gezelligheid waarmee we dit samen gedaan hebben! De hele afdeling anatomie en embryologie wil ik bedanken voor alle adviezen en hulp, ik voelde me altijd thuis bij jullie.

Natuurlijk wil ik heel HB bedanken. Maar in het bijzonder de secretaresses, Claudia, Desiree en Ilona bedankt voor alle hulp! Paul en Laurens, bedankt voor alle technische ondersteuning bij onze studie. Jos en Loek bedank veur alle samples die geer veur mich hub geanalyseerd, mer auch zeker veur de memènte det ich efkes bie uch koos aafkeule. Alle mensen van het lab op nivo 2, bedankt voor de gezelligheid op de dagen dat ik naast jullie mocht werken, ondanks dat ik van nivo 3 (en later 0 ) was! Freek, zónger dich hej dit beukske väöl minder hoofdstjukke. Ut woor erg lehrzaam en gezèllig om mit dich same te wirke! Jammer det veer neet tegeliek promoveren;). Ping, thanks for your elaborate explanations.

Velen zijn mij voorgegaan. Femke, zonder jou was ik überhaupt niet hier terecht gekomen, dank daarvoor! Je bent een super reserve-paranimf, fijn dat ik altijd (ook nadat je weg was) met alles bij je terecht kon! Ananda, dank voor de gezelligheid op onze kamer, maar ook daarna. Alberto, noooo, thanks for the many laughs. Anneke, bewondering voor je optimisme in je drukke leventje. Astrid, dank voor je enthousiasme en taxi-ritjes tot thuis. Jurriaan, de koffie/thee-momentjes met jou werk(t)en altijd erg relativerend en rustgevend, thanks mede-bioloog! Marcel, bedankt voor je snelle hulp, ook nadat je weg was, met afzender of anoniem ;). Margriet $\mathrm{V}$, denken aan jouw 
doorzettingsvermogen heeft mij er vaak doorheen geholpen. Sofie, ik heb veel lol met jou gehad, maar ook veel van je geleerd, bedankt. Stijn, wat een bewondering voor jullie down-under avontuur.

Stefan, ut woor ein fijne tied om neet allein ein kamer, mer auch ein studie mit dich te deile. Ich hub väöl (euver michzelf) geljeard door ozze samewirking. Dien reacties op zoewaal werk es privé kwesties waore altied erg rustgaevendj, bedank! Blandine, nice to have another mom in the group. Eveline, je doorzettingsvermogen is echt bewonderenswaardig. Guillio, het was altijd gezellig kletsen met jou. Guy, wat heb jij vaak mijn gezeur aan moeten horen en dan ook nog met advies komen, dank hiervoor. Mandy, het was van korte duur, maar veel succes met je carriere. Mieke, bedankt voor de gezelligheid en als laatste voorganger voor alle hulp bij de laatste loodjes. Pilou, lekker om aaf en toe euver meziek en festivals te kinne kallen. Rick, dank voor de vele starters, de thee-gesprekken kregen toch altijd echte "diepgang" met jou erbij. Siti, thanks for your contageous enthousiasm. Tanja, je was een fijne buurvrouw, geïnteresseerd in werk en privé.

Dank aan Peter, Thea en de rest van het Trevianum voor het begrip dat jullie toonden voor mijn situatie. Hierdoor was het mogelijk om dit af te ronden, terwijl ik jullie mooie vak begin te leren. Ook dank aan alle docenten en mede-studenten van het ILS-RU.

Mijn paranimfen! Hanne, ik bewonder je harde werken en doorzettingsvermogen. Ik kon altijd bij je aankloppen met vragen over slaap, statistiek, maar ook thee, mijn gezeur en gezellige praatjes. Daardoor werd je niet alleen een super collega, maar ook een fijne vriendin. Dank voor alles! Kim, dich bis toch waal ein veurbeeld veur mich gewaes, al hub ich sommige dinger anges gedaon ;). Ut is fijn om ein zus te hubbe wo ich alle aspecten van mien leave mit kin deile. Heerlijk om tegeliek ut sjoanste in ozze laeves te belaeve! Dank dat jullie mijn paranimfen willen zijn!

Wendy, bedankt voor het super ontwerp van de omslag en uitnodigingen!

Al mijn lieve vrienden van de middelbare, van biologie, oet Ech en omstreken, van de bands, ik heb het niet vaak over mijn werk gehad (Wim, doe bis de oetzunjering!), maar nu kunnen jullie zien waar ik al die tijd aan gewerkt heb. Jullie bedankt voor alle momenten waarop ik juist even NIET hoefde te denken aan al het werk!

Familie Vergoossen, mam, we zien elkaar niet veel, maar wat kunnen jullie vertellen! Heerlijk om zo'n schoonfamilie te hebben. Debby, Marcel, Nine en Ties, waat ein gezellig gezinneke zeent geer, ich kom altied gaer sjpringe op 't hinge. Kim, Don en Malu, jammer det geer (nog) neet naeve de deur woontj, mer det duit niks aaf aan oz contac. Pap en mam, zelfs uch hub ich neet väöl euver mien werk vertèld, mer weit det uch onväörwaardelikke leefde en veural vertroewe in mich derveur höbbe gezörg det ich dit höb bereik. Dank veur de vrieheid dae ich van uch kreeg! Geer zeet de biste pap en mam (en opa en oma) die dur zeen.

Mark, papa van mien kindje, ich kin neet omschjrieve wieväöl ich van dich hauw (ondanks alles, hihi, ;)). Waat is ut heerlijk om naeve ozze drukke werklaeves van elkaar te geneete in ein laeve vol leefde en humor, A\&A, LVPV!! Trouwe den maar ;)!! Evi, wats dich veur mich beteikens, is hie neet oet te lèkge. Doe bis mien alles! 



\section{List of publications}




\section{First Author}

Verhoef SPM, Meyer D, Westerterp KR. Effects of oligofructose on appetite profile, glucagon-like peptide 1 and peptide YY3-36 concentrations and energy intake. $\mathrm{Br} \mathrm{J}$ Nutr. 2011; 106(11):1757-62

Verhoef SPM, Westerterp KR. No effects of Korean pine nut triacylglycerol on satiety and energy intake. Nutr Metab. 2011; 10;8(1):79

Verhoef SPM, van Dijk P, Westerterp KR. Relative shrinking of adipocytes by paraffin in proportion to plastic embedding in human adipose tissue before and after weight loss. Obese Research \& Clinical Practice. 2013; 7(1):e8-e13

Verhoef SPM, Camps SG, Bouwman FG, Mariman ECM, Westerterp KR. Physiological response of adipocytes to weight loss and maintenance. PloSOne. 2013; 8(3):e58011.

Verhoef SPM, Camps SG, Bouwman FG, Mariman ECM, Westerterp KR. Genetic predisposition, dietary restraint and disinhibition in relation to weight loss and maintenance. submitted for publication.

Verhoef SPM, Camps SG, Gonnissen HKJ, Westerterp KR, Westerterp-Plantenga MS. Concomitant changes in sleep duration and body-weight and body-composition during weight-loss and weight-maintenance. Am J Clin Nutr. 2013, in press.

\section{Co-author}

Rutters F, Nieuwenhuizen AG, Verhoef SP, Lemmens SG, Vogels N, WesterterpPlantenga MS. The relationship between leptin gonadotropic hormones and body composition during puberty in a Dutch children cohort. Eur J Endocrinol 2009. 160(6):973-8

Rutters F, Gerver WJ, Nieuwenhuizen AG, Verhoef SP, Westerterp-Plantenga MS. Sleep duration and body-weight development during puberty in a Dutch children cohort. Int J Obes 2010, 34(10):1508-14

Camps SG, Verhoef SPM, Westerterp KR. Weight loss, weight maintenance and adaptive thermogenesis. AJCN, in press.

Camps SG, Verhoef SPM, Westerterp KR. Weight loss induced reduction in physical activity recovers during weight maintenance. submitted for publication.

Gonnissen HKJ, Adam TC, Hursel R, Rutters F, Verhoef SPM, Westerterp-Plantenga MS. Sleep duration, sleep quality and body weight: parallel developments. submitted for publication. 
Valenti G, Camps SG, Verhoef SP, Bonomi AG, Westerterp KR. Validating measures of free-living physical activity in overweight and obese subjects using an accelerometer. submitted for publication.

\section{Abstracts and presentations}

Verhoef SPM, Westerterp KR. Effects of PinnoThin ${ }^{\mathrm{TM}}$ on satiety and food intake. International Congress on Obesity; 11-15 July 2010; Stockholm, Sweden. Poster presentation.

Verhoef SPM, Westerterp KR. Mixed effects of PinnoThin ${ }^{\mathrm{TM}}$ on satiety and food intake. NWO werkgemeenschap voeding; 14-15 October 2010; Deurne, The Netherlands. Oral presentation.

Verhoef SPM, Camps SG, Westerterp KR. Determinants of weight regain after weight loss. European Congress on Obesity; 9-12 May 2012; Lyon, France. Poster presentation. 



\section{Curriculum vitae}


Sanne Verhoef was born on November $22^{\text {nd }} 1984$ in Elsloo, the Netherlands. After she completed secondary school at Trevianum in Sittard in 2003 she started the study Biology at Radboud University in Nijmegen for which she obtained her bachelor's degree in 2006. In 2008 she obtained her degree for the master Medical Biology at Radboud University.

In august 2008 she started her PhD research at the department of Human Biology of the Faculty of Health, Medicine and Life Sciences of Maastricht University under the supervision of Prof. Dr. KR Westerterp. The research performed during this period is described in this PhD thesis entitled 'Body weight loss and maintenance as affected by environment and genetic predisposition'. During her PhD project Sanne presented several abstracts at international conferences. In February 2013 she started the educative master at Instituut Leraar Scholing at Radboud Universiteit in Nijmegen. 